



\section{THE STATES}

OF

\section{THE RIVER PLATE.}


LONDOX

PRINTED BY SPOTTISWOODE AND CO NEW-STREET SQCARE 


\section{THE STATES}

OF

\section{THE RIVER PLATE:}

THEIR

\section{INDUSTRIES AND COMMIRRE.}

SHEEP-FARMING, SHEEP-BREEDING, CATTLF-FEEDING, AND MEAT-PRESERVING; EMPLOYMENT OF CAPITAL; LAND AND STOCK, AND THEIR VALUES;

LABOUR AND ITS REMUNERATION.

BY

WILFRID IATHAM.

LONDON :

L ONGM ANS, GREEN, AND CO. 1866. 



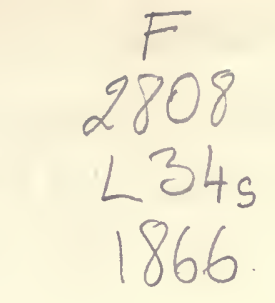

PREFACE.

The Author of this work presents it to the public, not as the production of a traveller, or with any pretension to the detail, interesting or amusing; which usually makes up works descriptive of foreign countries.

He presents himself as a plain thinker on subjects of material interest connected with the country in which he has resided or been in relation with for, more or less, twenty-four years, and in which there are settled a very large number of British subjects and their families, towards which there is a continuous stream of emigrants from Europe, a large portion of whom -especially those possessing small or moderate capitals-entertain most erroneous ideas of the country, its industries, and the work that is before 
them; between which and Great Britain there are very important commercial relations, and in which there is a very large British capital invested.

His object in writing this work has been truthfully and intelligibly to describe the country, its resources, and climate, with a view to its industries-pointing out various channels for the advantageous employment of capital, fields for labour, and its remuneration, and to usher in the dawn of a more advanced and more sound system of working those industries, by explaining the principles which should regulate the practice of parties engaged, or about to engage, in them; and he claims from the 'lettered' public that consideration which they may fairly accord to a writer, whose daily avocations are the practice of the industries of which he treats. 


\section{CON'TENTS.}

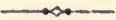

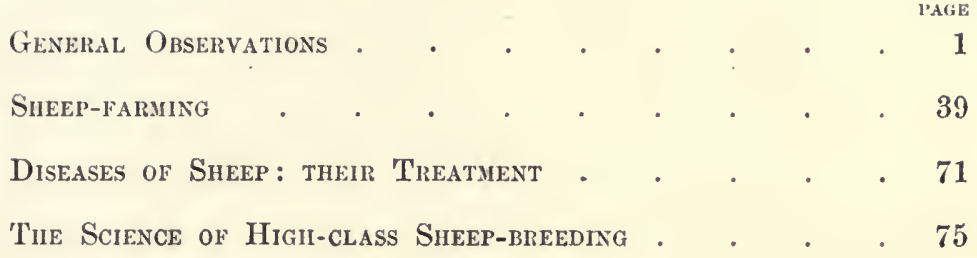

Detalls of Management . . . . . . . . 93

Observations on tile Utilisation of River Plate Beef • 111

Proper Condition of Animals for Killing • • • • 126

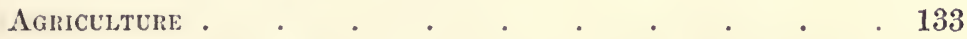

'I'ine Thistle, Sejo Caballo, Abrojo, and Poisonous Herbs - 160

'T'ue River Plate as a Fiked for the Eurloyalent of

Capital and Labour . . . . . . . . 175 



\section{THE STATES}

OF

\section{THE RIVER PLATE.}

\section{PAR T I.}

GENERAL.

The countries of the River Plate or Rio de la Plata are those of the Banda Oriental or Republic of the Uruguay, a small state on the northern bank of the Estuary or Rio de la Plata, whose chief city and port is Montevideo; and the Argentine Republic, on the southern bank, extending south, west, and north, and comprising fourteen provinces, viz. Buenos Ayres, Santa Fé, Cordoba, Mendoza, San Juan, Santiago, Tucuman, Salta, Rioja, Catamarca, San Luis, Jujuy, Entre-Rios, and Corrientes; its chief city and port being Buenos Ayres.

The Banda Oriental lies on the southern limits of, and is bounded by, the Brazilian Empire; its eastern coast is washed by the Southern Atlantic, its southern shores by the River Plate, and its western by the magnificent river Uruguay-a semicircle of sea-board and navigable rivers.

The Argentine Republic extends south to the Indian territory and Patagonia, north to Bolivia and Paraguay; 
and is bounded to the west, in its whole length, by the Cordillera; the Ocean, the River Plate, and the magnificent rivers Paraná and Uruguay constituting its other boundaries; the Paraná separating two of its provincesEntre-Rios and Corrientes-from the rest; the River Uruguay separating the Argentine province of Entre-Rios from the Banda Oriental. These territories comprise a range of temperate climate, from that bordering on cold to the south, to the tropical to the north; with an extensive sea-board, and an internal and arterial system of rivers counted among the finest in the world.

A very extensive commerce is carried on between these countries and the various nations of Europe, North America, and the Brazils; and a very large and important interior or coasting trade, extending over hundreds of miles of river coast in the La Plata, Paraná, and Uruguay, where the great deptl of water admits of vessels of considerable burthen and draft, the Paraná being navigable for over a thousand miles. Numerous vessels course these rivers, carrying passengers and goods; and their number is constantly augmented by steamers built here or brought from England or the United States.

The foreign commerce consists in imports of the staple productions of the various countries of Europe and America; England, France, Germany, Denmark, Sweden, Syain, Portugal, Italy, United States, Canada, and Brazil ; cotton, woollen and silk goods, hardware, iron, wines, spirits, oils and fruits, lumber, tar, naval stores, sugar, rice, flour, furniture, jewellery, \&c. \&c.

The exports are chiefly of animal products, on which, in due course, I propose specially to treat. Minerals and vegetable products are also exported.

'The delicious and salubrious climate, the extreme fertility of the soil, the wide range and capabilities of 
production, and the unsurpassed adaptability of these countries for stock-breeding, as well as the extent of their river system, constitute them as eminently favourable per se to receive an European emigration, and offer many opportunities for the advantageous investment of European capital.

The natural richness and extent of their resources, the facilities of water transit, and the paramount desire for progress which animates the influential portion of the population, their commercial tendencies, the unfeigned welcome and protection extended to foreign settlers, and the full recognition of the advantages derived from immigration and foreign enterprise are in themselves guarantees both to settlers and individual or Stock Exchange investments. Moreover, the recognition and thorough comprehension on the part of the governing classes, of the importance and policy of national good faith, is a feature which necessarily must weigh with capitalists, and produce its fruits in the development of the incalculable resources of the country.

Land and stock are to be had at comparatively low figures, and constitute advantageous investments for individuals and companies.

Railways, steam navigation, canalisation, mining and other undertakings, worthily claim the attention of the Stock Exchange.

Wages are high, and employment far in excess of the supply of labour, which, accompanied, as they are, by cheap beef, are the greatest inducements that can be offered to the industrious classes.

Montevideo, the capital of the Banda Oriental (or Republic of the Uruguay), is situated near the mouth of the River Plate. It is a well-built city, on a rocky promontory, forming one side of the bay, and offering a safe and 
commodious harbour, capable of containing several hundred vessels.

The population of the city, which, from the water, displays a very imposing and handsome view, is estimated at 60,000 souls, comprising people of almost every nationality in Europe, the United States, and Brazils, the foreign element considerably outnumbering the natives, and among the former, the Italian portion of it predominating.

The commerce is large and increasing.

There is a noble hospital, a cathedral and other churches; also an English Protestant church. Forts command the entrance of the bay from the mainland and an island in the bay; there are several moles and jetties, a customhouse, lighthouse, and other public buildings.

The country of the Banda Oriental is undulating, with spurs of hill ranges here and there. It is well wooded in some parts, but the timber is of no great size. It is remarkably well watered: through the heart of the country flows the Rio Negro, into which innumerable tributaries empty themselves, as seen on the map. This river and its affluents stand in relation to the country not unlike the arterial system in the human frame, a main trunk with ramifications extending everywhere, vivifying and fertilising.

The face of the country, as I have said, is of undulating rocks and boulders, cropping out of the higher parts; rich soil, luxuriant herbage, with broad sketehes of woodland descending to and in parts following the courses of the rivers and brooks. On the borders of the Rio Negro and its tributaries, great quantities of sarsaparilla grow, and the waters are more or less impregnated with it. Certain points of these rivers are, in consequence, visited by invalids. 
II.

BUENOS AYRES.

A large and handsome city, the streets intersecting each other at right angles, equidistant, and forming blocks of houses of about 140 yards square. The extension of the city during the past few years, and the number of magnificent houses built, many of them meriting the denomination of palaces, is astonishing. It possesses several large and handsome theatres, an opera house, concert hall, club houses, exchange, custom-house, and other public buildings; the cathedral, a large and handsome building, with a noble composite façade, and many large and solidly built churches.

The population is estimated at 200,000 souls, and comprises representatives of almost every civilised nation in the world-more or less half its population is foreigna perfect babel of tongues; English, French, German, Italian, Portuguese, salute the ear at every step : foreign banks, commercial houses, shops, wholesale and retail general stores. Every trade and calling is pursued with perfect liberty by foreigners of every denomination, and their establishments are everywhere. Many ship-building yards exist, where steamers and other vessels for the river-trade are built; and there are an English church, Scotch Presbyterian, American and German churches; an Irish Roman Catholic chaplain and several assistants; the British hospital, a large and well-regulated establishment; the Italian hospital, a remarkably handsome building; an Irish hospital ; the convent and schools of English and Irish sisters of mercy; British newsroom; 
library; English daily newspapers; a cricket club, and racecourse.

There are three lines of railways in the province of Buenos Ayres, gradually extending farther and farther into the country-one to the north, taking the line of the principal northern traffic, and the others to the west and south-all opening up the most important trading districts in their respective directions.

Another railway-the Central Argentine-is in course of construction, not in the province of Buenos Ayres, but with its terminus in the province of Santa Fé, at a port called Rosario, and taking its line through the province of Cordoba to the city of the same name, the focus of communication with the northern and north-west provinces. The importance of this line of railway cannot be overestimated. At Rosario, several lines of steamers from Buenos Ayres call, touching en route at several ports on both banks of the Paraná above and below Rosario. Each of the several ports is a distinct centre of trade, to which goods are shipped from Buenos Ayres, and the produce of these districts is forwarded to be shipped per steam or river craft to Buenos Ayres or Montevideo.

The port of Buenos Ayres is an open roadstead, with inner and outer roads, divided by a sand-bank, or bar, with good anchorage in both. The vessels are discharged by, and loaded from lighters, which land and receive cargo at moles or jetties, or are beached, and their cargoes taken from or to them in high wheeled carts, or at wharfs on the banks of a small river, the 'Riachuelo,' in the vicinity of which are situated the chief ' Saladeros,' killing and salting establishments for hides, tallow melting, \&c.; also barracas, or warehouses. River craft, with produce from the several ports of the Rivers Paraná and Uruguay, 
frequently lay alongside or discharge their cargoes at once on board the foreign vessels in the roadsteads.

The articles of export, both from Montevideo and Buenos Ayres, are chiefly animal products-hides, dry and salted, jerked beef, bones, horns, tallow, hair, wool, skins, ostrich feathers, \&c. Tobacco and some other vegetable products are also exported, but in comparatively insignificant quantities; also copper and other minerals. This class of products will doubtless form a comparatively larger proportion of the exports than at present, when the communication with the interior provinces is established by means of the railway now in course of construction, and by the canalisation of rivers which flow from there to the Paraná.

The scene at the 'Saladeros,' in the killing season, is strange in the extreme to European eyes. Herds of fine semi-wild cattle, consisting of several hundred head, are driven in from the country by mounted herdsmen, looking as wild, if not really so, as the cattle they drive-the affrighted animals bellowing and making desperate attempts to break away as they approach the pens-the mounted herdsmen swinging their lassoes and dashing at the cattle on flank and rear, to close them into a compact phalanx, so as to force the foremost on. The slightest break in the mass, from an inequality of pressure, through which an animal or two can contrive to turn, and there is a wheel and a stampede: and then look out! away go the gaucho drivers, as if fleeing before the galloping, maddened herd; but, with their fleet horses, crossing and recrossing in front and on the sides, they gradually close up the ranks, succeed in turning the cattle again, and so work them till they get them into the pens (corrals) of tall hard wood posts, six to eight inches in diameter, by eight or ten feet high, ranged along side each other, and 
bound together by eross bars securely lashed. Occasionally, indeed frequently, a point of two, three, or half-adozen animals will break away from the lot, and then away go the skirmishers of the party of drovers, lassoes whirling in the air, at headlong gallop, to come up with the runaway beasts; a vain attempt would it be to turn them, so the lasso is thrown, the noose goes over the animal's horns, the well-trained horse answers to the rein, he gallops to one side and comes suddenly to a stop; the animal is swung round, a seeond lasso is thrown by another horseman; one takes one side, the other the other; the enraged animal rushes to and fro, but he is checked by the lassoes; and so, by the dragging of the lasso-men and his own mad rushes, he is worked on to the remainder of the herd. At other times, he is hamstrung by a third person, and left until the herd being penned, they return to kill and skin him.

The process of penning the cattle being in due course achieved, the slaughter commences, and the operation is effected as follows :

To the corral or pen, there is a narrow neck, eight to ten feet long, closed with cross bars at the end, the lower bar being suffieiently high to admit a low truck to be run under it, in and out, with its burthen; the top bar consists of a roller. By this neck there is a stage, on which stands the lasso-man; the truck being run in, the lasso-man takes the noose and coils of the lasso, swings it and throws it over the horns of one of the animals; a horseman outside has the end of the lasso attached to the saddle (reeado) of his horse: the signal is given as soon as the lasso is cast, the horseman moves rapidly on, the lasso running on the roller bar, drawing the animal into the neek of the pen and on to the truck, bringing the horns 'taut' against the roller bar. The slaughterer 
stands on the stage, knife in hand: as soon as the animal is in the position required, he introduces his knife behind the horns, and, dividing the spinal marrow at its junction with the head, the animal instantly collapses; the lasso is loosed from it, and the truck is run out on a tramway which occupies the centre of a flagged platform, under a shed, along which, on each side, are ranged the flayers. The dead animals are cast off the truck to the flayers in turn. The hide being taken off, it is doubled up and taken to the salting house, where it is stretched on the pile of hides, and salt cast over it with shovels; meanwhile, the carcase of the animal is cut up and carried to another salting house, where the meat is sliced into thin flakes and laid in a pile, with salt. The fat and the bones, with that portion of the meat which is unsuitable or cannot be conveniently cut into flakes, goes to the vats, and is steamed to extract grease and tallow.

When the beef has lain in salt a sufficient time, it is taken out and hung on rails (tendales) in the open air to dry ; from there it is removed and built into large piles, square or round (in the open air), and covered with tarpaulins until ready for shipment. The meat thus prepared is known as 'jerked beef,' and is chiefly shipped to, and consumed in, the Brazils or Havannah.

The business of preparing hides, tallow, and beef, is one of the most important carried on in the province of Buenos Ayres, Entre-Rios, and Santa Fé, and in the Republic of the Uruguay.

The hides of the animals slaughtered for the consumption of the town or country are nearly all staked and dried.

At the Saladeros, mares in large numbers are slaughtered, the hides salted, and the carcases steamed for grease. The tallow and grease having been drawn off, 
the refuse matter-bones and beef fibre-are removed; the shank, shin, and other large bones are picked out for shipment; and the smaller bones and beef fibre are used as fuel for the furnaces of the steaming apparatus, to the extent required: the remainder is made into large heaps and burned. The ash from this and from the furnaces is the bone-ash of commerce. The manes and tails of mares, and the tails of cattle, furnish hair, \&c., for shipment. The hoof's and horns are likewise shipped.

The killing grounds for the supply of beef to the towns present an animated and singular scene:-A large open space, with lines of pens, or 'corrales,' into which the cattle of the different dealers are drawn. The butchers purchase and select the animals they require out of the pens; all are mounted on well-trained horses. To take out the sclected animal, a lasso-man enters, throws his lasso, and darts out of the corral, half dragging, half chased, by the bellowing animal, while others keep back the rest of the cattle. Another and another is selected, lassoed, and drawn out: away they go with the lasso-men, the animal either rushing after them or on some of the groups, and followed by other horsemen at full speed, until within reach to throw the second lasso, which is cast over the horns or on the hind legs, and the two, taking contrary chrections, bring the animal to a stand, or throw it over. One of the men dismounts; the horse, knowing his work, keeps the lasso 'taut,' while the man approaches the animal, and, according to its position, either hamstrings it as a preliminary, or at once 'piths' it, by introducing the knife behind the horns. The flaying then eommenees, taking care that the carcase remains on the hide, on which it is cut up, so that the meat is not soiled. The groups of flayers, three or four to each animal--sometimes as many as sixty or eighty animals undergoing the operation of 
flaying and cutting up at the same time;-these flayers, wild-looking fellows, dressed or half-dressed in various bright colours, scarlet predominating; the gaily caparisoned horses of the butchers, many of them glistening with silver trappings; rude carts, ruder-looking drivers, and various coloured horses; the background of pens, still half full of cattle, all contributing colour and artistic grouping, make up, if not a pleasingly picturesque and gay scene, at least, illuminated by the oblique rays of the morning sun, a very sparkling and brilliant one, and novel in the extreme to Europeans.

The 'emissaries' of the sausage-makers, dogs and swine, serve as the scavengers, aided by clouds of gulls and hawks; the snow-white and grey plumage of the swooping whirling thousands of the winged inhabitants of the Pampas, ever moving in the sunlight, adding not a little to the brightness and singularity of the effect.

\section{III.}

The aspect of the country or 'campo' of Buenos Ayres, and its geological character, is altogether different from that of the Republic of the Uruguay, or Banda Oriental.

The province of Buenos Ayres, excepting far away south, where there is a spur, or high range, is one vast level plain-a rich alluvial soil without wood-except here and there, where one or two trees, or a small plantation, mark the site of an ' estancia' house, or a 'puesto' or station. A solitary 'ombú' tree, with its enormous trunk and great arms, its dark green and dense foliage, affords, here and there, shade to a group of cattle or horses, or to the weary traveller: a plain clothed in rich herbage, watered by sluggish streams, shallow lakes and 
pools, and covered with vast herds of cattle, horses, and flocks of sheep.

I cannot conceive anything more exhilarating than a gallop across the plains of Bnenos Ayres on a bright, clear morning, or in the cool of the afternoon or evening; a cloudless sky of deep azure, an atmosphere light and pure in the extreme, communicating a sense of indescribable buoyancy and pleasurable existence-a soft breeze flowing, as it were, over the vast plain, boundless as an ocean, contributes to engender an irresistible feeling of joyous freedom.

One of the effects of the climacteric influences on residents in the plain is to render them comparatively independent of what in England are called comforts; men seem to revel in mere existence; life is pleasurable to them for itself, and this frequently renders them careless of accessories and prone to take things easily, often too much so. It being easy to live, and wants few, there is a disposition to eschew exertion. The sense of the expanse doubtless contributes to this; there is no obstacle, all is open and wide; resistance stimulates to exertion, something to grapple with; something within reach is needed to excite action and develop energy. When the plain fades away in the far distance, and the long vista presents no objects but such as are insignificant in relation to the expanse, a consciousness of impotence is engendered, reacting to produce a disinclination to effort. Who has not stood on a rock overhanging the sea, and looked forth on the wide surface, and not felt something of this? In the plain there is a similarity of cause and effect.

In the 'campo,' the horse is man's companion and resource, the one thing that leads him to motion, which carries him through space and shortens it. No one is a-foot in the plain; from comparative infancy to old age, every 
one rides; all work is done on horseback, and only with the stimulant of the movement of the horse is energy awakened.

The 'campo'-a plain-has its own peculiar beauties and aspects, varying with the season. The unbroken carpet of short green herbage of the winter is changed to vast sheets of colour in the spring. Luxuriant grasses, tangled clover (spotted medick), with its broad leaf of rich green and black spot, intermixed over vast tracks with the young variegated-leaved thistle, remarkable by its large green and white foliage; a little later on, the wild flowers mingle with the tall grasses-rye-grass and many spreading panacled grasses_or overtop them, forming immense sheets of colour. Acres upon acres of the brilliant scarlet vervain, gorgeous in the light, or purple or white verbena. Leagues of a rich purple flower, the 'flor morada' (a plantain), changing to bright rose as the setting sun casts its warm oblique light upon it. The tall 'biznaga,' with its head of clustered white florets ; the branching manyflowered camomile, and numberless others, white, pink, yellow, \&c.

From these broad lines or sheets of colour, we enter on the great thistle camps. There are two varieties of thistle, the one annual, tall, variegated, broad leaved, known in the garden in England, and growing in this country to the height of eight or ten feet, in dense array, impenetrable except in the cattle track. These beds of thistle extend leagues and leagues, and at the time of flowering, as far as the eye can reach, they present an almost unbroken sheet of rose purple flowers; and in some districts, a day's ride along a road or track, on either side of which stretches this forest of thistles, leaves the traveller still with the same stretching to the horizon. Thousands of cattle browse unseen amongst the thistles, working tracks through 
them, feeding on them and the grasses which grow up with them. On the lower lands and edges of pools, the thistles do not grow. About midsummer they seed, wither, and fall, a heavy rain and a stiff breeze quickly knocking them down, the soft stem breaking up under the action of the sun and rain. The cattle and sheep feed on the oleaginous seed and withering leaves and grow fat. In the autumn, other grasses, distinct in variety, which spring up and cover the ground, obliterate almost all trace of the fallen thistles. In the autumn and winter the thistle seed germinates, and the tender leaves of the plants, with the various grasses, are fed on by the cattle and sheep.

The other variety of thistle has a life of several years; this variety is in fact the wild artichoke, and has the same colour and foliage as the cultivated plant: the stem is stout and hard, and makes excellent fuel. This also occupies large tracts of country; the cattle, horses and sheep feed on the young leaves, and, by breaking down the plant with their hoofs, reach the heart, which is palatable; they also bite off the thistle head and feed upon the seed.

There are other tracts of country which, lying low, produce a coarse reedy herbage and Pampa grass, which, growing tall and spreading, affords shelter for whole herds of deer, numberless partridges, large and small; and in the marshy ground and pools, myriads of wild ducks in great variety, plovers, cranes, spoonbills, flamengos, geese, swans, wild turkeys, and snipe in the season.

The tracts of land covered by the tall sodgy Pampagrasses are called 'pajanales;' such portions of them as do not lay too low are converted into excellent pasture lands by burning; on a clear dry winter's day they can be fired with ease, and without danger. On the land, sweetened by the burning and enriched by the ashes, a fine palatable grass springs up, much relished by the sheep. 
I have seen a 'pajanal' fired, and aided in firing it in fifty different parts, of a winter's morning - the flames rising to a considerable height, and travelling with the course of the wind until some break is reached or some "green patch restrained them; these fires will sometimes continue through the night, producing a singular effect.

In the summer time, on the great thistle beds, when the light dry stems are like so much touchwood, there is great danger of fire; from time to time much damage is done by the accidental igniting of the dry annual thistles.

The best lands for sheep in the Argentine Republic are those of the province of Buenos Ayres, within a radius of fifty or sixty leagues of the city. They are likewise superior to those of the Banda Oriental: the grasses are less coarse, more tender and shorter. They have been more fed over, and to this may be attributed the finer character of the herbage. An improvident practice of over-stocking has, however, very much deteriorated some of these otherwise 'superior camps,' which will require some years, or a year or two, of comparative rest to resuscitate them: many of the best grasses have almost disappeared, a natural consequence of over-stocking, especially as most of the grasses are annual, and having had no opportunity of seeding, they have become extinct, or only grow to a limited extent. The consequence of this is that their place has been almost entirely usurped by the clover (spotted medick) which, from its luxuriant trailing growth, and the great abundance of its seed, protected by prickly spiral pods, propagates itself readily, aided by the thistle and strong weeds. The result is, that when the annual clover dies down and dries in the sun, all is brown and parched, and strong winds sweeping over the higher grounds roll up the withered stems and carry 
them away, leaving the bare soil, into the dust of which the seed is shaken, and out of which it sprouts with the autumn rains. On such lands the sheep and eattle pick a seanty subsistence from the roots and seeds in summer. In a season of continued drought they no longer find this food, and die in numbers.

The aspect of the country or camp in the summer and commencement of autumn presents a marked contrast to the other seasons. All is parched and brown; the thistle has dried and disappeared; the trifolium, in like manner; in the lands where there are tall grasses, they too, are brown and fallen: under the shelter of these, however, if there have been a few summer showers, young grasses spring up, and this tender herbage and the dry grasses intermingled, constitute good food; and when there is water, the animals do well. In great droughts, on the other hand, all lakes and most of the brooks and streams are dried up, so that if there is no means on an establishment (which through improvidence there sometimes is not) to draw water from wells sunk for the purpose, immense loss is sustained; eattle die by thousands, and others stray away to great distances in search of water ; the majority of those which have not perished returning to the land on which they were bred, on the reappearance of a better state of things. Sheep farmers have occasion, in districts visited by drought in an unusual degree, to travel their sheep to other lands, taking them many leagues. It is, however, only in an extreme case when this has to be done, and generally this necessity arises on those establishments where over-stocking has been practised.

The seed-pods of the trifolium (medick clover) are a great detriment to the wool of the sheep of Buenos Ayres when the shearing is delayed to the season of the ripening, 
and is known to the wool buyers as 'carretilla,' or small burr.

In the Banda Oriental, Entre-Rios, and Santa Fé, there are very good sheep lands, some few of which can be compared to those of Buenos Ayres; the coarser lands, however, will improve under judicious stocking. In the province of Buenos Ayres, without the radius spoken of, there are lands which have the same disadvantages as those of EntreRios, \&c. The grasses are somewhat coarse and strong, and in many parts of all the above-mentioned provinces they are so much so as to be quite unfit in their present state for sheep, and will be so until they have been well stocked with cattle or fired; the seed-sheaths and stems of the grass, known as the 'flechilla,' or arrow-grass, which abound in certain districts, adhering to the wool and matting it, also working their way through the skin of the sheep into the very flesh. This 'flechilla' is well known in Australia.

Around the large towns there is generally a radius dedicated to agricultural purposes; outside this, for a number of leagues, say forty or fifty, in the province of Buenos Ayres, the lands for the most part are devoted to sheep pastures; beyond them again, the cattle establishments predominate, the advance of sheep-farming gradually and steadily driving back the cattle to greater distances, and on to the coarser grasses. The latter, eating down the coarser herbage, fit the land for the reception of sheep, and I have little doubt that, in due course, many tracts of country, at present unsuitable for sheep, will become equal to those now esteemed as the best.

The soil in the province of Buenos Ayres, parts of Entre-Rios, and Santa Fé, is a deep rich alluvium, that rests on a subsoil of siliceous clay, as the rule, without sa much as a single stone or pebble. In the lower lands, 
those more recently freed from surface-water by the rising of the land or the receding of the waters, the layer of vegetable loam is less deep, and the soil retains somewhat of the character of mud deposits, with more or less sand, clay, or shell lime. In the Banda Oriental and parts of Entre-Rios a rich loam rests on rock formation, more or less near the surface, or on a subsoil of compact sandy shale and clay; rock crops out from the soil, and the débris of rock mingle with it. There is a considerable extent of woodland, furnishing everywhere abundance of fuel and materials for 'pens' and hut building; also affording shelter, but diminishing the available space for grazing purposes.

\section{IV.}

As the exports and the nature of the country, its climate and special adaptability for the purpose, and the foregoing indicate, the chief industry of the Rio de la Plata is pastoral. Within a radius of a few miles or leagues round the cities or towns, the lands are occupied by agricultural farms, where grain, wheat, barley, and maize are grown; also lucerne, for soiling and haymaking; likewise potatoes, pumpkins, and other items of agricultural produce. And there are a few establishments in which this is combined with the breeding of fine stock and fine sheep-for ram-breeding of the Negretti and Rambouillet breeds, shorthorned cattle, and where English blood sires, Cleveland bays, and cart stallions are kept for breeding purposes. The land within the radius is all fenced in with wire fence or hedges of the napondy, a prickly plant of the mimosa order, closing its leaves at sundown and in rain. There are also large plantations 
of peaches, apricots, and nectarines sown for fruit, but the majority for faggots, and are cut for this purpose every third or fourth year. Other plantations are of paraiso and acacia, and supply posts for fencing purposes ; also willow groves and Lombard poplars. In the Banda Oriental, Entre-Rios, and in the islands of the rivers, there are, besides these, woods of tala, espinilla, goiava, and an exceedingly hard wood known as ñandubay, valuable for fences, cattle pens (corrales), \&c. This wood is durable in the extreme, so much so that posts that have stood in the soil for a hundred years have been taken up from the corrales perfectly sound. In the villas and gardens, in the outskirts of the cities, there are vineyards, orange groves, pomegranates, apple and pear trees in great variety. The vegetables and flowers are of the sorts cultivated in the flower-gardens, and green-houses, and in the kitchengardens of England. Many of the hedges of gardens and villas are of the varieties of aloe, cactus, prickly pear, elder and blackberry.

Outside the agricultural farms of Buenos Ayres, the great sheep-walks almost monopolise the campo. The development of this interest has been rapid and important in the extreme during the past thirty years. Estancia after estancia, district after district, has passed into the hands of the sheep farmer, or the estancias have been dedicated to this by the owners. To the British settler, the country is mainly indebted for this, and it has grown year by year into greater importance under their auspices, while they have become some of the largest landowners in the country.

The value of sheep has increased tenfold within the past twenty years, and land has improved in value in the same ratio, though at first more slowly. I remember the time when flocks of sheep were offered and sold at $7 \$$ or $10 \$$ per head; and a few years prior to this, Creole 
sheep were of so little value that they were killed that the carcases might be cast into furnaces to serve as fuel.

The improvement in the sheep, and their increased value, is due to the introduction of Spanish Merino and Saxony breeds, with which the Creole and Pampa sheep were crossed and continually refined. The flocks were reduced in numbers and better tended, the increase in consequence facilitated, the animals more domesticated, the flesh as well as the wool improved, and the yicld of grease augmented.

So important was the improvement of the sheep in all points that, with the course of refining, the value year by year rose until good cross-bred sheep reached the prices of $40 \$$ and $50 \$$ each, and the wool of the best flocks could be compared at no great disadvantage, in point of fineness, with the Merino; but in consequence of the dirty condition and large quantity of 'carretilla' or burr, had a market value in no way commensurate with its degree of fineness.

As may readily be supposed, with the rapid increase in numbers, equivalent to a compound interest of 25 to 35 per cent. per annum, and augmentation in value both of sheep and lands, considerable fortunes were made from very small beginnings, and with little or no trouble or outlay in the management. In lieu of payment in cash to shepherds, the owners of the land and sheep freely gave flocks on halves, say half the increase and half the wool, and these men, many of them of the poorest classes of English and Irish immigrants, participating in the benefits of this rapid augmentation in value of the stock, throve with their employers; and on the expiration of their contracts, and the division of the increase, moved with their flocks on to lands rented at a mere nominal figure, 
and finally became purchasers of land, half a league or one or two square leagues in extent, and owners of many thousands of sheep.

This phase of sheep farm management in due course reached its climax, and, passing the interest or share given in lieu of wages, soon became much more than an equivalent to a good wage ; and the interest given was reduced in the new contracts to one-third, and then to one-fourth, and ultimately, according to situation of the land and the quality of the sheep, to one-third and one-fourth of the increase, without wool; and the majority now pay their shepherds' wages in money. From the first, many flock-masters, resident on their property, have pursued this latter course, and consequently have had a more rapid augmentation of wealth.

Sheep-farming practice is again entering upon a new phase. The comparatively higher value of land, and the fact of the land within forty or sizty leagues of, and in one or more directions considerably more distant from, the city of Buenos Ayres, being fully stocked, is forcing the tide of sheep-farming extension into other provinces and other States, into the Banda Oriental (or Uruguay), EntreRios, and Santa Fé, as well as to more distant parts of Buenos Ayres, where lands, if not quite equal to those of the accredited sheep lands of the latter, are lower in price, more easily obtained, and are capable of being much improved by stocking; also the maximum of improvement attainable on the old system of management, and from the Merino cross, under such system, has been attained, and the lands are found to bear a value fully up to that of the sheep and the yield of wool therefrom. The fleeces are very light, the wool short, fine, and deficient in strength, the result of slovenly breeding, management, and overstocking of the land. In view of these things I 
am convinced that the 'actual' position of sheep-farming in the Rio de la Plata offers a brilliant opportunity to the pioneers of an improved system of management and breeding, with the object of producing a more robust animal, one of larger carcase, yielding much more grease, a flecce double the weight, and wool as long again in staple; at the same time more sound and elastic than the average of the present stock-the means to attain which end will be suggested in another part of this work.

\section{V.}

Sheep estancias are of various extents from half a square league to four and five or more square leagues. There are combined cattle and sheep 'estancias' of very much greater extent; many proprietors count from 20,000 to 100,000 , and in some instances a still greater number, of sheep in their possessions.

An establishment of this class consists of an estancia house of more or less pretensions in size, round about which there generally are plantations of paraiso, acacia, poplar, willow, mulberry, and some few sturdy 'ombú' trees; also in some cases peach plantations, out-offices, sheds or 'galpones,' horse 'corrales' or pens, and sheep 'corrales.' These 'poblaciones,' habitations, with their foliaged surroundings, stand out clear in the plain, and are seen for considerable distances. Travelling farther and farther out into the plain they become fewer and further apart. On different parts of an estancia there are erected the huts of the shepherds, with their 'corrales,' called 'puestos' or stations, which, with a certain extent of ground, are allotted to the different shepherds or "puesteros' for the run of the flock under his care. For the 
maintenance of the 'puesteros,' the meat of a wether (capon) is allowed between three or four of them, the skin, tallow, and grease being set apart for the proprietor, and collected periodically. The 'puestero' provides his own 'yerba' (Paraguay tea) and sugar, and, if he indulges in the luxury, his own biscuit and salt.

Fuel he provides himself with from the stems of the hard thistle, 'bisnaga,' or the excrement of the sheep, cut out of the corrales in solid cakes and dried, dried cattle droppings, and animals' bones. He makes his fire either in the open air, in the centre of his hut, or under a shed outside; he runs a long spit, 'asador,' through the meat, and sticks it in the ground with an inclination over the fire. There are many, however, chiefly foreigners, who show more refinement, and possess a table and chairs, fryingpan and saucepans, plates, knives and forks, and will set a benighted traveller, seeking their hospitality, down to a good.stew, with rice and eggs, in addition to the customary exceedingly sweet roast or ' asado,' laid out on a clean table cloth, a cup of genuine Congou or Souchong, with ewe's milk, and the never failing 'drop' of spirit to drive the cold or keep the heat out; and last, and best of all, a hearty English, Irish, or Scottish welcome. If there is a tidy 'wife' in the cabin, a clean pair of sheets and a blanket, and a gay quilt to sleep under. In some rare instances, a 'beautiful fither bed,' brought all the way from the 'Ould Conthry,' will be produced for highly honoured guests, in which, if the temperature happens to range at about $80^{\circ}$ Fahr., the perspiring guest is fairly smothered, and overwhelmed with the intended kindness.

The life of a shepherd in the camp is solitary enough : a man who does his duty should never leave his flock, until, at least, they are shut up at night; and then not for long. It is not always that a flock is shut up in the 
' corral;' in fine weather they are left on the 'rodeo,' a bare piece of ground near the house, to which they are driven to pass the night, where they have more space, are kept cleaner, and can rest perfectly quiet; in wet and dirty weather it becomes impossible, without serious prejudice, to put them into ' corral,' on account of the accumulation of excrements and mud. Under these circumstances, on stormy nights, the shepherd is required to be up with his flock, riding or walking round them (' rodeando' them), to prevent their driving before the wind and rain ; in licavy gales there have been instances of large numbers being swept away, running before the blast, and, encountering a swollen brook, plunging head foremost into it, under the influence of the hindermost, and perishing to the last.

In the daytime, in a storm, they are very apt to drive, and especially in a dust storm, by which, occasionally, great losses and considerable inconvenience through the mixing of the flocks is incurred.

The ordinary routine of the shepherd's duties is to take out his flock of a morning, as early as possible in the summer time, while the dew is on the thirsty grasses, and return with them at sundown, taking them to the natural drinking places, when there are any; and in droughts, on those establishments where wells are sunk for the purpose, to drinking troughs supplied by drawing water with what is called a 'manga' (or sleeve), a long canvas bag, with a hoop at the upper end, and a rope at each extremity, so arranged that the 'manga' fills (in part) and comes up doubled until ont of the well, when the upper' end or mouth is elevated, and the lower drawn out, shooting the water into the trough or drinking pool. The drawing of the water is done by a horse.

In the winter time, and especially while hoarfrosts and cold dews are on the tender grasses, the sheep are not 
taken to the pasture until the sun is well up and the frost dispelled.

The events of the sheep-farmer's year are those of 'señalando,' or the marking, the cutting of male lambs, and the shearing.

All the men and women of the district are put in requisition for the shearing, for which they are paid per 100 head the usual price of $40 \$$, making, with the tying of the fleeces, a cost of about $1 \$$ or $2 d$. per sheep.

All districts possess their musical geniuses, 'paisanos,' or country folk, who 'strike the light guitar,' and sing impromptu ditties. These gentlemen bring their guitars to the shearing, and, the work of the day over, a fire is lit in the open, the ' asado' is put down to cook, and the 'ting-ting' commences; laughing, chaffing, singing, and dancing are the order of the night, until the fires go out, and the parties stretch themselves out to sleep.

In the majority of flocks, there is no separation of young or old, and the rams run all the year round with the flocks exposed to the same vicissitudes; there are, in consequence, lambs the progeny of under-aged half-grown ewes, and aged and toothless ones; and though the lambing falls chiefly in the spring and autumn, there are more or less lambs dropped throughout the year: the rams, too, are put into the flocks at, or left in them from, an early age. These various practices are very great stumbling-blocks to the improvement of the sheep, prejudicing the weight of flecce, the soundness of the wool development of the animals; a marked tendency-indeed a positive degeneracy - to delicacy, is the consequence, which a modification of system, practice, and the use of stronger and healthier rams will alone correct.

The true principles of breeding are little known, and less practised. On many establishments of some preten- 
sions there is a flock of finer sheep kept at the estancia house for the purpose of furnishing rams to the other flocks. These sheep are of Merino origin, and certainly are as fine in wool as the average of Spanish Merino fleeces. These, though having a little extra attention, and in some instances sheds for protection, have been treated as breeding flocks in the same way as the others, all ages procreating and lambing, and all seasons of lambing. These fine-wool flocks have almost everywhere diminished in the weight of wool yielded, in some instances not averaging over $2 \frac{1}{2} \mathrm{lbs}$. per fleece. From such flocks the rams for the cross-bred flocks (Mestiza flocks) have been drawn; hence it is easy to account for the general character and deficiencies of the wools of these countries; and it accounts for the still (compared with other woolproducing countries) small value of the individual sheep.

There are other estancias, on which a much higher class of sheep are bred, for the sale of rams. A considerable number of fine Saxony and Negretti and Rambouillet rams and ewes have been imported, the rams of which in most instances have been put into the Merino flocks with great advantage, though by no means as the rule, with all the benefits that would have been attained on a better system of management. The same practice, as described, as that with the Merino flocks has been followed with these higher classes in the majority of cases.

There are other establishments again where the pure breed of these imported varieties is maintained, and where there are large, and in some cases, costly sheephouses and sheds, 'galpones,' and paddocks fenced in. On these 'cabañas,' pure-bred and various grades of crosses are produced for sale of rams. Pure Negretti or Rambouillet, and crosses of the two: crosses of one or the other with the Merino, and with cross-breeds to meet the 
fancy of the buyers. I do not hesitate to pronounce this intermixture of breeds as very bad practice, tending to obliterate anything like a definite type. The sheepfarmers are inconstant; one year they will put into their flocks rams of Rambouillet cross, another year they will supplement these with Negretti, and another Merinos, in the same flock.

It is true that, with the rapid extension of sheep-farming, and the comparatively small proportion of high cast rams at present bred, and, moreover, the comparatively recent introduction of the Negretti and Rambouillet breeds, something of this was inevitable. The rams and ewes imported from Germany and France possess various degrees of merit, and, sold by auction, fetch prices accordingly. Sums equivalent to from $15 l$. to $150 l$., even $200 l$., have been paid for rams.

Some few of the British breeds have been likewise introduced, Leicester, Southdown, and Shropshire, and there are cross-bred flocks from these.

\section{VI.}

\section{CATTLE.}

The great cattle establishments, 'estancias,' as before said, occupy lands for the most part farther distant than those devoted to sheep-farming in the province of Buenos Ayres; but there are many estancias within the sheepfarming districts still occupied by cattle, or on which both sheep and cattle are bred.

There are many tracts of land on a large estancia, say of ten to twenty-five square leagues, as well as certain districts or lines of country, which are unsuitable for sheep : 
for instance, low strong land, with rank reedy grasses, often flooded, and on some of which the 'leech' is generated; there horses and cattle hold their own.

In the Uruguay and Entre-Rios cattle prevail almost everywhere, and there are comparatively few estancias whereon sheep alone are reared; but the same process of gradual encroachment of sheep on to the previously pure cattle lands is going on there as in Buenos Ayres.

The distribution of a cattle estancia 'plant' is similar' to that of a sheep farm :- the estancia house, with horse corrales and cattle corrales, and puestos in different parts of the ground for the herdsmen. Each puestero has his herd (rodeo) of cattle and tract of land appointed to him.

There is a 'capataz' (overlooker) to a certain number of puestos, and a mayordomo, or manager, over all : also there are immense troops of wild mares and horses. A ' rodeo,' or herd, is various in size, consisting of a few hundreds or a few thousands semi-wild cattle. The puestero tends the cattle and keeps them within certain limits, and prevents them mixing with other herds. On some establishments they are brought up to what is called ' el rodeo,' a bare piece of ground near the station or puesto, at sundown, or they are only thus gathered up occasionally. They are settled to rest on the rodeo by 'peones' riding round them; it is from this practice of herding them-'rodeando,' surrounding or riding round - that both the ground and the herd take the name of 'rodeo.'

In these estancias we see the true type of the gaucho of the Pampas-a type now-a-days rarely found in the sheep districts-men familiar only with the plain on which they were born and have lived, without ever having known or seen anything beyond it. 
Their faces are blackened by exposure, their long black and matted hair reaching the shoulders and mingling with the beard. They are rarely off horseback. They are dressed in long wide cotton drawers, and a garment called ' chiripá,' in lieu of trousers, girdled round the waist with a long woven belt (faja), a leather pouch-belt, into which is thrust, across the loins, a long knife, a shirt and poncho, a coloured handkerchief over the head, and felt hat. The skin of a colt's hind legs, freed from the hair, and dried and softened by rubbing, serves for boots, the point of the 'hock' forming the heel, and the big and second toes protruding. They wear huge iron spurs, with rowels three inches in diameter, and have rarely known other bed than their ' recado' (saddle) stretched on the ground, their 'ponchos,' or cloaks, with the saddle-cloths, forming their covering. Their horse-gear is their sole furniture. The lasso, when not in use, is coiled and fastened behind the recado, and lays over the rump of the horse, and with balls ('bolas') for balling wild horses slung in the belts, a powerful bit in the horse's mouth, and hide reins, the man and his outfit are complete. He rarely knows any other food than beef, 'asado,' with or without salt; his luxuries are 'maté,' Paraguay tea, sucked through a tube from a gourd, and cigarettes. Born to the horse, as it were, the gaucho is a splendid horseman, dexterous with the lasso. In full career after a wild bull or cow, he swings the lasso and throws it unerringly over the animal's horns; then checking the horse, the lasso, which is fastened to a ring in the broad hide girth of the saddle, 'recado,' is drawn taut, and the animal swung down or thrown.

A single man will thus catch and kill his meat in the plain; the animal being thrown, the trained horse will stand or move onwards in such a way as to keep the lasso tight, and prevent the animal from rising, while the 
gaucho dismounts, hamstrings, and kills it with his long knife. Swinging the 'balls,' he will pursue the wild horse, and when within range cast them, striking the legs or the ground within the horse's stride; they wind round the fleeing animal's hind legs, and cause it to fall. His horse falling with him, even at full gallop, the gaucho rarely comes to grief, for loosing his knee hold, he is impelled forward on his legs, and catches his horse before he is up.

As an instance of the extraordinary sagacity and cleverness of a horse perfectly trained to work among cattle, I will relate an encounter which took place only two or three days ago, on the town killing-grounds, at the southern extremity of the city of Buenos Ayres, and witnessed by my son. An unusually large and powerful bull was loosed from one of the corrales; he was approached in the usual way by the lasso-men, whom he charged, freeing himself from the lassoes; he became infuriated, and charged and charged again with such velocity that none of them could succeed in throwing him; he unhorsed two of the men, disembowelling one of the horses, and injuring the rider; he gored another horse in the leg, and finally beat his antagonists out of the ground. There was a moment of suspense, for none seemed willing to try their chances against him, when from the far side of the killing-ground an old man was seen to approach cautiously on a somewhat lean and ancient-looking roan horse; a cry was raised by the beaten lasso-men to warn the old man, and induce him to return and avoid what appeared to be certain death; but the old man heeded not, and availing himself of the diversion of the bull's attention to the cries in the front, ran his horse, breast on, against the infuriated animal's flanks, which staggered and then instantly charged. The old man dexterously avoided the onslaught, cast his lasso over the horns, and, at the same moment, drew a rug 
(pellon) from off his saddle ('recado'), shook it in front of the bull, and threw it forward, and at the same instant slipped from his saddle unperceived by the beast, whose attention was drawn off by the rug, and away went the horse, the bull charging him. The horse, having no weight on his back, headed and turned with great rapidity, got a strain on the lasso, and continued to 'work' the bull until he finally threw him, and then keeping the lasso 'taut,' moving with every struggle of the bellowing animal, prevented him rising, till the old man approached on foot and gave him the coup de grâce.

The 'events' in cattle estancia life are those of the ' branding,' with the owner's ' mark,' the young cattle, and cutting the young bulls; also parting out cattle sold for the markets or saladeros.

The marking or branding is a great time; the mayordomos and capatazes of the neighbouring estancias have notice to attend, if they wish, so as to part out the cattle of their employers' brands should any have strayed or mixed. The 'peones' of the estancia are mounted on their cleverest horses; the cattle are driven into the estancia corrales; a large fire is made of cattle bones outside the corral, wherein to heat the 'brands.' Girths and saddles are looked to, and rearranged, if not quite in order, a matter of the greatest importance, as on the girth (cincha) and recado the whole strain of the work falls. Lassoes are buckled on and held in coils in the hand. The group is picturesque. The cattle in the corrales, the large fires outside, the dense smoke curling and rolling along the plain, the groups of boys and men at the fires, the 'stokers' and the brandsmen half enveloped in the smoke, and on the alert to climb the posts of the corrales in case of danger ; add to that twenty-five or thirty horsemen, freed from all superfluous garments, with coloured 
handkerchiefs tied tight round the head, many and bright coloured shirts, ' chiripaes,' of all colours, scarlet, drab and scarlet, blue, green, and white, mayordomos and capatazes overlooking, and distinguished by their gay horse trappings and their huge silver spurs.

The work commenced, the animals are drawn out of the corral as required, lassoes cast over the horns and round the hind legs, the young bull thrown to the ground and kept stretched, so as to be unable to rise. One of the brandsmen darts from the fires, steadies himself by placing one foot on the prostrate animal, and plants the brand. The castrators perform their operation. The lassoes are slackened and cast off, the animal rises; some trot quietly off, downcast and surly; others glare around and charge the nearest men, horses, or group, furiously. Away gallop the horsemen, with loud wild shouts and laughter, - the pursued to escape, others to draw off the maddened animal from those that are hard pressed, edging him away further into the open, where he is left. The day winds up with the 'asado' (roast) in the usual way, and the men 'yarn' over the feats of the day, as hunting men are wont to do, of the 'run' and its incidents. The guitar and the ditty are, as usual, in requisition, and the younger men frolic and spar with their knives.

The parting out of cattle sold for the 'saladeros' is another busy time. A certain number, hundreds or thousands, are sold of a specified age and condition. The purchaser picks from the herds such as correspond with the definition in the contract; these are parted out from the herd, and for this purpose there are trained oxen termed 'señaleros' or decoys, which are placed at a certain distance. The selected animals are parted out and chased by the peones until they join the group of 'señaleros;' when the number is complete they are driven off for their 
destination. The 'tropas' (droves) are accompanied by a chief drover and peones, corresponding to the number of head of cattle, usually one man to every hundred head. They travel with their change horses ('tropilla'), headed by a mare with a bell, which go in front of the cattle. Behind these, driving them, and keeping the cattle from rushing forward, rides one or more peones; others are on the flanks of and behind the 'tropa.' At night time the cattle are stopped, and the peones ride round them until they settle and lie down. Horses are changed, fires lit of thistles, bones, or what can be picked up, and the 'asado' puts down to roast, an animal having been killed to furnish it.

The cattle are long-horned, generally of from small to medium size, and of varied quality, according to the locality and nature of pasturage on which they are reared and bred. In some 'partidos' (districts), consequent on the nature of the pasture, the cattle vary, yielding larger carcase and heavier hide, lighter hide and more grease, and of smaller or larger size. On some of the Banda Oriental campos, and in parts of Entre-Rios, they are fully as large as those of Buenos Ayres, and the hides exported are heavier, partly, it is true, owing to the bullocks, or neats, being as a rule killed when somewhat older, but likewise owing to the stronger nature of the pasture, greater shelter of trees, \&c. The oxen, when fully matured (five or six years of age), are powerful and weighty, carrying enormous horns, and make very good draught animals. Except on the lines of railways, nearly all the transport of goods and produce from and to the country is effected in large, ungainly carts, with huge, hard wood, and untired wheels, to which six oxen are yoked by the horns. The cows are but scanty milkers as a rule; there are, however, some marked exceptions. 
The dairies for supplying the town with milk are of the most primitive fashion, consisting of a hut and a corral, a greater or less number of cows, and a tract of campo to graze them on. The cows are milked once in twenty-four hours-at dawn of day-and the milk at once transferred to a inumber of small, round tin cans, which fit into hidelashings on each side of the saddle, or pad, of the milkman's horse, on which he mounts half-sitting, half-kneeling, and trots off to the city to supply his customers. The calves are allowed to run with the cows during the day, but parted from them and shut up in the pen or corral in the evening, the cows being left at liberty to graze. There are a few establishments better regulated, where good cross-bred (shorthorn cross) cows are kept, and a little lucerne soiling and hay supplied them when grass is scanty; and in some of these are milk-rooms, or dairies. Excellent butter is made in such establishments, which commands a high price, especially in the winter time. In the spring, when milk is abundant, some of the milkmen make an inferior kind of cheese, as also butter.

During the past dozen years, many English-bred cattle have been imported for the purpose of crossing with and improving the native breed. The majority of those imported, both bulls and cows, have been of the shorthorn variety.

The value and importance of this movement can hardly be over-estimated. Nevertheless, it has not found general favour, as few have hitherto derived that direct pecuniary benefit which is needful to give it wide-spread acceptation.

To understand this, it is requisite to take into consideration the uses made of the great bulk of the cattle of the country, and from which they take their value, as also the position and management of the cattle establishments.

The chief value of our cattle at present is in the hide; 
and, secondly, in the tallow and grease. The cross of the shorthorn does not, to any very great extent, raise the weight of the hide, and in this particular, apparently, does not augment the value of the cattle in a degree commensurate with the cost of introducing high blood into the herds. The introduction of these higher class animals, whose good qualities have been perfected under domestication, high breeding, selection, and feeding, into the semiwild herds of the plain, subjecting them to similar treatinent and obliging them to seek their food as best they can, and exposing them to all the vicissitudes which the common herds are, as it were, born to, is not likely to lead to immediate appreciable advantage in any other particular. Subject to the same treatment, as I have said, and acquiring the habits of the half-wild cattle of the country, the cross-breeds after a few generations, where cross-bred bulls only are used, make little more fat and not much more beef than the common stock. The often precarious and unequal feeding or pasture, the long driving of the animals to the slaughter, unfit the cattle for any purpose other than the common one of hide-salting and steaming for grease. Ninety-nine out of a hundred of the estancieros know no other use for their cattle, and have no conception of any other principle of breeding than that of a state of nature; and immediate and palpable benefit alone would induce them to step out of the accustomed course, and in many cases not even this would induce them to take the trouble. It is not likely, therefore, that cattle-1efining will, for some time to come, attain any wide-spread development. The spirited pioneers of the attempt find themselves without the support which they anticipated; they find no sufficient sale for the bulls which they breed, so that the improvement is limited to their own herds. On these establish- 
ments the ultimate result cannot be doubtful, as the principle of greater domestication is applied, and the best pasture lands are dedicated to the cross-bred herds, by which the tolerably even growth of the young animals is secured, and the breeding stock not allowed to fall into absolute low condition. A decidedly improred stock will, therefore, be created on these estancias, and in the course of time, a not very far distant time, their superior qualities as beef makers and fat producers will be recognised, and a profitable use will be found for them. The cities and large towns cannot long continue indifferent to the existence in their vicinity of animals that will yield a superior meat, in much larger proportion per head, under a system of at least 'half-fatting,' and the call from Europe for meat supplies, must sooner or later induce the possessors of well-bred herds to take steps to put their neats (steers) into a condition that will give beef of a quality more or less 'up to the mark' of European requirements. The problem of ways and means of putting cattle into at least a fair condition, has yet to be solved. As it is totally new ground, men hesitate to take the initiative. The growing necessity, howerer, must compel it, and a company of breeders and others might very well make the venture; they could do so with small individual risk, and with every prospect of a highly satisfactory result.

Such an undertaking, an initiatory and experimental one, would have necessarily to be placed under the direction of a party, or parties, having a good practical and theoretical knowledge of cattle-feeding, and also of the country, its climate, products, and agricultural capabilities, accompanied by perseverance and zeal.

The locality should be well chosen, and within a reasonable distance from, and easy reach of, the city. The cattle with which the experiment should be made should 
be domesticated, well-formed cross-breeds, calculated to lay on flesh of a superior veined quality on moderate feed. The system probably most feasible would be one of a combination of yard and paddock (potrero) feeding; to maintain which a succession of forage crops would have to be grown. It is noticeable that the cattle of the country, even when on the best pastures, do not vein the meat with fat, and the flesh, by consequence, is wanting in flavour, richness, and delicacy, and they are comparatively unprofitable feeding for beef.

The unchecked development of young stock, the produce of crosses of shorthorned and Hereford bulls with selected native cows, when somewhat extra care is taken to secure the even growth, is, as I have seen and proved, highly satisfactory, especially so in the second and more advanced crosses. Exceedingly neat, level, and square animals are produced of fair size and 'good hair,' manifesting really good fatting and beef-making qualities, so much so that on the same feed they will make nearly double the beef and fat that can be obtained from the native breed; as also excellent milking ones when this object has been sought after. I have cows of this class which give me in the height of their milk as much as sixteen and eighteen quarts per day.

The power of transmitting type and colour resident in pure-bred (Herd Book) bulls is manifest in a high degree in the crosses with the cows of the country. All the established and accredited colours of the shorthorn, from pure white through all the grades of roan to red, prevail in a carefully managed shorthorn cross herd; and I have seen a herd, the only one that I know of in the country, the produce of three Hereford bulls (of Mr. Naylor's stock) and cows of this country, in which every animal got by these bulls, from the first cross upwards, was 'true' in 
colour, and possessed, in a marked degree, the form and features characteristic of the Hereford blood. There were, by the way, four young animals which formed a singular exception, but an exception which proved the rule; they were the prodnce of two calvings of two black cows, which by accident got into the herd, and were allowed to remain in it. These young cattle had the "white' markings of the Herefords well and truly defined, as also the form and features; the one exception was in the 'colour,' which was black instead of red.

It must appear strange, indeed, to those who know the value of the shorthorn and Hereford blood, to learn that the owners of very valuable stock of these breeds are compelled to 'cut' the whole of the young bulls which they do not require for their own herds, in every grade of cross-first, second, third, and fourth.

I know several gentlemen who have very fine herds, including the party whose well-bred cattle I have alluded to above, who have not sold a single bull out of them. The loss that is sustained by the country at large from the 'cutting' of these young bulls is, unquestionably, very great; as these bulls put into the more domesticated herds, and into dairy kinds would, in a brief time, materially improve such stock; and, in course of time, furnish animals admirably adapted for the meat supply of the city, as being profitable to feed, making, with equal food, much deeper and more meat than the 'habit' of the indigenous cattle admits of. 


\section{PART II}

SHEEP FARMING.

\section{I.}

Is considering the adaptability of this country and climate to the various pursuits which constitute its national wealth, and the advance made in them respectively, we cannot fail to be struck with the predominance which sheepfarming is assuming. Equally as all must be struck with this, must they be impressed with the fact of the very low standing of its products, as compared with those of other countries (many of them much less favoured in soil and climate) in the markets of Europe.

It is imperative for the future prosperity of this important interest, that some well-defined principles should be laid down: some sound and sure method be adopted, to save us from further decline, and, as far as possible, to raise the standard of our products. To this end it is necessary that we should consider the source-the original - stock-from which our flocks have been derived, the course of refining adopted, and the class of animals with which the crosses have been effected; as also the manner in which the flocks have been treated: moreover, examine into the breeds, crosses, and practice of other countries resembling this in climate, and compare the results in the different countries. Also, enquire into the proposed and actual practice of these things, at the present day, as bearing upon the wants of the great markets. 
The original stock from which, with few exceptions, our flocks have proceeded, was the Creole sheep ; a legey, small-carcassed animal, with an open fleece, small and of light weight, coarse and without elasticity; possessing, in fact, no qualification to recommend it as a basis to breed from; the exception is that of the Pampa sheep, which is an animal much superior to the Creole in all points for the breeder's purpose. So small, however, is the proportion of the Pampa blood in our flocks, that it is not of importance to consider it; at the same time, it may be observed, that wherever that blood has been adopted as the basis, and its influence not obliterated by subsequent intermixture with sheep of the Creole origin, a marked superiority in weight of fleece and length of staple is observable.

The choice of the breed with which to refine our Creole flocks very naturally fell on the Merino, through which so general an improvement has been obtained in almost every country, in point of fineness, and with various results in other points, according to the basis employed and the influence of soil and climate.

The prevailing idea, but a comparatively few years back, was fineness of staple, and that was sought to be grafted on an infinite variety of sheep; with some it has been a success; in other cases it has been abandoned, and breeds adopted more suited to the necessities of climate and general requirements. The Merino itself has been modified and improved in different countries under different treatment and special selection. The Saxon, Merino, Negrette, and Silesian, are far superior to the original Spanish breed. The French Merino, or Rambouillet, is another example, and is a perfectly distinct type in almost every point, bidding fair to eclipse all otleer branches of the same family in general usefulness. The English Merino, of Saxon origin, introduced by George III., 
resembles in general and particular type, the best of the French Merino, i.e., those of the 'Cabaña Imperial,' the Rambouillets, par excellence, which are truer in shape and finer than any other French Cabañas.

The characteristics of the Merino, with which our flocks have been 'mestizado,' are small carcass, fine and not very long wool, and rather open in fleece. This openness of fleece has been considerably increased through the cross with the Creole; and the progressive tendency of the existing breed, coupled with the method of breeding pursued, and the maintenance of the sheep, has been, and is, to reduce, step by step, the weight of the fleece, as well as the length and strength of the staple.

There are many causes which contribute to this. Amongst them I will name the inequality of maintenance, whereby the development of the young animal is impeded or curtailed, and the wool rendered short, brittle, and false in staple-the use of small cross-bred rams of remarkably light fleeces-the putting of these rams into the flock at too early an age, and allowing them to run with the flock all the year round, whence they are often reduced to the lowest degree of wretchedness, debility, and diseasepermitting old ewes to remain in the flock to breed poor weedy lambs, which in turn transmit their hereditary debility and weedyness to their progeny; also allowing 'borregas' (immature ewes) to take the ram at too early an age, thereby producing the same results as breeding from old ewes.

The consequences of these causes combined are marked in the extreme, even in the finest flocks of those extensive estancieros who have been the pioneers of sheep-farming, and from whose stock, directly or indirectly, nine-tenths of the Mestizo flocks in the country have sprung. I believe that I am correct in stating that the Merino flocks 
of the greater part of these extensive estancieros do not average over three pounds per fleece, and many not even that. Notwithstancling the general fineness of the River Plate Merino and Mestizo wools, they are ranked among the lowest in the estimation of the great home markets; and this is directly attributable to the quality of the wool in point of length and soundness of staple-points in which it is markedly deficient, owing to the causes which I have named.

We have, in fact, no redeeming quality in our sheep; for the one point which has been aimed at, and attained at the cost of all other qualities, viz., fineness, is proving one of our greatest banes. Fineness without length, elasticity, and softness, is the reverse of desirable and does not pay.

The great consumption of the world at large is of longstapled wools: long and coarse have their especial value, and long and fine (fine without prejudice to strength) have theirs. So imperative has this qualification of length become, that we see the highest authorities of Spain contemplating the modification of the Spanish Merino breed, with a view to obtain length of wool and larger development of forn. In England the fine-woolled sheep are at a discount, as such sheep, as a rule, do not combine the various qualities which render sheep-breeding profitable. I have a recent report from England of the returns yielded by three varieties of Leicester, and one of Coteswold sheep, - the long-woolled sheep of England-and I find that the value of the fleeces of these breeds are $14 \mathrm{~s}$. to $16 \mathrm{~s}$. each ; the fleece of one of these sheep in England being worth more than two 'good Mestizo' sheep here.

These sheep, or 'capones,' at the age of eighteen montlis, under high feeding, attain the weight of 150 to $180 \mathrm{lbs}$. each, as they stand, and are worth for the butcher $3 l .10 s$. to $4 l .10 s$. Mature capones attain a weight of 260 to 
$350 \mathrm{lbs}$. The policy of introducing such sheep into this country is, however, doubtful under the present circumstances of our flocks; there being so great a disparity in type and wool, nothing would be gained in the matter of wool, as no cross that could be effected with our finewoolled breeds would result in anything but shortening and weakening the wool of the English blood, and vice versa, destroying the characteristics which give it value; and it would be a long time before any distinct class of wool could be produced in sufficient quantity to assert its claims in the markets; but where a vein of the English blood already exists it will form an excellent basis to refine on with English or French Merino; and with a few years of refining, a very useful and valuable class of wool, and a valuable animal, will be the result. At an earlier date in the formation of the types of our breeding stock, a strain of these English breeds would have been of the greatest value, but the opportunity has passed for the generality of our flocks. There are, however, certain native coarse-woolled breeds-instance the Cordova and the Pampa (which, if steadily crossed with the English long-woolled rams-Coteswold, Leicester, and Lincoln) would, in a few generations, produce a wool of special value, and a breed, perhaps, the most suitable for certain localities-in the localities in which the native long-wools still exist, and in others more or less similar, such as in and about the Sierras, Bàhia Blanca, \&c. In the case, too, of Creole sheep, or ordinary Mestizo, a couple of crosses of some of the English long-wools, and subsequent persistent crossing with the Rambouillet, would establish a very useful class.

The strongest analogy in circumstance and climate, with the most marked difference in results, exists between this country and Australia and Tasmania. Both countries 
have sprung out of the colonization of the Old World. In both, the climate is similar, and in a high degree favourable for sheep-farming; though the preference must be given to this country for general advantages of climate and soil. In both, the breeding of sheep has become the most important rural interest, and, by consequence, commereial interest. But here the similarity ceases, and the contrast commences. The wools of Australia and Tasmania stand unrivalled in their class; as a national product they are preeminent for length of staple and softness of texture. The Australian wool sales in the home markets are more important than, perhaps, all others put together; and the prices obtained mark the estimation in which they are held. Australian wools are attaining greater and greater perfection; so much so that, even in their own speciality, the great flock-masters of Spain consider it requisite to modify their famed Merinos to compete with the Australian and Tasmanian wools.

As we have traced the origin of the Buenos Ayrean sheep, and the causes of their degeneracy, so let us now trace the rise and progress of the Australian :-

As it was natural in a colony deriving its origin from Spain to select its animals from the famed ones of the old country, so also was it in an English colony; and the English breeds of sheep-Leicester, Coteswold, Lincoln, Southdown, Merino, and others-were naturally taken there, as were also the Spanish Merino and Saxony. In the forming of the flocks the English breeds took their part, and imparted size, weight of fleece, and length of wool ; giving a useful and well-developed animal as the basis of the colonial flocks, placing them in a most advantageous condition for refining. Long and persistent refining on this sound basis with the best English Merino rams (Cabaña George III., the term Cabaña with the French 
Imperial Cabaña Rambouillet : see the work of the Marquis Perales) and the best French Merino rams, procured regardless of cost, has done all that could be done in point of blood and quality. Thus the colonists, having from the first made their flocks of such value that it would pay to take care of them, as flocks from which progression is expected should be taken care of, they have zealously taken care of them, and dedicated themselves to their improvement. Physiological laws have not been neglected there as they have been here; the debilitated or diseased ram was not looked to as the sire of the coming generation, but well selected, well-cared-for, and vigorous rams were put to their ewes; old ewes went to the butcher, and the tender ewe lambs (borrequitas) were not allowed to be dams of a weakly offspring. Thus have they attained their present perfection, and they are still drawing firstclass rams, at first-class prices, from England and France; and, as I have been informed, the Cabaña Imperial supplies them with not a few of its unsurpassed Rambouillet Merinos.

\section{II.}

In the foregoing brief sketch we have traced the origin, course, and causes of the comparatively inferior quality and value of the wools of this country in the midst of the vast extension of sheep-breeding interests; and I read in this little short of an impending national calamity - the work of half a century, as it were, lost, and a new start to be made to enable us to hold our way at all with other wool-producing countries. We have also traced the rise and progress of another young country, following a different line of treatment and selection.

It now remains, knowing the causes, and knowing the 
effects, to determine on the requisite remedies, and to at once check the decadence, and raise the type of our flocks.

It will be recognised that the primary cause of all the existing and impending evils, has been the absence of the employment of a sufficient capital to form our flocks on the higher types, and of the labour and care needful to develop to the utmost all the good qualities calculated to give solid and enduring value to this most important branch of national industry. The principle hitherto (I speak generally) has been to look for profit in increase of numbers rather than in the increase of intrinsic value in the individuals; and under this aspect, people have considered their flocks as not worth taking care of (or expending money on), as care and attention is understood in other countries.

There is a limit, however, even to the profitable increase of numbers, without regard to intrinsic merit. Vast tracts of camp have already more stock than they can carry, and a great evil is imminent therefrom.* Allied with this erroneous principle, and being part of it, is what is known as the Medianero system as hitherto carried out. So long as flock-masters were content with mere increase of numbers as the source of profit, and souglit to obtain this profit without direct outlay of capital, it answered well for both parties; but it has been, and ever must be, fatal to any great improvement in class and quality of sheep. The estanciero could not afford to employ the requisite capital in the improvement of fiocks, as in such case the medianero would have reaped an undue advantage; and on the other hand, the medianeros had not the

* To such a point has this reached, that I have little doubt, ere long, sheep 'al corte' (all round) will not find purchasers at $15 \$$ and $20 \$$ each; they will be only worth the skin and fat. When capitals are brought into play to stock more distant lands there will be a reaction. 
means to meet the estancieros' outlay, by the employment of corresponding labour, to bestow upon the flocks that care which material improvement rendered absolutely necessary; and very few 'medianeros' had the knowledge of the business essential for the suitable management of an improving flock. Again, under the 'Nedianero' system, the estanciero ceases to be the sole master of his property, and can zot dispose of his sheep as is desirable; that is, he cannot, year by year, throw out the old or inferior ewes, or separate the 'borregas;' it being the ' medianero's' supposed interest to breed from everything young and old, in order to acquire the greatest possible number during his term of contract.

Under existing circumstances, I see but one course, which is, that flock-masters (estancieros) should make up their minds to a present sacrifice-an apparent sacrifice to lead to an ultimate benefit to themselves and the nation; let them get rid of a considerable portion of their stock, all the old and inferior, if only for the vatand the vat is unquestionably the best place for them-so that they may not mar in their progeny the future of sheep-breeding; then, with the capital realised, secure suitable rams, and take increased care of the remainder of the sheep.

\section{III.}

We now pass on to consider the individual defects of the sheep, and the best means of correcting them.

First, the diminutive size of the sheep is noticeable. It is clearly a great defect, as it offers no porvenir (future) of general usefulness and value; moreover, a small-carcassed sheep cannot, ceteris paribus, produce so weighty a fleece as a large-carcassed one. 
The first thing, therefore, to be done, is to increase the size of the sheep by crossing with large true-shaped rams; and on this subject I will quote the high authority of Mr. Carrol, inspector of cattle exhibitions and veterinary, Dublin. Mr. Carrol writes (Agricultural Gazette, October 29, 1864): ' I know well all the different breeds of sheep; the native Cotthonge, the Shrimonghs, the Scotch Highland Stornico, the Cheviots, the different Downs, the large Roscommons, the Coteswolds, the Lincolns, the pure Leicesters, Border Leicesters, et hoc genus omne, and the best crosses I have ever had, or have known to be had by anyone else, were those from the large, strong, sound, well-bred rams on every description of ewe, large or small ; and the very worst from small rams.' This is directly to the point, and should be pasted up on the wall of every flock-master's house. Then we have the unnatural, unhealthy fineness of wool, coupled with light fleece, short and unsound staple. The remedy for this is equally clear-the large, sound, well-bred ram, with heavy close fleece, of long sound and strong staple. Now I will lay down as a rule that no flock-master should admit into his flock, any ram that is not of a given weight and size of carcase, and that does not yield a given weight of close fleece, of long and sound staple, and that is not sound in constitution, strong and vigorous, for ' like beget like.' I must leave it to each individual to determine, according to his requirements and means, the minimum weight of carcase and fleece admissible into his flock; it being understood that the greater the weight and size, consistent with true form and type, and the size of the ewe, the better. I may suggest, that in no case should anything under a $12 \mathrm{lb}$. fleece be admitted. Breed of ewe, degree of fineness of wool; its class to be considered also in reference to the selection of rams. 


\section{IV.}

Next, as to the treatment: It is essential that the rams should not run with the flock. Nothing is so fatal to the sheep-breeder, as to turn his young rams into his flock. Degeneracy is the inevitable result; and in no country in the world, where sheep-breeding is in a state of progression, is it practised. No ram should be put to ewes until he is between twenty months and two years old; and then, only when he is sound and vigorous. All rams must be kept apart and well fed, and only put with the flock for a certain number of weeks at a certain season of the year. I have no hesitation in stating, from experience, that he will get more lambs under this system, as well as infinitely better ones.

Every estanciero should keep his rams at the estancia under his own care, or that of his mayordomo ; have them well fed, classified, and distributed among his 'puestos' at the proper season; and the 'puesteros' should be bound to feed them while in the flock. Rams that are not worth this expense and trouble, are not worth having. 'Borregas,' under eighteen months old, should be parted out from the flock before the rams are put in-'corraled' apart, and 'pastoreada' apart-under care of a shepherd. As to old ewes, get rid of them at any price. The rams should be put with the ewes at the season of the year when the camps are good; and no effort should be spared to keep the flocks in good, even condition. These are the only means which will make a flock of sheep 'worth taking care of,' and give it progressive value. 


\section{V.}

We will now pass under review some of the breeds from which to select rams suitable, in greater or less degree, for elevating the type of our flocks.

In doing this, it will be necessary to keep in view the existing prevailing blood, size, and form of the sheep, and the characteristics of the wool.

I have pointed out the great benefit that has accrued to the Australian breed of sheep through early crosses with the English large-carcassed and long-woolled sheep. At the same time I stated, that I considered the course taken by the sheep-farmers in this country, during the past thirty years, and the type resulting from it, has placed them in a position which prevents them availing themselves of the adrantages which, at an earlier period, would have arisen out of the introduction of strains of the various British indigenous breeds. This of course refers to the flocks which have been long 'refined'-Mestiza-dowith Merino blood, to cross which with British long-wools, would bring them back in the matter of texture of wool to a near approach to the original Creole or Pampa wool; and it would require a long time, and very careful selection of the progeny, on which to refine, to produce a valuable and distinctive type.

Having an established variety, however inferior many of its characteristics may be in degree, we must be particularly careful not to mongrelize it; and the shortest, easiest, and best course, is to improve and raise the existing type.

Nine-tenths of our flocks may be said to be Merino in blood, a little finer or coarser in wool, according to the higher or lower strains of this blood. I am, therefore, 
decidedly of opinion that, under circumstances, we may expect the best results, and the speediest, from a persistent use of rams, of such special type of the Merino family as will most effectually correct the defects of the majority of the flocks.

Of the Merino there are several distinct types created from one parent stock, by selection and treatment, and many subdivisions of the same.

The principal are the Spanish (original), the various German, French, and English branches.

The exquisite Prussian Silesian Merino-A perfect animal in its class, with a wool marvellously fine, long; and soft, a something to see to comprehend its full beauty; but, alas! unsuited to us for general purposes. Destroy its purity of blood, 'Mestizar it,' and you have relatively nothing. Only under the highest degree of breeding, intelligence, and minute care, could such a breed hold its way.

The Saxon Electoral Negretti, the Rambouillet, and the half-breed between the Rambouillet and Negretti.-This last let us at once discard. The one has spoiled the distinctive qualities, or type, respectively, of the parent breeds. As rams they are mere mongrels. In all cases, the rams used must have a fixity of type, and persistence of the same blood through several generations، Thus, while the half-bred ram between pure Rambouillet and pure Negretti is not admissible in good practice, on the other hand, if you take Negretti ewes, cross them with imperials, and continue to breed out of the ewe progeny, using always Rambouillet rams-in the course of three or four generations there will be established the requisite fixity of type and blood to render the rams so produced desirable stock.

The Saxon Electoral Negretti-Beautifully true in 
shape, fine and soft in wool, and a fair weight of fleece in the higher strains of blood.

Bearing in mind, however, that size, yield of fat, weight of fleece, and strength of staple, are the points that are needed in the highest degree, I cannot see that, as a general rule, these breeds fulfil our most urgent requirements. There can be no doubt, however, of the desirability and value of this blood in its higher grades, (nine-tenthis of those imported are almost worse than useless, they have neither purity nor quality,) when parties have flocks unusually well-suited to an union with this blood; but, as a rule, the animal is too small to produce, in its cross, the first essential improvement, viz. considerable increase of fat and fleece, and can never be so profitable as the larger varietics.

Again, our wools have already a degree of finenessan unhealthy fineness-which is its defect-so that it could hardly be expected that the graft of the Negretti fineness would effect an improvement in this respect, or give us a more sound basis for development.

Besides, the weight of the Negretti fleece* is not, as a rule, so great, nor the wool so long, as to suffice, in a few crosses, to raise the standard of fleece in the 'Mestizos' to an extent that would make the Mestizo rams the most desirable to put into our flocks. We urgently require an immediate, material angmentation in the length of wool, weight of fleece and carcass, as the sine qua non for the present position of our flocks. This breed, nevertheless,

* In the highest grades of the Negretti there are weighty fleeces, when, as they are usually, heavy in grease. This condition of greasiness in the wool is remarkable in the Negrettis; and, as the loss is very great in wa:hing, it will always be taken into consideration in the price paid, expecially as the fleeces have a decided tendency to collect dirt. These animals are procurable only at great cost, and, like the highest types of other varieties, are only suitable for the high-caste breeder's purpose. 
should be carefully preserved and fostered in the country by those parties who have attained a considerably advanced stage by means of this blood. These parties, however, would do well to put their 'Cabañas' through a severe course of purification and classification, rejecting everything that does not come up to a given mark in size, form, and fleece, and rigidly adhering to the general principles of management laid down in this work.

The Rambouillet (French Merino).-This breed is derived from several 'Cabañas :' the Cabaña Imperial standing far in advance of all others for trueness of shape, and fineness and texture of wool; but the high price of the Imperial stock has prevented its introduction into this country; and there are, perhaps, not more than two 'Cabañas' in the province, where the blood exists in its purity. The majority of the so-called Rambouillets introduced here are from other and inferior Cabañas, and many of them, judging from their quality, cannot be considered pure French Merino. I say 'so-called Rambouillet,' because this term, properly speaking, belongs only to the Cabaña Imperial.

The 'Cabaña Gilbert' produces an animal distinct, in many points, from the Cabaña Imperial. The rams of high class from this Cabaña are large (larger than the Imperial) imposing-looking animals, with large head, shoulders, and chest; but the wool is not so fine nor so elose, nor is their shape so true as the Imperials. English Merino (George III.) more nearly resembles in type the Rambouillet Imperial than any other branch of the same family.

I believe that it is to this blood (Rambouillet_French Merino and George III. Merino) that we must look for the regeneration of our flocks. I am confirmed in this by observation here, by the knowledge of the wants of the great manufacturing interest in Europe, and by the practice 
of the Australian breeders. The beantiful little Negretti, with its fine silky fleece, may be a more attraetive object; but it cannot fulfil the requirements of our flocks so well as the solid, imposing Rambonillet and English Mcrino; from whose progeny, in a few erosses only, a size of careass, a trueness of shape, a weight of fleeee, length, fineness, and texture of wool, can be obtained (as I can testify from aetual observation) equal, if not superior, under proper management, to nine-tenths of the sheep of the French Merino Cabañas.

Like all other high-bred animals, they require to be well kept to retain their good qualities, and in this they in nowise differ from any other fine breed. The effects of bad keep and bad treatment may be more manifest in this, but not more real, than in other fine breeds of smaller size; for their very grandness makes bad condition more visible. It is worthy of note that these are much less subject to scab (sarna) than the Negretti breed. In this particular they have a decided advantage, and the wool being longer and stronger, it is not so much injured by carretilla, burr, or impurities, nor does it accumulate so much dirt.

At all cost, we must bring up our sheep in size, yield of grease, weight of fleece, and length and strength of staple. That done, it may be an after consideration what distinctive characteristies we may give to the sheep in different localities, aeeording to the nature of soil, pasture, temperature, or elimate, markets, and other matters.

Distinctive eharacteristics can be created by a course of selection without departing from the blood or breed, or they ean be grafted by means of a cross and subsequent selection. The nicest judgment is required to adopt such eross and selection to the locality, soil, and climate. I believe I should be borne out by facts in the assertion, that 
for general purposes home-bred, i.e. acclimatised rams are infinitely preferable to imported. For the high-caste breeder it is another thing. It is his province to introduce the best and highest blood, acclimatise it, and modify it to suit general purposes.

\section{VI.}

Let it not be supposed that I am ignorant of the enterprise and great cost at which many gentlemen have, during the last few years, endeavoured to work out improvement in their flocks with both the Negretti, and in a few cases, the Rambouillet breeds. I could name a score who have spared neither expense nor efforts within their compass and knowledge; yet, in nine cases out of ten, failure and disappointment has been the result. One is disgusted with Negretti, another with Rambouillet, and each with apparent reason. But this is a fault which does not depend on the breed, for both strains of blood, within certain limits, are capable of improving our stock in one or other direction. The fault in both cases lies in the management, and in many, if not in most instances, in addition to erroneous management, the parties have made their trials with inferior 'blood' and small rams, and have, moreover, used the half-bred rams of their own breeding to put into their flocks. To succeed, the management must be a complete system. One point omitted will mar half a dozen practised-will mar, in fact, the whole. I have seen costly ' galpones,'-the most costly,but in no single one have I noticed a thermometer. I have experienced a sense of oppression on entering them, and breathed an air redolent of accumulations of foulness, owing to their insufficient ventilation; and I have seen in 
these costly 'galpones,' costly 'Negrettis' wheezing and looking wretched_costly 'Gilberts' 'tisicos' and miserable, without texture in the wool or firmness in the skin; and I have seen the decrepid progeny of these unhealthy animals running or hobbling with the 'majada' from year's end to year's end, and yet expected to beget improved stock out of 'borregas' and ewes of all ages! I need no one to tell me of disappointment and failure-it was patent and palpable everywhere. Only in one 'Cabaña' that I have had a report of, or seen-a small unpretending establishment belonging to, and under the immediate direction of, a native gentleman-liave I recognised the practice of a thorough system, more or less perfect in all points as adapted to the climate, \&c. and there success is as marked as failure is in other establishments of much greater pretensions, as far as extent and costly appliances are concerned. It suffices that success has been attained by one or two to demonstrate that it is attainable by others: and one instance of complete success should animate us with a hope that, despite our present backward position, a great future is open to us, if we know how to avail ourselves of the natural advantages at our command.

There is a great 'want' felt in the absence of a bond of union amongst the intelligent sheep-estancieros, which would be supplied by social club-meetings for the interchange of our respective experiences, agitating questions of interest, and for the promotion of exhibitions, ferias (fairs), and the like, which, as in all enlightened communities, should have the moral and direct support of the governments, both national and provincial; and medals and other prizes awarded for successful breeding of improved stock. Distinction is gratifying to all men; and many a persevering effort would be made, were there a hope of 
its being duly appreciated and rewarded with some lonourable distinction, such as a national gold medal, \&c.

\section{VII.}

Before concluding this brief review, I will quote from the highest Spanish authority, that of his Excellency the Marquis of Perales, President of the 'Asociacion General de Ganaderos.' He says (speaking of the Australian sheep-farmers and their flocks): "The extraordinary development which the sheep attain ; the zeal with which the sheep-farmers attend to their improvement, importing, regardless of price, the best breeding stock from England (George III. Merinos) and France (Rambouillet), adopting the best methods of breeding and caring, and the best system of feeding, puts it beyond doubt that the Australian wools must hold the foremost rank for general purposes and manufacture.' Then, after referring to the extraordinary length and softness attained by many Australian breeders, he says: 'It is undoubted that their wools must successfully compete with, and lower the prices of European fine wools, and that, therefore, it would be very desirable (muy conveniente) that the Spanish flock-masters should, in imitation of the English breeders, modify their breed with a view to increase the weight of the fleece, lengthen the staple, and increase the size, so as to be more productive of meat and fat.'

I apprehend, that with such an authority confirming the opinions I have emitted in this paper, there will be little doubt left on the minds of its rcaders, that herein are laid down the principles which should guide the great sheep-farming interest of the Rio de la Plata. 
I may observe also that the Germans are now recognising the same fact, and are actually getting rid of their small class of sheep to introduce the French (Rambouillet) and English breeds. Entire flocks of numerous German Cabañas are offered for sale as umprofitable stock.

The property of meat and fat producing, is one wholly lost sight of in this country, and a greater mistake could hardly be made. The sheep-farmers are placed by it at a disadvantage of a most serious character, as by reason of the small size of the sheep, and small yield of fat, they are at best of times unprofitable to kill, whether it be for the meat or for rendering for grease; but on overstocked or even fully-stocked camps, owing to the scant food, the little they would otherwise yield is often reduced to nil; so that unless purchasers for stocking purposes come forward to purchase by the million (the augmentation annually is now rated at from ten to fifteen millions)a demand little likely to take place-the sheep-farmers must remain with their sheep destroying their campsthat is, virtually eating up their capital-or they must throw them away, sell them for little or nothing-the value of the skins-or they will die by the thousand.

Now, it must be clear on reflection, that this evil would be avoided by having a class of sheep whose yield of meat and grease would bear a fair relation to their yield of wool. There would then be a double outlet for the increase at a remunerative price. There can be no doubt that it would pay to grow grease in the shape of sheep, and there are breeds of sheep which would yield 8,10 , or $12 \mathrm{lbs}$. of grease for every pound yielded by the existing breed as at present managed. Let us look a little closely into this. What is the annual yield of wool per head from the average class of sheep? Certainly not $3 \mathrm{lbs}$. Its average value is not $3 \$$ per lb.; but take it at that, and we have $9 \$$. The 
same animals would probably not give over $5 \$$ in grease. Sheep of a fat-producing description, would yield, say, on

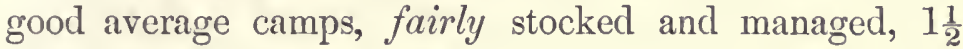
or 2 arrobas of grease ( $I$ went through a flock the other day, flock maintained on camps, estimated by one of the best of judges to yield $2 \frac{1}{2}$ arrobas, some of which would yield 5 arrobas: sheep were weighed to arrive at this estimate, and among them some young ewes weighing $7 \frac{1}{4}$ arrobas, shorn) worth about $50 \$$ per arroba, which would be $75 \$$ for sheep at an arroba and a half, and $100 \$$ at two arrobas yield. Add to this the value of the skin, and I think it will be seen at a glance, that such a class of sheep would be a better paying stock than that which only yields $9 \$$ per annum gross product in wool, and which are not worth over $5 \$$ per head for the grease and 10 to $12 \$$ for the skin. Moreover, it must be taken into consideration, that a class of sheep that yields $75 \$$ in grease would yield $25 \$$ in wool per annum, and probably more.

It will be understood that, in throwing out these figures, I do not refer in either case to 'capones' (wethers) for the markets.

Taking a glance back at these few figures, we see that the estimated yield of wool in one case is $9 \$$ against $5 \$$ of grease, or nearly double. Let us, however, assume that the grease, under more favourable circumstances, may yield $S$ to $10 \$$ - say $9 \$$-or equal to one year's wool.

A class of sheep that under a fair system would yield $50 \$$ in grease, would probably yield 15 to $16 \$$ in wool; and a class that would yield 65,70 to $75 \$ \$$ in grease, 20 to $24 \$$ in wool.

In these, though the yield for wool is put down at double, more than double, the average return from the prevailing breed, the yield estimated from grease is equal to three years' wool, more or less. This may be taken as 
a fair relation of value between the yield of wool and yield of grease, and so long as a sheep-farmer can get anything approaching this relation of value, it will pay him better to steam than to keep anything in excess of the breeding ewes, even under favourable circumstances ; and he need never liave his camps over-stocked, and need never be hard up for dollar's, as so many must be when the wool market is dull. In fine, one of the main sources of profit in sheep-farming consists, - after the accumulative increase has reached a certain point in relation to the extent of land,-in a marketable increase, in being able to realise in one form or another the increase year by year ; failing that, the business ceases to give a fair return for the cattle represented by land and stock. It is a mere truism, that meat and fat-producing qualities constitute marketable stock, and the breeders' sheet-anchor.

Some few years ago the flocks were larger-double what they now are in general. The reduction of the numbers in the flocks was found to be advantageous, and was a move in the right direction. To the end that an improvement in the class of sheep may be effected, that they may yield a better class of and more wool, and much larger quantity of grease, and that the increase may be larger and of stronger and better lambs, it is desirable that the flocks should be still smaller-half what they now are-and consist of breeding-ewes only. This suggestion is the reverse of unimportant, and, coupled with the lighly important aim of fat produce, merits the earnest consideration of the sheep-farming body.

It results from a careful consideration of the all-important matter of selection and development of breeds (as adapted to the country, in its extent and variety of soil and climate), and of the existing stock, that there are four types which stand prominently out:- 
First,-The first, and most important, by reason of the circumstances and position of the sheep-farming interest, is that which is and can be produced by the persistent use of large vigorous rams of the French and English Merino blood, which will give length, strength, and abundance of wool of a high value - the highest value in the European markets-with good carcass and fat value.

Second,-A breed or type suited to certain localities would result from the cross of the English, long, lustrouswoolled sheep with the Pampa, Creole, Cordova, and other long and coarse-woolled races of the country persistently followed out, which would, in a few generations, produce a most valuable and useful wool, and sheep that would be very valuable in carcass and fat.

Third,-Is a somewhat longer process, but would produce a very desirable sort; viz., the Creole or common Mestizo crossed with the long or medium wools of England, and then refined persistently with French or English Merinos. This wool would assume a special type, and in the course of time, good length and considerable fineness would be the characteristics, and the sheep would be an excellent carcass and fat-producer.

Fourth,- The German Mestizo type, on a more limited scale-when great attention is paid, and the largest animals only selected to breed from, as possessing the longest and most elastic staple-is a desirable variety to retain, having its special 'destination' or use. It is notorious that this variety, like the Spanish variety, its parent, is declining in importance, and, as it were, going out of date everywhere. It is, however, so valuable as the prolific nursery of improved types, and for crossing with certain inferior breeds, that it is desirable to retain it in the higher grades, and under a system consistent with its delicacy. 


\section{ADDENDA I.}

A good and simple practice in refining for parties whose means are limited-one perfectly feasible on the smallest establishment-is to commence with a good, useful class of acclimatised rams, and pursue the following course, say :-

Select from the flocks a given number of the very best ewes, uniform in size and class of wool. Take, for example, four hundred. Purchase for these ewes, six fine large suitable Mestizo rams* of more or less advanced type; each ram being calculated to give, say 11 to $12 \mathrm{lbs}$. of wool, or upwards.

The product in ewe-lambs from these 400 will be, say 170 , which should be separated when weaned from the dams, and formed to a flock by themselves. When eighteen months old, put into these three rams procured from the same 'Cabaña' as the six, but of a higher strain of the same blood, and of a weightier fleece. In the following year there will be, from the four hundred ewe flocks another 170 'Borregas' of eighteen months old, which should be added to the first lot, and two or three more rams, of the same type and family as the other three, would be required. The next year the same process must be repeated, and so on. Meanwhile this 'Borrega' flock will have produced lambs of a higher quality than themselves; and for these a still higher type of acclimatised

* In using the term 'Mestizo rams,' I may observe that after a few generations, when one type of Merino has been crossed with another, the progeny is, to all intents and purposes, pure in blood, and in some instances a type is produced superior to the sires themselves. The term, therefore, must only be aceepted as conventional when the erossing and refining has been effected persistently with one and the same blood and type. 
rams of the same blood would be advisable; and thus ascend the ladder.

I believe that few 'estancieros' can advantageously breed their own rams. According to the law of division of labour, perfection is attained by special dedication to the separate parts of a whole; and sheep-farming is not an exception to the general law. Such minute and cletailed care is required in the management of a rambreeding establishment, that it is incompatible with the direction of a large estancia, unless a perfectly distinct staff of great intelligence is appointed to the work.

\section{ADDENDA II.}

I have counselled the selling off a portion, i.e. the reduction, of the stock on all sheep-farms, when the number of sheep approaches the limit of the capability of the land for carrying stock with safety to the wellbeing of the sheep and their progeny. . Despite ordinary care, large flocks have a tendency to degenerate relatively, rendering necessary a constant dependence on the highcaste breeder, whose business it is, by extra care, to preserve elevated types and quality, and supply new blood. This reduction should be on such a scale as would leave ample room for future increase of better stock and, at the same time, furnish funds for organising and effecting requisite improvements.

When there is ample room for a flock of sheep, increase is so rapid (supposing the stock to consist of animals that have not passed the age of vigour) that we may estimate them to have doubled themselves in three years; and they may do much more or less, according to the system followed, and the composition of the flock, i.e. the proportion 
of breeding-ewes in it. A party who has 15,000 sheep will, therefore, have an increase of 5000 yearly, for which number he has to provide camp each year, or they will die on his hands if not otherwise disposed of. This is a self-evident proposition.

All sheep or ewes cease to be 'profitable stock' after they reach a certain age; after a certain age too, they rapidly die off in inclement weather. The life of a sheep may be set down as eight to nine years (many will live and lamb till ten). The profitable life of an ewe is considered six lambings; as any subsequent progeny, as a rule, is deficient in all desirable qualities. Infirmities, or bad seasons, will destroy numbers, before they reach that age or term of profitable existence.

The sheep-farmer, therefore, who has a lambing of any given number, say in 1860 , will have few of those animals living in 1868 ; consequently, if he has not previously disposed of them, they will have died on his hands. Ile will probably complain of his annual losses as sometling extraordinary, whereas they are merely a natural consequence of the termination of the 'span of life' of the animals. He will obtain more than a negative advantage by selling (for the vat), and will also avoid this loss. The risk of loss by deaths increases after the fourth lambing, as the ' cold waves' or the ' hot blasts' tell with more or less effect on declining vitality. The direct advantages of employing the capital realised by the sale of unproductive stock, in the improvement of the quality and yield of wool of the remainder, will be clear from the following explanation :-

A party who has any given number of sheep, sells, say, one-half of his stock, retaining only the 'borregas' and ewes that have lambed their first, second, and third lambs. Let us assume that the sheep-farmer at the time of taking 
this step, valued his stock, as they stood, at $35 \$$ or $40 \$$ per head; and that he sells all the ewes that have passed. their third lambing at $20 \$$ or $25 \$$ each ; then those which he retains will certainly represent a value to the flockmaster of $45 \$$ to $50 \$$ each.

The $20 \$$ or $25 \$$ per head realised for these elder sheep, will represent the probable nett product of their yield of wool during the remainder of the natural period of their profitable lives. Moreover, this sale is cash, and the yield of wool to give that amount would extend over a period of, say, three years; this cash, therefore, is worth an interest of 25 per cent., more or less. This 25 per cent. interest on the capital realised, in addition to setting free the camp for future and improved increase, is manifestly more than an equivalent to anything the flock-master could possibly have got out of the sheep sold, irrespective of the wool.

The employment of the capital realised in the improvement of the sheep, i.e. in the purchase of large, heavyfleeced rams, and in the requisite care, feeding, \&c. (as suggested in the foregoing paper on sheep-farming), may be fairly calculated to give the following results :-

At the end of three years the stock will have considerably more than doubled itself. This increase of improved or higher-bred animals will represent a value per animal of, more or less, double that of the previous stock; the yield of wool from them will be, more or less, double in quantity and much superior in quality, fetching, too, a higher relative price.

'The 'value' of sheep to the wool-grower is determined by the probable money-product of the wool. This value is rated as the nett product of three years' (or at most four years') clip. The product of three or four years' wool, therefore, represents the capital in, or value of, the sheep; 
and all product of wool, over and above three or four years' clips, stands as profit or 'interest' on that capital, and against contingencies. If, therefore, the sheep-farmer improves his sheep, and augments the weight and quality of their fleeces during that period, that 'profit' or ' interest' will be proportionately greater.

The increase of numbers represents the charges of care and management, and the interest on the money value of the land, ${ }^{*}$ plant, improvements, and the rams ; therefore, according to the value of the stock, will the interest of profit on this money value, or capital, be greater or smaller.

Thus, a party has a league of land, and on it, say, $8 ; 000$ sheep, which double themselves in three years; this increase of 8,000 sheep represents, as just said, expenses, interest on value of land, \&c.; the annual increase therefore averages 2,666 , from which he may deduct a fourth for expenses, say 666 sheep, leaving the 2,000 remainder as interest. Assuming that the land and plant are valued at $1,000,000 \$$ currency, and the 2,000 sheep at $50 \$$ each, this interest or profit would be $100,000 \$$, or 10 per cent. per annum. If the value of the increase is only 35.8 per head for sheep, then the interest or profit is 2 per cent.; if, on the other hand, $100 \$$ per head be the value of this increase, the interest or profit is 20 per cent.; or, this profit is divided, as it were, with the land, augmenting the value of that land, until an equilibrium is attained with the current interest of landed securities.

The calculation is different on establishments for the breeding of high-class sheep for the sale of rams. In these the value of the male lamb at the time of weaning, represents the value of the ewes and the rams. Assuming that two ewes lamb three male lambs in three years, the value

* The stock the land will carry fairly represents its value. 
of these three lambs represents the value of the two ewes, and the proportion of the value of the ram; the ewe lambs represent the interest or profit on the land, plant, \&c. after paying all expenses of management, feeding, \&c. After weaning, the ram-lamb is chargeable with his own expenses; and he augments in value according to these expenses, until he is ready for service; his proportion of galpon, potrero, corn, hay, cut-grass, bedding, care, and labour, risk and interest, all must go to his account, and the breeder must get back these expenses or he loses money.

\section{AdDENda III.}

I have before me the 'Journal of the Royal Agricultural Society of Scotland' of July 1865, and in it I find a direct corroboration of what $I$ have written on the subject of the Australian sheep and wools. In a paper from the pen of the renowned 'Old Norfolk Farmer,' there is a brief history of the origin of sheep in Australia, which is as follows :-

In 1788 Captain McArthur introduced into that colony a small number of Bengal coarse-woolled sheep. Nine years later three rams and six ewes of German Merino arrived at the colony unexpectedly - they had been destined for the Cape of Good Hope, for which they had been shipped by the Dutch Government. Captain McArthur purchased them, and continued systematically to cross and refine his Bengal stock with them. Ten years later he returned to England, and purchased from His Majesty George III. eight English Merino sheep, which he took out with him to Australia to continue the refining of his flock. Subsequently and continuously, as I have said in my paper, the Australians have bred from the best blood 
of English and French (Rambouillet) Merinos, as well as German, with crosses of Leicester, Southdown, and other British long and medium-woolled sheep.

The result, as stated by the 'Olk Norfolk Farmer,' is, that the Australian wool is of greater value than any other, 'being as fine as the Merino, at the same time that it is longer and stronger in staple, and, as he says, "its value in the market bespeaks its merits; for, while the finest (European) Merino is worth only $2 s .3 d$. per lb., the best Australian wool is worth $2 s .9 d$. per lb.'

The facts and results related by the 'Old Norfolk Farmer,' of the commencement and success of Austrahian sheep-breeding, bear so marked an analogy to an individual case of breeding and equal success in this country, that I give the facts : A gentleman of this country, possessing a number of pure Pampa long-woolled sheep, crossed and refined them for a series of years (20 to 25) with the Merino (Saxony). From the total of this refined flock he then selected 180 ewes-the flower of the flock. These he crossed with pure Cabaña Imperial Rambouillet rams, and for nine or ten years has continuously refined them with pure rams of the same blood. The result of his system of management and breeding is the success which I report. His breed now surpasses in weight of fleece, length and strength of staple, any and all of the imported European sheep, and possesses a degree of fineness, softness, and elasticity of wool, very remarkable, and sufficing for any purpose whatever. The result of the sale of his last year's clip in the 'Plaza Constitucion' (despite 'sarna' caught from a neighbour's flock), as per broker's account sales, was, for the 'borrega' and ewe flock, $53 \$ \mathrm{~s} / \mathrm{m}$ per sheep, equal to $7 s .10 \frac{1}{4} d$. per hear in wool on the spot. This same parcel of wool was re-sold at an equivalent to $60 \$$ per fleece-equal to nearly $9 s$. 
This gentleman is Don Manuel Benavente, of whose stock, my own flock (in association with Mr. Benavente) is composed; so that I write with a perfect certainty of facts, which any person may verify by a visit to the establishment.

I unhesitatingly add that these sheep have assumed a type of their own which will vie with any other for general usefulness, and for refining and improving the breeds of this country, are unequalled. They surpass in length and weight of fleece those of the Cabañas 'Imperial' and 'Gilbert,' are finer than the latter, and as fine as the average of the 'Imperials.' Many of the higher typesthe picked sheep-surpass the best I have seen of the 'Imperials' in all points.

These sheep, like the Australian high-caste, must take rank as an established special variety,-a variety the result of the climate-influences of the country and a treatment suited to it.

\section{ADDENDA IV.}

There are several establishments dedicated to the breeding of Negretti rams, the stock of which is highly creditable and equal to the majority imported. At these establishments the aim has been to transfer and perpetuate in this country, the identical type and qualities of the sheep of the European Cabañas from which they were derived, subjecting the sheep to the same treatment. But they have not produced-have not aimed at producingan improvement of type or a modification of it, to render them better suited to this country. It must be borne in mind that we cannot transfer the German climate to the River Plate, but we have a climate admirably adapted to the development of improved types. 
The proprietors of these establishments will not need me to apologise for this suggestion as indicating a higher sphere of action on a field worthy of their labours, viz. the reproduction of the German Merino blood under a special and more generally useful type by the influence of selection, perhaps, a judicious cross and treatment, in all respects suited to our climate, as has been done by the gentleman above referred to, with the French Imperial Merino, and as has been done by the high-class Australian breeders.

We have only to refer to the opinion of the high Spanish authority I have quoted in the foregoing paper, and the present recently adopted practice of the North German Cabañas to guide us to the direction in which modification should be sought, i.e. a general usefulness and consequent profitable return, length, strength, and abundance of wool, and large size in the animal, with good fattening properties. 


\section{PART III.}

DISEASES OF SHEEP.

THEIR TREATMENT.

The scab.-This is one of the most severe scourges of our flocks, and from its contagious character, there is scarcely a limit to its ravages. 'Prevention is better than cure;' therefore, every precaution should be taken against mixture with contaminated flocks, or feeding over ground on which such a flock has been pastured. Dirt, damp, illventilated 'galpones,' and over-crowding, as also insufficient and injudicious feeding, are direct causes of the disease, and should, therefore, be carefully avoided. Salt as a purifier-rock-salt-should be disposed in the 'corrals,' or in shade, where the sheep can have free access to it.

There are many remedies, but I consider none more effectual than preparations of tobacco and sulphur; and as soon as the disease appears it should be attacked.

The Southdown wash is a preparation of this class ; and there are agents in the city for the sale of the paste, each tin being labelled with instructions for use.

Demarchi's preparation of tobacco and sulphurous gas I have found efficient and convenient. It is sold at Demarchi's establishment in the Calle de la Defensa, in pint bottles. I have adopted two modes of using this preparation; one, when the wool is on the sheep, is as follows: To a demijohn of five gallons (five frascos) of water, put one pint bottle of the mixture, and keep it corked. 'Take such a tin as is generally used for filling 
lamps with kerosene, and having filled it from the demijohn, open the wool of the affected sheep the whole length of the back from head to tail, and pour in the liquid; that done, open the wool on the sides, and down the fore and hind-quarter, pouring in the liquid. A demijohn (i.e. one pint bottle of the preparation) of five frascos will probably suffice for thirty-five or forty sheep, or for fifty or sixty lambs.

After shearing I use it as a bath. I use an octave cask of water to six pint bottles of the preparation, keeping it closely covered. From this I put into a large tub sufficient to make a bath. As the sheep are shorn, I dip them thoroughly, covering the bath the moment the animal is taken out. I then place the sheep in another tub, with a platform in it, to drain for a few minutes, untie, and loose the animal. If there is any hard scab on the sheep, it should be well rubbed in the bath. This treatment I have never known to fail, if done efficiently. The bath costs about $18 \mathrm{~m} / \mathrm{c}$ per head. An excellent dip can be made on the farm by simply boiling tobacco and mixing the decoction with a given quantity of water. The dip should contain, in nine to ten gallons of water, the juice of forty to forty-five ounces of tobacco. Sulphur may be added to the decoction.

Foot Rot.-Another great scourge, and likewise contagious. This is produced by treading in soft, wet ground, and watery herbage.

Treatment._Cleanse the foot, and pare away the hoof wherever it is detached; wash the affected parts clean with chloride of lime water, or Demarchi's sheep-wash, or tobacco water and dry; then apply with a feather the butter of antimony (a very efficient caustic); after a few minutes for the caustic effect to be complete, a pinch or two of Cordova lime may be 'patted' over the foot, or 
coal oil, or tar and grease, with or without a mixture of lime, or a small quantity of spirits of tar-as the rule, I use Swedish tar or lime.

Leech in the Liver-Flucke.-No cure. The free use of salt is a preventive.

Hove.-Salt is a preventive; it is also a cure. A dessert-spoonful dissolved in water is often effectual; or still more effectual is half a drachm of chloride of lime; and in extreme cases 'tapping' between the last rib and the point of the hip. I have, however, found that in ordinary cases, taken in time, a good hard rubbing on the distended parts, or even running the animals about, suffices to give relief.

Costiveness and Fulness of Blood, with dulness and giddiness.-In these cases the following purgatives may be administered, say - 2 oz. Epsom salts, with a little ginger, or $2 \mathrm{oz}$. linseed oil in linseed gruel. When the giddiness is considerable, and the animal evidently much oppressed, bleeding is desirable in the neck or leg, if the party understand it ; if not, cut a joint off the tail, and if that fails to bleed (which in a far gone case it may), I have found a cut across the nose have the desired effect. This fulness of blood and vertigo arises from too luxuriant pasture in the spring of the year.

Spasmodic Colic.

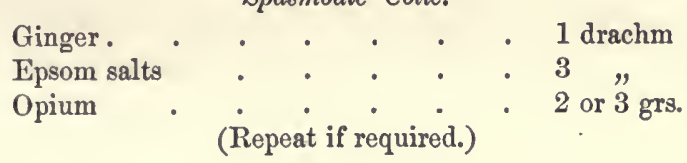

Dysentery.

Linseed oil . . . . . 2 oz.

Opium (powder) . . . . . 2 grs.

(Repeat with less quantity of the oil.)

Inflammation of the Lungs.-Bleeding, purgatives, 
Epsom salts, or linseed oil. A similar treatment may be followed in all cases of inflammation.

In acute inflammation with spasmodic symptoms, the use of opium or laudanum, in addition to bleeding and purgatives, is desirable-one drachm to two drachms of laudanum in linseed gruel, and one onnce of linseed oil, is a suitable dose. In cases of inflammation of the bladder and spasmodic contraction, it is the usual course. In extreme cases I have used tobacco water with success, no other remedy being at hand.

Maggots.-There are several remedies for these. The first thing to be done is to clear them out of the wound, and wash well with tobacco water or chloride of lime water. Train oil and sulphur will kill maggots; also pepper. The remedy I most commonly use is strong decoction of tobacco, or the pure preparation of Demarchi (tobacco and sulphur) poured into the wound, and then 'dust in' Cordova lime, and work the two up to form a paste; dress daily until cured. After a time the simple dusting with lime will suffice.

The foregoing appear to me to be the simplest and most available medicines and treatment; and, consequently, the most desirable for those who have to be their own farriers in the camp. 


\section{PART IV.}

THE SCIENCE OF HIGH-CLASS SHEEP-BREEDING; WITH DETAILS OF MANAGEMENT.

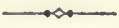

I.

Sheep-Breedivg must be divided into two distinct branches. One we denominate 'Sheep-Farming,' which is the rearing of sheep for the different purposes of woolgrowing and meat-producing; the other is the rearing or breeding of fine stock, with which to supply the wants of those who devote themselves to the other branch, or department. These branches are essentially distinct; at the same time that they are mutually dependent, in accordance with the law of the division of labour; a law demonstrated by political economists to be inseparable from rapid development, and the attainment of perfection in the great industrial pursuits of the world.

It is requisite to start at once from this point, and accept the law. It must be manifest to all practical men, on reflection, that these two departments of sheep-breeding, as a rule, must, in this as well as in other countries, be a separate business ; indeed it is probably more necessary in this than in any other, for the almost impossibility of procuring the means, or commanding the hands and intelligence requisite to carry out and do justice to the two branches, cannot fail to be recognised. Of course I speak generally; for there may be, and probably are, a 
few who, from unusually favourable circumstances in point of establishment, facilities, and large means, will succeed; and who, from combining energy, knowledge, and resources, need not be daunted, even by the great difficulties presented by such an undertaking; but these, I say, are the exceptions.

The object of the 'sheep-farmer' in this country is to rear a large number-tens of thousands-of sheep, of a good, thrifty class, to yield as large a quantity as possible of a generally useful wool, of ready sale at a good price. To bestow on his flock the requisite attention to secure their progressive improvement and well-being, will afford him ample work, ample thought, and ample employment for his capital. His occupation is on a large scale, and the distraction that would inevitably result from his dedicating himself to the minute details attendant on the other branch, would be extremely prejudicial to his main interest. For the higher blood he must look to the high-caste breeder, and from him procure the rams best suited to the condition of his flocks, and of his purse.

In a previous paper I have enumerated the paramount requirements of the flocks of Buenos Ayres, and sketched the main principles which should guide the flock-master in the selection of his rams, and the method of treating them, and of disposing them in his flocks to the best advantage; and there only remains for me to urge all 'sheep-farmers' to keep within compass of the capabilities of their lands for carrying stock, and to make a provision against scarcity for the maintenance of their flocks, as well as for the higher feeding of their rams. The sheep-farmer should cut and stack some natural grass as hay, if he should not have 'alfalfares.' He cannot go wrong in this, for the natural grass and trefoil, even though mixed with stray thistles, dock, 'flor morada,' and 
the like, make excellent food for sheep or other animals, provided they be 'got' with the sap in them. Good, elastic, sound-stapled wool is not compatible with ill-kept sheep; for the part of the wool that is grown during the period of low condition is 'false' or unsound, and it will inevitably break at that point in the working, thus rendering the short shorter. This is one of the causes contributing, in a very marked degree, to the discredit of Buenos Ayrean wools, lowering their value by a very large percentage. The sheep-farmer, too, should not fail to grow a moderate quantity of maize, for it is essential that having invested in good, large, vigorous rams, they should be corn-fed, and have the protection of a 'galpon,' or shed. No matter what breed of rams he may purchase, he will surely be disappointed in their progeny if the treatment of the sires is not generous and well-regulated. The tendency to degenerate of this or that breed is declaimed against by hundreds; and this tendency is an undoubted fact, when man or animal rarely, or only by fits and starts, gets enough to eat. Believe it, my friend, you would not long be the happy possessor of those brawny arms, bright eyes, and that portly appearance, did you get all 'farina' and no 'asado,' and those halfdozen magnificent $15 \mathrm{lb}$. fleece rams, that you have paid $5000 \$$ or $6000 \$$ apiece for, will not long look as they now look, and their next fleece will fall very far short of the 15lbs., if you stop their corn, hay, and cut grass, and turn them out on cold wintry nights.

The rearing of 'high-caste breeding stock' is, undoubtedly, the 'life-spring' of successful sheep-farming in all countries, and from this department of the business must flow all that is good, and all that is to determine the value of the products (and their standing in the eyes of the great consumers) of a wool-growing country. No 
great national product can long depend on foreign countries for its means of reproduction. The best and most suitable blood that the world can produce should be sought out and introduced into a country proposing to elevate itself in the production of an inexhaustible source of wealth ; and with this 'blood '-this breeding stockenterprising and intelligent men must work, to create for their country an equal, or superior race, to disseminate, to percolate, as it were, through the whole land. In this way have all nations, by means of crossing their owu breeds, or improving and acclimatising those of others, created for themselves breeds suited to the climate, and possessing, each in its way, special qualities and value.

In nations possessing the highest degree of civilisation, many individuals have earned for themselves an everenduring fame by their labours in this field ; and crowned. heads have wrought in the same field with enthusiasm and constancy, achieving great results ; and this too, in many instances, from very small beginnings acquired with difficulty: sometimes by national treaty, at great cost, and even by smuggling.

For Buenos Ayres, 'high-caste' breeding establishments for sheep are a desideratum. To this branch it is essential that men of special aptitudes should dedicate themselves, and work with the very best materials, regardless of cost. Men of considerable intelligence and good knowledge of the subject, great powers of observation, concentration of will, patience of detail, and enthusiasm in the pursuit, can alone hope to obtain marked success.

Perfection in the vegetable and animal kingdoms is obtained by skilful cultivation, by the judicious application of natural laws in the treatment, the laws of nutrition, thermal laws, the principles of selection, and climatic influences.

Everything that is superior in class, or quality, is essen- 
tially artificial, and the infinite variety of type in animals is due to the special application or accidental concurrence of conditions favourable to this production. Once a type, quality, or habit, is established or 'fixed' in any animal, it becomes hereditary so long as the progeny of such animal continues to exist under the same conditions as those under which it was created; but, if subjected accidentally or systematically to different treatment, and different influences, such type, quality, or habit, will necessarily become modified for better or worse ; and there is, unquestionably, an art in adapting treatment to the surrounding natural conditions of soil, climate, \&c. so as to produce advantageous modifications in the direction most congenial to those conditions. The perfections or good qualities attained by individuals, or nations, in breeding sheep, under the law of hereditary transmission, are available to others for pushing still further the course of refining and adaptation of breeds.

To avoid a toilsome course, chequered by many failures, in the work of improving and perfecting our sheep, the ' high-caste' breeder should have at least a fair knowledge of scientific principles, and the various ' cosmic' influences regulating and affecting the development of animals, their nutrition, and well-being. I will endeavour to condense a few of these principles, and give them a practical application. I need hardly apologise for here referring to 'primary natural laws,' with a view to trace their connection with the matter in hand.

In the whole universe no atom is lost. Force is ever existing-always equal-but ever changing, and passing from one form to another. All things are mutually dependent. Decay is the end of production-production the result of decay-life of death-and death of life. All life is the result of certain combinations and influences; and all growing and living forms are composed of the same 
elements. Vegetable substances spring from the earth, and inhale from the atmosphere. They contain within themselves mineral constituents, non-combustible elements drawn from the soil by their roots, and gaseous elements ; the combustible elements, drawn from the atmosphere by their leaves, \&c. elaborated into an 'organism' under certain ' cosmic' conditions-light, heat, the sun's rays, moisture, \&c. When these vegetable substances decay, their non-combustible elements return to the soil, and their combustible or gaseous elements to the atmosphere (the result of combustion), available to be transformed into other substances, or other forms. When taken as food, they enter into the 'organism' of the animal feeding on them.

Animal forms are composed of identical elements, or constituents, with the vegetable. These constituents are derived from the vegetable substances on which the animal feeds, and are elaborated into the higher organism of the animal under the action of the so-called 'vital force,' the circulation of the blood, and its oxidation by means of the respiration of the oxygen of the atmosphere, and are ultimately returned to the air and the soil in the exhalations and excrements, and the decomposition of the body after deatl.

All alimentary substances, vegetable or animal, are composed of mineral substances, nitrogenous or albuminous compounds (strength-giving), and heat-giving and fat-forming compounds ; also water.

In vegetables, the heat-giving, or respiratory compounds are in the form of starch, gum, sugar, and in many seeds, as oil-instance, linseed, rape, cotton, \&c. In the animal structure the albuminous compounds and minerals are the flesh, blood, juices, and bones; and the heat-giving compounds, which are as starch, \&c. in the vegetable, appear as fat and fatty tissue. Albuminous (or nitrogenous) 
compounds and minerals exist in large proportion in the hair or wool of animals, also in horn and hoof ; these are nitrogen compounds.

For the more facile elucidation of these matters, and to render more clear the propositions and indications, I will give some tables of analysis, made by the most eminent chemists of the age.

Minkrat Constiturants of the Ashes of Ferding Substances.

\begin{tabular}{|c|c|c|c|c|c|c|}
\hline \multirow{12}{*}{$\begin{array}{l}\text { Potash } \\
\text { Soda. } \\
\text { Magnesia } \\
\text { Lime. } \\
\text { Phosphoric acid } \\
\text { Sulphuric acid . } \\
\text { Silica } \\
\text { Iron, per Oxide: } \\
\text { Common salt }\end{array}$} & Maize & $\begin{array}{l}\text { Mixed } \\
\text { Natural } \\
\text { Grasses }\end{array}$ & $\begin{array}{l}\text { Alfalfa } \\
\text { in } \\
\text { flower }\end{array}$ & $\begin{array}{l}\text { Clover } \\
\text { Trefoil }\end{array}$ & Bran & \multirow{12}{*}{$\begin{array}{l}\text { Phosphate of } \\
\text { Lime and } \\
\text { Magnesia }\end{array}$} \\
\hline & $26 \cdot 63$ & $18 \cdot 11$ & $14 \cdot 03$ & $24 \cdot 928$ & A.1.15 & \\
\hline & $7 \cdot 54$ & $1 \cdot 35$ & 6.44 & 3.039 & $44 \cdot 15$ & \\
\hline & $15 \cdot 44$ & $6 \cdot 75$ & $3 \cdot 64$ & $12 \cdot 176$ & & \\
\hline & $1 \cdot 69$ & $21 \cdot 85$ & 50.57 & 34.918 & 46.05 & \\
\hline & $39 \cdot 85$ & 5.97 & $13 \cdot 68$ & $7 \cdot 352$ & & \\
\hline & $5 \cdot 56$ & $2 \cdot 46$ & $4 \cdot 23$ & 3.718 & & \\
\hline & $2 \cdot 29$ & $37 \cdot 89$ & $3 \cdot 46$ & $1 \cdot 313$ & $\cdot 05$ & \\
\hline & $\cdot 60$ & $1 \cdot 59$ & $\cdot 63$ & $1 \cdot 470$ & $\cdot 25$ & \\
\hline & ... & 4.03 & 3.32 & 11.096 & & \\
\hline & loss 40 & $\cdots$ & ... & $\cdots$ & loss $5^{\circ} 08$ & \\
\hline & $100 \cdot 00$ & 100.00 & $100 \cdot 00$ & $100 \cdot 000$ & 100.00 & \\
\hline
\end{tabular}

Nutritive Constixuents, \&c.

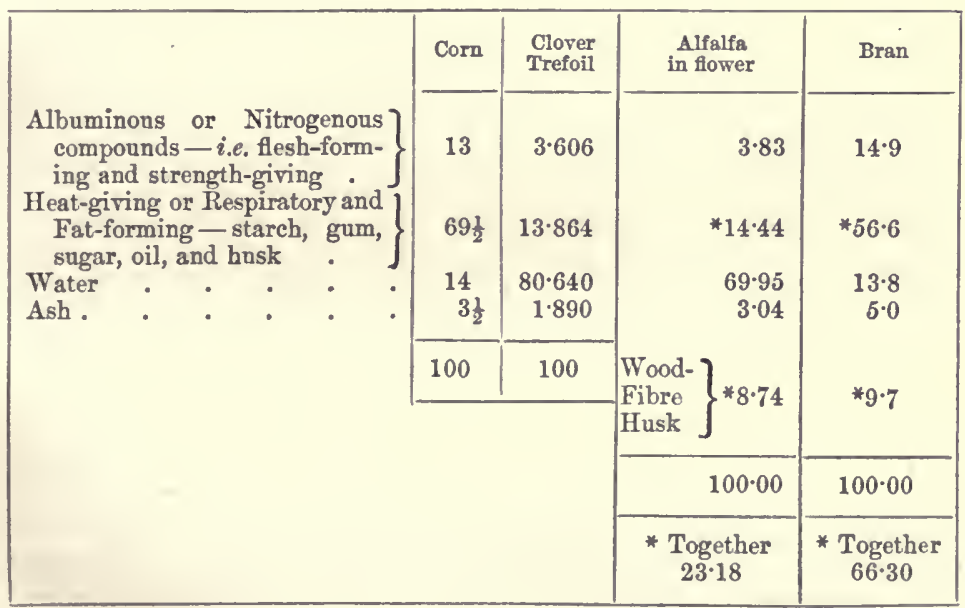


Minerals in the Ash of

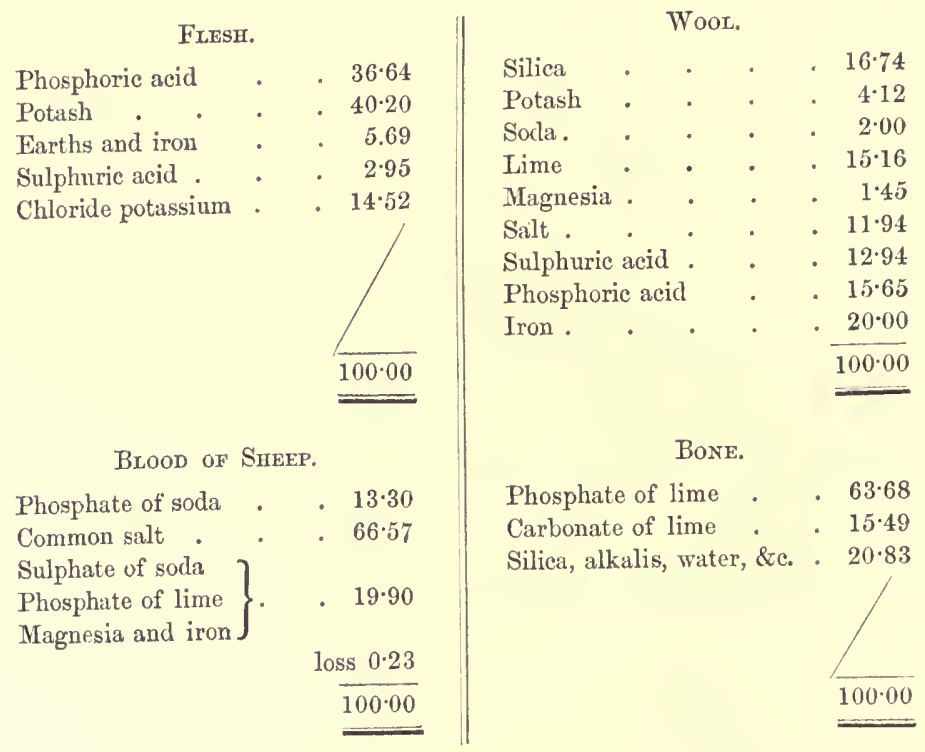

Nutritife Constipuents of Fat Mutton.

Albuminous or nitrogenous compounds, and sulphur, $\}$ Proportion 10 parts
ditto, in the flesh . . . . . . Fat.

WOOL CONTAINS:

Hydrogen and carbon

Nitrogenous compounds $. \quad . \quad 17 \cdot 72$

Sulphur

$24 \cdot 61$

$100 \cdot 00$

From a study of the foregoing, it will be seen that vegetable substances contain certain mineral constituents in various proportions. These they draw from the earth, and they are essential to the building up of the plant. The other constituents are the nitrogenous compounds, derived under the influence of light, heat, \&c. from the ammonia contained in the atmosphere; and the nonnitrogenous, the hydro-carbons, such as starch, \&c. derived 
under certain influences (called the vital force) from the carbonic acid of the air.

The other constituent is water.

It will be seen also, that in the animal feeding on these vegetable substances, there exists in the blood, bones, flesh, and wool, the same mineral substances; and these pass into them from the food taken by the animal. The flesh of the animal is formed of albuminous or nitrogenous compounds, which are assimilated from the like compounds of the vegetable matters; hence these compounds are called flesh-forming-flesh being merely a more highly azotised form of the same materials. Likewise, the nonnitrogenous portions, or constituents, of the plants which are present in these, in the forms of starch, sugar, gum, \&c. - which are hydro-carbons-enter into the animal organism, and, in the vital laboratory, are converted into fat-a more pure and concentrated form of hydrocarbon; hence they are called fat-forming. They are also styled heat-giving, or respiratory, for the reason that, while a portion of them are retained as fat, and go to form the fatty tissues as well as the fat deposits, another portion is burned in the animal system. The oxygen of the atmosphere being inhaled, and coming in contact with the hydro-carbon, a combustion takes place, from which the heat of the animal is derived; exactly on the same principle that coal (a hydro-carbon) is burned in a furnace, or tallow, grease, or oil, is burned in a lamp. The result of this combustion is carbonic acid gas, which is exhaled.

From this the very great importance of attention to the food of animals will be self-evident. The structure of the animal, its bones, nerves, flesh, fat, and wool, are dependent on it for their development and quality. Not only must animals be furnished with a given quantity of food, 
but of a class, and in due proportions, requisite for its fullest development in all its parts, with a slight increase of one or other constituent of food, when any deficiency is noticeable, or any special ' force,' or quality, is required to be brought out or developed. Should there be an insufficient proportion of fat-forming and respiratory materials in the food, the animal would become lean, and the heat of the body would be insufficient; and in the absence of a sufficient supply of combustible matter, it would prey upon its own tissues. In the like manner, an insufficiency of flesh-forming substances would cause the animal to shrink in muscle and decline in weight and strength: an excess of fatty matters would clog up and impede the action of vital functions and procreative powers; a deficiency of albuminous compounds would weaken these powers, and affect the progeny to a very serious degree; the inevitable result would be degeneracy in size, quality, and form, and deficiency in length, strength, and quantity of wool.

It is of the greatest importance to the breeder of fine stock, especially with respect to the males which are destined to cross with less highly bred ewes, that, by a course of judicious feeding, he should impart to them that predominance of size, force, vigour, and procreative power, which would ensure their transmitting to their progeny their own type and quality. It is equally important to this end, that the ram should be fully developed-have attained maturity (two years, or upwards), if possible, before he is admitted to ewes. It is on these perfectly intelligible grounds that I have, in my first paper, laid so much stress on keeping the rams apart from the flock and feeding them well; giving them, as part of their food, an allowance of corn and bran, as leing a more highly azotised or concentrated albuminous 
food; and that I have urged the selection of rams possessing the qualities desirable to be transmitted.

On the part of the young ewe, or 'borrega,' it is equally important that she should have attained a certain maturity, to enable her to bear, without injury, the great vigour of the ram; to nourish and develop the fœtus within her, and have a sufficiency of milk for her offspring when lambed. Not only would the immature ewe be unable to do justice to the begotten of a superior ram, but her own incomplete form would be stopped in its development, and she, and all her future offspring, would be far inferior to what they otherwise would have been.

In the 'Cabañas' of the highest perfection in fineness, silkiness, and length of wool-a Prussian Silesian highclass 'Cabaña' - the ewe is not allowed to take the ram before she is two years and a-half old; and the ram is not permitted to the ewe until he is three years old. I consider, however, that in this more genial climate, maturity is attained at an earlier age by several months; for as in vegetation a genial climate and higher temperature hastens the growth of a plant and ripens it, so it is also in animal life.

The reason why the results I have indicated above flow from too early connexion of the sexes, is, that in all nature, a certain time-variable in each class, and under different circumstances-is required for the development of the frame. Development is a gradual process of chemical combination and organic construction; and while these various changes and processes of building up the structure are going on, all the materials are in a more pliant form. Like the potter's clay, they are soft, impressionable, and ductile; and are all required to complete the work and harden it off. If, before this ripening and consolidation of the frame is complete, the powers of the 
animal are taxed for other purposes, and another life is given to the young ewe to maintain and form within herself, the means of her own development, the albuminous and the fatty matters, will be abstracted from her tender, ductile, immature body, to be used in the development of the fœtus; and as there is thus a double call, and an insufficiency for the two purposes, both suffer. Also, as regards the man; until he has completed his growth he has nothing to spare; so that too early a call upon his procreative powers is an obstruction of the albuminous compounds which are required to build up his flesh, muscle, and strength. So great is this drain on even the powers of a mature ram, during the season that he is with the ewes, that although he has, by careful and liberal feeding, stored up within him a reserve of substance and vigour, nevertheless he will suffer unless his feeding be fully maintained. Indeed to meet this drain, extra-careful and liberal feeding is advisable. There is a 'waste' going on, and this 'waste' must be constantly replaced by supplying to the body that which it parts with in another form. As the ram is restless and working at this period, it is desirable to give him his food in a form easily and speedily eaten; as otherwise his restlessness might prevent his eating a sufficiency; and, at the same time, it would be well to make it more digestible and more easily assimilated, by means of the finer crushing of his maize, and the addition of a little barley-both softened with a little boiling water, sufficient to swell the grain slightly. The corn so softened should stand for two or three hours before feed-time, adding dry bran to the corm, when cool.

The knowledge of the nutritive value of different foods is of importance to the breeder, as will be readily understood from the tables I have given. 
If we take the analysis of alfalfa at its highest point of nutritive value, we see that it contains of albuminous compounds, $i$. e. strengthening and flesh-forming substances, 3.83 per cent. ; against, of fat-forming substances - as starch, sugar, wood-fibre, \&c. $-23 \cdot 18$ per cent. The proportion here is as 1 to 6 .

In corn, we find that of strengthening matters, there are 13 per cent.; against fat-forming and husk, $69 \frac{1}{2}$ per cent., or more or less the proportion of 1 to $5 \frac{1}{4}$.

In bran, there are of strengthening matters, 14.9 per cent.; ditto of fat-forming and husk, 66.3 per cent., or more or less the proportion of 1 to $4 \frac{1}{2}$.

It is self-evident that by the addition of from one halfpound to a pound and one-half (according to size of animal and other requirements) of mixed corn and bran to his green food and hay, he receives a ration calculated to give him greater strength and vigour; and, while young and growing, greater means of development.

It will not be uninteresting to trace the course of conversion of food into the animal organism. Food, from the moment that it enters into the mouth, enters on the phases of conversion under the influence of chemical action. The secretions from the glands of the mouth and throat, known as saliva, in the course of the subdivision by mastification of the food, mix with it. These secretions are alkaline, and act on the starch constituents of the food, effecting the first change, or step in elaboration, by converting them into dextrine and sugar. The albuminous compounds of the food remain chemically unchanged, although mechanically prepared by subdivision, the result of mastication, for subsequent action. Alkaline secretions do not influence these compounds, which require the action of an acid. This awaits them in the acid secretions from the glands of the stomach, in the kyle, or gastric 
juice, through the instrumentality of which digestion is effected.

The digested food thence passes into the alimentary canals, which are lined with absorbent glands, which latter take up the nutritive matters of the food, prepared respectively by the saliva and kyle.

Ramified in every direction, and in contact with these glands, is the complex system of blood-vessels, into which these nutritious juices enter as blood, and are conveyed through the great vein-trunks into the lungs, where, coming into contact with the oxygen of the atmosphere inhaled, combustion takes place; and this burned, or oxydised blood, is forced into the arteries, by them conveyed through the system, and, under the so-called vital action, becomes flesh, fat, tissue, bone, \&c. \&c. Every portion, every organ of the body, being endowed with the power of selection, absorbs its own constituents, which become elaborated into it, replacing the incessant waste of substance resulting from action and life, and adding to the bulk of substance, flesh, or fat, any excess over such waste.

Should there be any deficiency in the component parts of food taken-a single item, mineral, albuminous, or hydro-carbonic, wanting, or deficient in quantity, the substance, or organ, of the body requiring such ingredient in excess of the quantity contained in the food, would necessarily suffer, as its 'waste' would not be replaced, and uniform development would be impossible. Thus, in the absence of lime in the food, bone could not be formed; the absence, or deficiency, in alkalies, and the liquefaction of the blood, would be impossible or defective; a deficiency of starch, sugar, or oleaginous matter, and fatty tissue could not be formed. On the same principle, within limits, we may graduate the proportions of food 
constituents so as to give special development and engender a special habit of body in animals; for instance, producing a greater or less tendency to fatten, or to make beef or flesh; accommodating the mechanical treatment so that the health may not suffer; and, in order to seeond the object aimed at, more or less exercise, shelter, or exposure, are material influences, which the skilful breeder should know how to graduate according to the proposed end.

Following out the subject of nutrition, or feeding, of animals of great value, whose perfection of type, special properties, and constitutional vigour, are so intimately connected with it, it is desirable to indicate certain conditions of the natural and other pasture, under various circumstances, so that the high-caste breeder may supplement such fodder with other matters of food, when there is deficiency in any essential ingredient. It does not suffice that the animal is supplied with any given quantity of food-matters; but, as I have said, such food must be in fit condition and possess the right proportions, more or less, of feeding-ingredients, to form, sustain, and renew every portion of the body, and to enable all the functions to be performed harmoniously, naturally, and with facility.

In the winter season, by reason of the low temperature and feeble heat of the sun, the growth and organisation of herbage is in comparative abeyance. Owing to the non-concurrence of all the cosmic influences in the requisite degree, the winter herbage does not assimilate harmoniously with the various elements of its organism, and there is wanting in it the due proportions for its complete development. It has an excess of water, and a deficiency of saccharine, or starchy elements, as also of the alkaline salts. It is deficient in nutritious properties generally. It 
is not fully organised, and, consequently, does not-taken as food-meet the requirements of the animal organism. Animals, therefore, fed exclusively on it, grow lean and weak. In a season of much rain and cold, these deficiencies in nutritious and mineral matters are augmented, and animals are affected with purging and other ailments. Low, banado-land herbage is particularly deficient at that season in alkalies and saccharine matters, by reason of its constant washing. To correct this, and prevent the purging of the sheep (or other animals), the use of salt - common or rock-salt - is desirable. In Europe the winter's grass is supplemented with turnips, mangoldworzel, and hay. These roots-containing largely of alkaline salts and saccharine matters, and good hay, that is, well-got hay, or even chopped-straw-corrects the excess of water and supplies an organised matter; and in good hay all the nutritious ingredients which constitute good nourishing food are present. No flock of value, therefore, should be without a supply of hay (turnips and chopped-straw are not at present available in this country, their use being an 'economic' of adranced farming). In the winter, they should never be turned out on the cold grass pasture in the morning before they have had their bite of hay; and they should always have their ration of hay to come home to of an evening. The deficiency of the due proportions of nutritious ingredients in food has the effect of producing disease ; and, in many instances, parasitical disease ('Entozoa'), which, according to the nature of the deficiency, attacks different organs-worms in the intestines, leech in the liver, \&c. This deadly plagueleech, or fluke-'Sobaissé,' for instance-is a parasite generated by the sheep feeding on vegetable matter in a state of fermentation, or partial decomposition, under the action of the sun's rays, from which the alkalies 
and sugars have been largely abstracted by an excess of water, with which the ground has been long saturated, and in which the plant has been immersed wholly, or in part. There is little doubt that all the varieties of 'Entozoa' are generated from similar causes.

In the early spring, when there is rapid growth of vegetation - ' trefolium' more especially - there is considerable danger from hove, blood-strike, vertigo, or apoplexy. The organisation of the vegetable has been too rapid to be perfect in all its parts; it, in consequence, too readily ferments, and produces these evils. A morning's feed of hay obviates considerably the danger from this, and the use of salt is very beneficial.

In the summer, when the grasses have shed their seed, the dry leaves and seed-stems contain little nourishment. The albumen and starch have departed from them, as well as the alkalies. They, therefore, do not contain the needful for the formation of blood. The water, likewise, has dried out of them. It is, therefore, requisite to supply, in artificial food, these deficiencies, otherwise the animal shrinks in flesh and fatty tissue. If there has been an abundant seeding of the grasses and trefolium-and these seeds, and the oleaginous seeds of the thistle, lie intermingled with the dried grasses - sheep will keep in fair condition, provided that they have sufficient water ; but valuable animals should have a little aid from artificial grasses-alfalfa, in a green state. There can be no question of the advantages of giving such animals a little green food in the cool of the evening. During the long, hot days, with all the insect annoyances, animals cannot feed. They collect in groups, seeking shade from one another; and it can be well conceived how grateful a bite of cold green fodder must be to them in the evenings. If they are 'shedded,' put into ' galpones,' or sheds, 
during the heat of the day, a bite of green fodder will be equally grateful to them at that time. The 'high-caste' breeder is amply repaid for these attentions to the comfort and requirements of his stock, as he will have little sickness and a much higher development in his animals.

The dfferent requirements of young and mature animals in their food-matters, is also a point of mark with the 'high-caste,' or, indeed, any breeder. In the young and growing animal 'construction' bears a much greater proportion to the waste than in mature animals. There is a quicker circulation, and a more rapid oxidation is needed. The albuminous compounds of the food are required to be in a condition easily and speedily assimilable; and there is required, to meet the rapid oxidation of the blood, that predominance of the saccharine element which exists in green, succulent herbage over that which is passing into ripeness and seed; and, more especially, that which is over-ripe, and from which the saccharine and alkaline elements have, in a great measure, departed, and in which the woody-fibres-the non-digestible mattersprevail.

The action of 'good feeding' on the wool can also be understood by a reference to the foregoing tables; for we see in the 'ashes' of wool the minerals of the food which the animal eats, and in the 'substance,' a very high proportion of nitrogenous and sulphurous compounds.

\section{II.}

I will now proceed to make a few remarks and suggestions on important points in management.

The selection of the most desirable season of the year for the lambing must be determined by the more or less 
advantageous condition of the herbage at certain periods of the year, to suit the dam and her offspring at the time of suckling and weaning.

First: At the time of impregnation, the ewe should be in good condition; the result of good, succulent food; she should be 'sappy,' and prone to conceive.

Second: At the time of lambing there should be rich, succulent grass, in order that her food may be easily converted into milk.

Third: At the time of weaning there should be rich, nutritious grass, to compensate to the lamb for the loss of his dam's milk.

The extremes of cold and heat should be carefully avoided as periods for lambing. A lamb should be wellgrown and strong before he has to face the heats of summer, which wither and burn up everything, vegetable and animal. Little or no nutriment remains in dried grasses. Their albumen, alkalies, and saccharine matters, have passed into their seeds, or descended into the earth ; or are extracted by sun and rain; and they are, consequently, particularly unfit for young stock.

The season of the year when the first proposition can be best realised, is that when all nature is springing, and animal life animated with the instinct of propagationthe spring of the year. I should, all things considered, select the months of October and November as the most suitable for putting the rams to the ewes. If the rams are in high condition (as they ought to be), five weeks will be sufficient for ' tipping' every ewe in the flock.

The ewes will consequently lamb in the month of April (in cold districts the lambing may advantageously come in earlier), when the autumn grass is abundant, and the weather still genial, and free from any excessive heats. The lambs will become strong and hardy before 
the winter sets in; and the ewes, being kept in good condition by a daily ration of hay, in addition to the grazing, and a little corn for the highest bred ones, coupled with the requisite protection, there will be no fear of the lambs suffering.

The weaning time will fall in September, and the lambs will have the rich, succulent spring grass to supply the place of their dams' milk, and will be well-grown and strong before the summer heats come on; the ewes will have time to accumulate strength and condition by the time of their next impregnation; and, I believe, that under no other arrangement could so favourable a combination of circumstanees be obtained.

\section{III.}

Thermal influences, and their regulation, are not less important matters. It is necessary in respect of these regulations that the mean temperature of a locality, or climate, should be taken into account, together with the extremes of thermal variation; and it is essential to have a right understanding of their influences.

There must be a certain heat diffused throughout the body, or the vital action is in abeyance, or ceases, and reconstruction, or development, cannot proceed. This heat is generated as explained by the combustion of the hydro-carbons of the food taken; and the quantity of such constituents of the food required to maintain this heat, is influenced by the external temperature - the temperature of the surrounding atmosphere.

The action of external cold is that of reducing the heat of the body, on the principle of transmission, or evolution, of heat-the equalising of the temperatures of substances 
and elements in contact. At a low atmospheric temperature, the superficial parts of the body part with their heat more rapidly than it can be generated and diffused under the action of combustion of a given quantity of carbonaceous matter taken in the food. The effect of cold, when below a certain degree, is to contract the parts, contract the blood-vessels, and force back the blood; consequently, to impede the process of formation, or reconstruction, which is dependent for its realisation on the blood, and in a certain temperature being maintained in all the parts. A larger amount of carbonaceous food, within limits, being supplied, the equilibrium of evolution of heat and its generation, is more nearly maintained.

Shelter, producing a warmer surrounding atmosphere, and non-conductors used as covering, diminish the necessity for an increased quantity of heat-giving food, and are, in effect, equivalent to a certain amount of food. The absence of shelter and external warmth cannot, however, be wholly compensated by food. An unusual degree of cold produces an effect, inevitably. The skin, and parts adjacent, will always be affected, as will also the natural covering-hair, or wool, of animals. The contraction of the hide and inner skin-from which the wool springs and draws the means of growth-restricts the passage into the wool of the elements of its growth, and diminishes the supply of yolk-which is its natural protection and softener-and it becomes wanting in texture and elasticity. In like manner, the wool suffers from the effect of wet. The yolk is not of the wool, but is provided as its protection. Its composition is oleaginous and alkaline; mainly, animal grease and compounds of potash ; forming, in fact, a true soap, which is washed away by rain, leaving the wool comparatively dry and harsh.

The action of external heat greater than the normal 
heat of the blood and body, prevents the evolution of the heat generated in the body; it, therefore, disarranges the equilibrium, which is needful for health, between the generation and evolution of the vital heat, producing an excessive expansion, or relaxation, an excess of cutaneous secretions-to meet which a plentiful supply of water is requisite-a waste of the juices and of the tissues; and consequent general relaxation and debility, or the blood becomes fevered, and its fatty and albuminous elements have a tendency to lose, to a certain extent, their individuality.

It is an object with the high-class breeder to protect his sheep from both extremes; and, as above-stated, to do this to the greatest nicety, the variations and mean temperature of a climate must be taken into account. Here, in the River Plate, we have a very temperate heat during the greater portion of the year. During the winter months, though raw and bleak, we have rarely any continuance of severe cold at all comparable to the cold of England, North Germany, and France-the cold here rarely exceeding a hoar-frost, which disappears with the morning sun. On the other hand, the summer heats range considerably higher, frequently reaching, and ruling for many days together, $90^{\circ}$ to $95^{\circ}$ Fahr. in the shade, and from $100^{\circ}$ to $125^{\circ}$ Fahr. in the sun. Under these circumstances, a slight protection from cold, and an airy shade, or protection, against the summer heats, is what are desirable to aim at; and, of course, an efficient protection against wet. The close housing required to meet the severe cold which prevails for months in Great Britain, North Germany, and the North of France, is quite unnecessary and undesirable here, even in the winter; and such houses would be intolerable during the summer months, both by reason of the heat and the effluvia. 
In direct connection with this is the subject of ventilation. The assimilative and formative process is sensibly affected by it. As I have stated, the food taken by the animal is elaborated into the 'organism' through the blood, and this is effected through the instrumentality of the oxidation of the blood. The oxygen of the atmosphere being inhaled into the lungs, comes into contact with the blood, and is taken up by it, effecting a combustion of the hydro-carbons of the food, by means of which animal heat is generated, as before said ; and through its agency the machinery of elaboration (the manufacture of flesh, fat, \&c.) is kept in operation. Stop the supply of oxygen, and the fire goes out and the machinery ceases to work. Diminish the supply of oxygen, and cause this diminished supply to enter into the lungs, associated with deadly and noxious vapours, and the work is imperfectly. performed, and disease and wasting ensue.

The vapours generated in a close shed or house in which animals are kept are carbonic acid gas, sulphurated hydrogen, and ammoniacal vapours, which have the effect of thinning the blood and paralysing its circulation; while the deficiency of oxygen causes to be left unburned in the blood fatty globules, which obstruct the circulation, and to a certain extent poison, as it were, the system, by clogging it with unassimilated matter and depriving it of all tone or vigour of life, which constitutes health and development.

The want of cleanliness, as well as of fresh air, with its life-spring of oxygen, is of very serious prejudice to health. I may here call attention to the very grave evil which appears to have taken chronic possession of many flocks from which the 'galpon'-the shedded sheep of many, if not most, of our first-class sheep-breeders-are never free, viz. the scab; and more especially those of 
German and Merino blood. There is no doubt in my mind that, from the habit of excessive confinement, high feeding, dirt, and impure atmosphere combined, the tendency has become chronic in their blood; and a total change of system, and much care, may be required to eradicate it.

The course I would recommend is, in the first place, to select a genial period of the year, when sweet succulent grass is abundant. Shear the sheep, 'dip ' them thoroughly in Demarchi's preparation of sulphur and tobacco, or other similar 'dip, and remove them at once to new, clean ground, which would have to be reserved and fenced off in anticipation of this. In this clean 'potrero' I should leave them day and night, or, if the situation was inconvenient, bring them into a smaller ' potrero'not a 'corral' - at night. Pure water to drink at discretion, and rock-salt to lick. Shade (of trees, or other) to drive them under during extreme heat of the sun. While the sheep were getting thus a two, three, or four months' run-effecting a change in their whole system and purifying their blood-I would recommend all sheds, racks, and every portion of the 'plant' where they had been kept, undergoing a thorough cleaning and purifying. I would not allow any sheep to enter on to this 'plant' or ground for some months.

I should certainly allow sheep to run in the fresh air as much as possible. I have no doubt, from my own experience, that much greater vigour is attained by animals that are as much in the open air as is practicable, without exposure to extremes of heat or inclemencies of weather. There are few days in the spring, autumn, and winter, when the sheep may not be out grazing the greater part of the day; and in the summer, early in the morning and in the cool of the evening, with decided advantage; 
and as breeding-stock, destined for the regeneration of the flocks of the country, especially so. There is also an economy in the practice. They, however, should not have an opportunity of ranging over too great an extent of ground.

\section{IV.}

With a knowledge of thermal and atmospheric influences, we can rightly estimate the immense importance of a judicious arrangement and ventilation of the buildings, or 'galpones,' where sheep are housed. An ill-contrived 'galpon' will suffice to mar the entire prospect, and defeat every attempt of the breeder. Packed in a close ' galpon,' the sheep soon consume the oxygen, and fill the place with the carbonic acid gas which they exhale-a vapour fatal to health and, in quantity, to life. Add to this (should the 'galpon' not be kept clean) the sulphurated hydrogen, and other foul vapours, which are generated; then, suppose these sheep, after passing a night in this heated and foul atmosphere, turned out to encounter the chill of a winter's morning, and we need no fuller catalogue of fatal evils. Under such circumstances, the benefits of the best of blood are lost; the circulation of the blood is sluggish, its oxidation is imperfect, and the process of formation (the vital action) is feeble, the flesh flabby, and the wool deficient in texture, elasticity, and quantity. Skin, lung, and bronchial diseases, become chronic; and the progeny of such sheep is contaminated and will infallibly degenerate, and be afflicted with the chronic state of sarna, noticeable in many flocks.

The construction of sheds,' or 'galpones,' should be regulated according to the number of sheep to be housed. For a flock of from one, two, to three hundred and 
upwards, I consider the best form of protection to be a long shed, open in its whole front, built at the south side of a large 'corral,' with the open front facing the north. Brick and mortar 'galpones' I consider the very worst possible; I should be sorry to house sheep that I valued in such an one.

I am convinced that a simple shed of pine boards, with board, shingle, or thatched roof, is the best for these climates. The boarding at the back should not come down to the ground. A few inches should be left between the lower plank and the flooring, and the space of several inches should intervene between the upper plank and the roof. Large openings, with shutters to raise up or let down, should be placed in both gables, so as to ensure the free circulation of air. The best flooring is that of well laid brick, with a sufficient fall, and should be kept clean. The accumulations of litter and dung permitted in many establishments is decidedly objectionable, as being productive of skin diseases, lice, fly-blows, and foot-rot, besides creating exhalations unquestionably unwholesome.

The sheep should be free to lie in the shed, or ' corral,' at will-stormy wet nights excepted-and for the purpose of shutting them in on such occasions, movable open hurdles should be used. Wet should be avoided as prejudicial to health and to the wool.

Where a few choice rams, or ewes, are 'stalled,' a closed 'galpon' is necessary. This, likewise, should be of plank, and bricked-floor, with a fall to both sides. A space of three to five inches should intervene between the ground and planking, and of eight to twelve inches all round between the top planks and the roof. Half-aninch to an inch should be left between each plank, and there should be! arge openings with 'flap '-shutters in the 
gables, to be shut or opened as required. The bedding should be taken out and dried daily, and the clean portion returned, with the addition of a little fresh litter, after the stalls have been well brushed out and dried.

Such a shed would be sufficiently warm in the winter with the shutters down, and cool in the summer with the shutters up. If the closed shed is large, there should be ventilators in the roof from end to end.

By reference to the table of the ash of the blood of sheep, it will be observed that $66 \frac{1}{2}$ per cent. of that ash is common salt. Alkaline salts are essential to its liquefaction. Lumps of rock-salt should, therefore, be placed in the 'corrals,' or sheds, so that sheep may have free access to them. Salt is also a preventive against skin diseases, leech, and hove ('sobaipe' and 'empacho'), and it renders both the male and female more fruitful. Cleanliness in the food, feeding troughs, and watervessels (bebidas), and pure water, are of the highest importance.

The plan of making a loft in the 'galpon' or sheephouse, wherein to store corn and fodder, is extremely objectionable. On the one hand, the provender so stored becomes more or less contaminated with the exhalations from below, and on the other hand the lower part of the building is rendered close and unwholesome.

V.

The physiological question of the advantages or disadvantages of in and out-breeding respectively, that is, of breeding from near relations, or from perfectly distinct, or far removed branches of families, is one of great importance, on which much has been written. The consideration 
of expediency as to the crossing of two distinct breeds or races for specific objects, or with ulterior views, though apart from the question itself, has its connection with it. There are numerous advocates of both systems, and each claim to have met with success in the prosecution of each principle; and therefore recommend the adoption of the practice which they believe to be, and have succeeded in, best. I am free to admit, that there have been successful breeders on both principles, followed out consistently over a considerable period of time and through many generations. The fact of success under both systems goes to demonstrate that there was a difference of circumstances and objects, and that there can therefore be no arbitrary rule applicable to all cases.

The principle of 'out-breeding' is accepted in these countries generally as the acmè of sound practice; and it is believed by many that if the rams of flocks are changed every two or three years, little else is required. To such an extent is this idea carried in some cases that the veriest mongrels are produced; and I have even known cross-bred rams of Negretti, Saxony, Rambouillet, and long-woolled British extraction, all running in the same flock, at the same time, and changed for an equally mongrel lot-picked up here, and there, and everywhereafter two or three years, under the impression that the 'principle' of 'out-breeding' was being carried out.

My own experience goes to show that 'out-breeding,' as a rule, is destruction to uniformity of type. A judicious 'out'-cross is, under many circumstances, attended with good in flocks in general, and even in the flocks of high-caste; but such 'out'-cross must be made with sheep of an identity of type, and of the same race, if purity of blood and high quality is to be preserved. All successful founders of breeds of improved sheep have made 
the distinctive characteristics of their stock by means of 'in'-breeding, frequently of the very closest. I believe it to be one of the greatest 'powers'-selection and 'in'breeding -in the hands of a skilful breeder, especially the 'in'-breeding of the rams. There can be no doubt that defects of constitution, or type, are strengthened and perpetuated by ' in '-breeding, rendering especially necessary skilful selection. On the other hand, good points and special type are, undoubtedly, transmitted with greater certainty and fixity when 'in'-breeding is the rule, and an out-cross, not too far removed, the exception. An 'out '-cross is desirable when there is any manifestation of failing vigour, or other degeneracy, or when any animals of one branch of a family have attained, by reason of favourable combinations of circumstances, higher and better quality than other branches. There can be no question that, in such case, the selection of the breeder should fall on the most perfect and vigorous ram.

When failure, or a certain degeneracy, has resulted from ' in '-breeding, I do not hesitate to say that it has been rather the fault or error of the breeder than of the principle. It will be found that, in the majority of sucli eases, the breeder had directed his attention to certain qualities which he sought to advance, and in so doing lost sight, in some degree, of other qualities which were essential to the perfect animal. The result has been that one special quality, engrossing the attention of the breeder, has dominated, causing constitutional weakness. Take the instance of early excessive fatting qualities, which, if carried beyond a certain point, must result in weakening the procreative power (hence so many barren cows and ewes, as well as some unfruitful rams and bulls), and in the diminution of muscle, bone, and general vigour, to a degree prejudicial to a race, and the transmission of 
true quality, ending, ultimately, in defeating the primary object. The 'out'-cross, to repair decreasing vigour, becomes a necessity. It is required to restore the equilibrium of healthy development. 'In'-breeding carried beyond a certain limit would, it is more than probable, of itself produce degeneracy; but the danger in sheepbreeding is remote, except when a very small number are kept; as, by the rule of selection, the most perfect rams should always be destined to propagate the race; and when the stock comprises several hundreds of ewes, there are several families in different grades of relationship, and the probability is that the best rams result from different branches, and different combinations of these branches, in the comse of selection.

The object of high-caste breeding is to produce rams to raise the type, and generally to improve the stock of the country, and to create new varieties by crossing with others. In this operation, it must be borne in mind, that there is something more than an 'out'-cross-it is a cross between distinct varieties; and as this is done--i.e. the improvement of races, or the creation of new typesthrough the dominant procreative power of the males of superior caste, it is very desirable that the power of transmitting type should exist in the males in the highest degree- a result of 'high' or ' in '-breeding. It is, therefore, of the greatest importance to the sheep-breeder that the rams which he uses, with the object of improving his stock, should be 'in'-bred. I have had signal success by adopting this practice; and I have extended the practice with the like success with the ewe progeny of these ' in '-bred rams-putting rams to them closely allied to their sires, and even the same sires.

There is a very large number of sheep-farmers-in fact, the majority - who in their practice commit one of 
the greatest of errors. They have a vague idea of improving their stock and, with that end in view, purchase one, two, or three fine rams. These they put into one of their flocks, or with a number of ewes selected from their flocks. The half-bred male produce of these they use in the other flocks, and even in the same flock, expecting, of course, brilliant results, and are grievously disappointed at finding they make no, or, at all events, very little progress. It is a recognised fact among breeders that a farmer who uses his half-bred rams in his flock commits a fatal error. The higher blood of the sires of these half-bred rams is always dominated (vencido) by the blood of the dams in the progeny resulting from the ewes of the flock and the half-bred rams. Half-bred rams have no fixity of type; whereas, the ewes of any race, or variety, though it may be ever so inferior, have such fixity, even if it be a fixity of bad quality ; and that fixity will always prevail over anything that is half-bred in rams. To refine, or improve, simply means to dominate inferior blood and quality by higher blood and higher quality, in superior force.

\section{VI.}

The foregoing explanations will suffice to show that the man who purposes to form and carry on a high-bred sheep establishment has no light task before him; that mind and will must be directed to the undertaking; that there is no detail unworthy of his close attention; that the details mentioned herein, and very many others, which will continually present themselves in the course of his undertaking, cannot be neglected; that he must be ever observant, and ever prepared to meet all contingencies; 
that his employés and labourers must be intelligent, trustworthy, and orderly; and, finally, that he must be rigid in the exaction of the most systematic management.

The man who is not prepared to meet all these requirements had better leave high-caste breeding alone. On the other hand, he who will fulfil its requirements, and breed from the best blood, will succeed to his own satisfaction, and prove a great benefactor to his country.

A great expense and much thoughtful care is necessarily entailed in the production of superior animals; and there will naturally arise a fear that in this country, where the general habit is to go in for lo barato (the cheap), adequate prices might not be obtained. But, it may be taken for granted, that there are many among the wealthy and intelligent sheep-farmers sufficiently alive to their own interests as to be ready and willing to pay a good price for superior stock. Indeed, we often see in the auction sales of imported sheep (in the absence of sufficient thoroughly good home-bred stock) animals of questionable blood, inferior size, and in every respect illcalculated to benefit our flocks in any appreciable degree, sold at prices far above their intrinsic value for the purposes for which they were destined.

Our climate is admirably adapted to the production of the highest class sheep; and I know that results have been obtained by one or two, under proper management, which leave little or nothing to be desired; and that there are rams bred in the country which far exceed anything that is imported. I see no reason why, in a few years, we should not have a breed of sheep extensively established in the country, yielding a product that may compare and compete in general usefulness with anything that is produced in other countries. I trust that the day is not far distant when a flock of sheep which yields less 
than 6 lbs. to 7 lbs. of wool per head, will be a rare exception; and I likewise feel assured that the day is close at hand when there will be more than one flock of highcaste breeding ewes averaging $10 \mathrm{lbs}$. to $12 \mathrm{lbs}$. of wool each per fleece, and rams bred from them yielding $181 \mathrm{bs}$. to $22 \mathrm{lbs}$. of wool each.

\section{VII.}

While individuals contribute to the general good by their intelligent management, and well-directed employment of capital, in the improvement of stock, they are entitled to something like systematic protection; a protection not only direct as regards the safe possession of their property, but considerate and fostering as being the depositaries of the Porvenir of the country.

Such protection should be extended by the authorities of all grades, and by the population at large. The good sense and correct feeling of neighbours cannot always be counted on, whether from incapacity to understand the good that is growing up at their side, or from less excusable causes. In such case, the paternal care of the authorities should ever be ready to protect individual rights and the good work in which the breeders are engaged.

The individual loss and the national loss accruing from any direct violation of the rights of property, or indirect violation of the same, by which the labour of years might be sacrificed, can hardly be over-estimated. The direct loss, by the taking away under any pretext whatever, or by theft ; the indirect loss, through the contamination of the flocks; the contamination of the blood, by means of the mixture of inferior stock, so frequent when so 
little respect to limits, or even fences, is observed, and contamination by disease, scab, and the like. Could anything be more disheartening to the high-caste breeder, as well as serious in its consequences to the progress of a great national industry, than an irruption of an ordinary or inferior flock with its rams into the choice ewe flock of a high-easte breeder? And if to this we add, that the scabby flock of a neighbour is participating of the camps, depositing infection not only on the herbage, to be carried by the winds into the neighbours' 'potreros,' but on every post and every wire, by rubbing their scabby bodies against them, and leaving the scabbed wool attached thereto; surely, might he say that there is little encouragement held out for, and little of carrying out, improvement! Yet, these are occurrences which we are constantly subjected to. Our pens are invaded by neighbours' dogs, our 'potreros ' by neighbours' rams and flocks, or an unscrupulous neighbour will lay his scabby flock against, or near to, the 'potreros' - the grazing ground of the choice rams-to entice them out of the bounds that they may 'encastar' with his sheep, and return to contaminate the rest with the scab. I may suggest-for the consideration of the governing powers and the public-the question whether or not the law as it stands, or as it is understood, provides redress or compensation commensurate with the injury, or whether or not any redress or compensation is to be had, and if to be had, at what cost, and with what trammels and difficulties?

The high-caste breeder is not alone entitled to protection and justice, although in his case protection is more especially calied for. What flock-master can hope to have a sound flock of sheep so long as his neighbours are entitled to keep on all sides of him infected sheep? 
The serious ravages of the scab are notorious, and are spreading to such an extent as to give just cause for alarm; but there is no law, and no remedy.

It is absolutely necessary that something should be done to check the spread of this disease, and protect the flock-masters who expend money in the care of, and when necessary, in curing, their sheep. I may cite the example of Australia in this matter.

With the view of checking and keeping down the scab, the most stringent laws were enacted, compelling the flock-masters to cure, i.e. to dip their sheep, under penalty of heavy fines; and even, at the requisition of neighbours, I believe the killing and burning of incurable flocks. The travelling of infected flocks was and is prohibited; and I am informed that any party attempting to cross the lands of a sheep-farmer with a drove of infected sheep, such sheep-farmer can compel the halt of the drove, and even exact the slaughter and burning of the same. Such is the paternal and wise protection accorded by law to a great national industry, rescuing it from inevitable ruin.

To numbers of flock-masters I have put the question (well knowing the answer that would be given, but wishing to strengthen my representation of the evils accruing by the testimony of numbers), "Why do you not dip your sheep when you experience so serious a loss, year by year?' The invariable answer is, ' Of what use would it be? All my neighbours have scab; and if they had it not, any drover can cross my "camps" with infected sheep, as is almost weekly the case, strewing my lands with the falling scabbed wool, and, in some instances, with the carcases of the sheep which, eaten up by the disease, become too weak to travel, and die on the road.' As an instance of this, I may quote an occurrence as 
complained of by a gentleman to me but a few weeks ago. A neighbour of his bought, from an establishment some distance outside of him, a flock of sheep, scabby in the extreme. These the party purchased for a mere nominal sum, calculating that a very large portion of them would not reach their destination. With these sheep he crossed my friend's lands, and the line' of their passage was strewed with the dead and the dying; and, as he said, "Of what use would it be for me to "dip ;" my lands are infected; the remnants of this diseased flock are located now at my very door, and I have no redress!'

This may be an extreme case; but it suffices to show that legislation is required in the interest of all; for an extreme case proves the license to injure. It is of vital importance to this great national industry that welldigested and stringent laws should be enacted for the protection of individuals, and at the same time, and as a consequence, the protection and preservation of the most important and valuable interest of the country.

The inefficiency of the rural law, or its operation, in its bearings on this great industry, and the requirements that have grown and are still growing with it, is a natural consequence of its rapid development. It has outstripped all precedents of campo regulations, as well as the icleas or conceptions of the great majority of the population. My strictures imply nothing beyond this, and are made with the object of calling attention to a pressing necessity which it is of importance to meet suitably. 
PART V.

OBSERVATIONS ON THE UTILISATION OF RIVER PLATE BEEF.

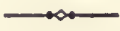

I.

There is a subject in connection with one of the great rural interests of the Rio de la Plata, which is attracting much attention both in the country and in Europe, more especially in Great Britain.

The vast herds of cattle that graze on our plains are pointed to as an inexhaustible source of food. Here, in the River Plate, the utilisation of the meat, or its nutritious matter, of the hundreds of thousands of the animals annually slaughtered-the food part of the majority of which is wholly lost, yielding little or nothing to the breederis a matter which essentially touches the interests of the country at large as well as of individuals, and it is anxiously canvassed in all circles. In England, with increasing scarcity and rising prices of meat, there is naturally a longing and expectant look cast towards this land of cattle and beef; and persevering efforts are being made in numerous districts to introduce for consumption South American salt-beef. These efforts are only partially -and apparently transitorily, even when they are partially, - successful. When there are craving multitudes able to pay a fair price for the nutritious food they require, viz. flesh meat, which is annually becoming a greater necessity 
with all classes, not only from habit, but also from an absolute want, to sustain the extraordinary wear and tear to which the system is subjected by quickened thought and accelerated movement, and they decline to avail themselves of that which is urged upon them as 'the thing' which they require; as 'the wholesome beef of the untainted (by artificial feeding) herds that feed on the virgin pastures'-it may suggest itself to thoughtful minds, that there may be a cause for its rejection. Is it really what it is represented to be? Does the fact that the cattle roam almost in their naturally wild state over plains vast in the extreme, suffice to make the beef especially good, or even good at all? And is the expectation well-founded that this beef can, by any and many processes, be preserved good and wholesome?

In another paper, I have described the habits and treatment of these cattle, as also the lands and pasturage on which they feed, and the customary manner of their slaughter.

During several years my attention has been more or less directed to this subject, as a matter of general interest rather than with any immediate purpose; nevertheless with the idea that information obtained on so manifestly important a matter would prove available and practically useful.

Under this impression, in the course of recreative study, I have sought and noted matter bearing on the subject in the works of authorities of the highest standing, more especially in those of Dr. Carpenter (Carpenter's 'Physiology') and Baron Liebig's ' Letters on Chemistry, Physiology, Dietetics,' \&c. ; the latter work being but recently published (1859), when the subject presented itself to my consideration,

It became evident to me on studying these and other 
works, that there were many considerations and conditions to be taken into account; that it was not a matter to be resolved by process alone; that a little more or less of salt or other antiseptic, or one or other method of using the same, or of packing, \&c. would not solve the question of the utilisation of our beef. It became clear to me that the habits of the cattle, their precarious feeding and water supply, the long distances (often sixty or eighty leagues) they were driven, the excitement of parting out, the heat and the thirst, the storm and the cold (as might be) to which they were exposed in long travelling, the mode of slaughter and butchering, and many other matters or conditions, must necessarily have an influence which could not be counteracted by a mere process.

I have known a variety of experiments made, and processes tried, and of numerous shipments; I have heard and read of sanguine expectations, and even favourable reports, some of which have appeared under sanction of high authority-one no less than the 'Lancet;' but knowing well the cattle of this country, their habits and condition, and the system followed in respect of them, as also the methods resorted to with the object of preserving the beef, I have held, and do hold, the opinion that by no process of salting or curing can the beef of the cattle, in the condition in which they are as a rule brought to the slaughter, be made a desirable food.

Admitting that certain sample shipments have been sound and comparatively good, an infinitely greater proportion have been unsound and bad; and I hold $\grave{a}$ priori that the prohibition of the sale of South American beef, some short time ago, by the Sanitary Board in England, was well considered and well founded. When sound beef has arrived in England, it has been made from animals in an exceptional condition, and these exceptions 
go to prove the rule which I desire to inculcate for the good of producers, shippers, and consumers.

The reason of my belief that a sound nutritious food cannot be obtained by any process of salting or curing the flesh of the unfed and 'driven' cattle of this country is simply, that the means taken to preserve the beef are exactly those which most surely, in the state of the cattle, would deprive it of the greater part of its nutriment. Salt is a powerful solvent of meat juices (this power existing in the acid of the salt, i.e. muriatic acid_salt being muriate of soda, or chlorine of sodium, of which more anon), and it is in the juices or soluble substances (albumen, fibrine, \&c.) of meat that all the nutriment exists. Water will also, and unaided, extract the nutritious matters of meat. The most accurate experiments have been made to determine these points, and therefore I need merely state the facts. When lean meat is subjected to the action of salt, the deliquescent properties of the salt cause it to attract the juices of the meat, and a brine is formed, which runs from the meat. This liquid which is thus extracted from the meat, together with the salt, contains the mineral basis of the meat, its phosphoric acid, potash, \&c. and its albuminous matters, together with its peculiarly vivifying principles, kreatine and kreatinine; consequently, in an equal clegree as these matters are abstracted from the meat, so its fitness for food is diminished; and it is impossible to salt lean meat without its parting with a very large portion of its nutriment. All housewives know that meat in certain conditions does not, what they call, 'take the salt;' and the meaning of this is simply that the meat yields up its nutriment to the action of the salt, and that it drains away with a portion of that salt. Meat to ' take the salt' must be exceedingly firm, and highly fed with food rich in nitrogenous or 
albuminous compounds, so that the like compounds in the beef (or other meat) being solidly packed in its substance, resist the solvent action of the salt ; and by consequence a larger portion of nutriment remains in it. There is another condition in highly fed meat favourable to this, viz. its solid fat, fat which is in solid layers on the flesh, and also veined through the flesh: to this fat the salt adheres, or combines with it, and its antiseptic properties act, while its solvent action is diminished.

This property of veined or mixed flesh, in which the fat and the lean are intermingled throughout, is a condition of well-bred animals-animals bred for beef purposes and domesticated. Cattle of wild habits, constantly in motion, and getting unequal and irregular feeding, both as regards quantity and quality of food, can never produce this condition of meat, or its richness and flavour. It is an hereditary quality engendered by feeding, selection, and domesticity, by which, also, an even growth of parts and large fleshy development is made a habit-a fixed, hereditary habit. In contradistinction, constant motion, roaming over great distances to feed and in search of water, engenders a lean habit of body, as there is a continuous waste which, more or less, equalises the replacement effected by the food, admitting of small accession of bulk in the flesh. At many seasons of the year, when the herbage is in its lesser nutritious stages, there is a positive diminution in bulk and depth of flesh ; and when herbage is in abundance, and in that stage of growth when its fattening properties prevail, the fatty accumulations are more rapid than the flesh formations, and the fat, as a consequence, is deposited in parts internal, around the kidneys and viscera; there is little external layering of fat, and little or no marking or veining of the flesh with fatty matter. 
Animals which have been driven or subjected to considerable fear and agitation before being killed, have their whole flesh relaxed; their albuminous juices are in an actual state of dissolution or waste. The saccharine element is in a state of transition into fat, and the fat itself is in a peculiar state : it is softened or dissolvedwasting-and neither flesh nor fat will, to use the homely expression, ' take the salt.'

Herein are involved highly interesting physiological laws, which it is convenient to define in a few propositions, so as to render more clear my deductions.

'Organisation,' construction or the 'laying on' of flesh, is the result of food taken. 'Organisation' is the storing up of force. There is a latent force in all substances. The latent force of vegetable substances taken by an animal as food passes into the flesh, muscle, \&c. formed by their assimilation, and endows the animal with the power of exercising force in proportion to the store accumulated.

This store of latent force can either be expended by effort, or it can be transferred to other and higher organisms, as food of a highly nutrient or azotized quality.

Force dissipated or expended by exercise passes into other elements; and organs which have exercised 'force' to any given degree cannot again exercise an equal amount until that which has been expended has been restored by an accumulation of fresh elements. Physical effort, the efforts or impressions of the mind in man, sensibilities in animals, equally result in an expenditure of force; and this having taken place in the case of an animal, its flesh has, in a like degree, parted with its nutritious power; such power and the capacity for effort being identical.

The 'secretions' of the body, and the climinution of 
substance effected by physical or mental effort, are the result of a positive decay or decomposition of the various parts; and this continuous waste of substance, and its replacement through the instrumentality of food, is an absolute condition of animal life. Therefore long travelling, anxiety, loss of rest, will materially reduce the substance of the body, and without a continual and sufficient replacement of that substance in the form of nutritious food (with time for its assimilation into the organism), the decomposition or waste of substance would be such that, in a short time, there would remain little else but the 'fibre' of flesh ; all the ' nitrogenous,' all the hydro-carbon substances, would be consumed in the efforts made by the animal, dissipated as gases, or passed off as secretions. Moreover, this general decomposition (or combustion) having set in, it would be in vain to hope to arrest it by any process. Hence the reason why so much of the beef which has been shipped from time to time has been found bad, or become bad immediately that the oxygen of the atmosphere has had access to it. Close packing, hermetical sealing, \&c. suspends this decomposition, but does not stop it.

Anyone knowing these facts, and the condition of our cattle in general, how they are brought to the slaughter, how they are killed, the semi-wild habits of the animals, and their excitement on the approach of man, can well understand that their beef cannot be nutritious, and cannot be salted without parting with by far the greater portion of such nutriment as it contains, and becoming almost valueless as food, if not altogether unwholesome. It is well known that the fibre of meat-that which is left after the juices are withdrawn-has no sustenance in it. So loosely is the nutritious matter-the juice of meatheld in the substance of our beef, that no hash, stew, or 
other similar dish can be made out of it at all palatable. The meat itself, in all such dishes, is hard and tastelessit is little else than meat fibre.

Pure cold water will withdraw all the nutriment from the lean of any meat. If lean meat is cut up into pieces and laid in a vessel with cold water, and allowed to remain for a short time, it will part with the whole of its minerals and albuminous compounds, that is, the whole of its nutritive and constructive matter, to the water, and the solid remains will be indigestible, innutritious fibre. It is, therefore, clear that if meat of animals, in the condition of our cattle, is immersed in a brine-salt and waterthere being a double solvent power at work, all vestige of nutriment will pass from the meat to the brine, and that, by consequence, such a method is, and will be, wholly impracticable until means are devised to feed our cattle. Even the superior salt-junk of Europe, if used for any length of time without acid, sugar, fruits, and vegetables, will produce scurvy, not by reason of the salt, but by reason of the deficiency of potash, phosphoric acid, and albumen.

There are partial means of causing a retention of elements : thus, the use of lime in the preparation of meat will cause the retention of phosphoric acid by rendering it less soluble. Subjecting meat to a certain heat$133^{\circ}$ to $158^{\circ}$ Fahr. - will cause coagulum of the albumen (the degree of coagulation being in relation to the heat), and render it less soluble; but these methods are partial, imperfect, and in some cases expensive, and less likely to succeed with ill-fed than with well-fed meat.

To me it is perfectly clear that we must either feed our animals (such as are destined for the butcher, and animals of a superior and beef-making breed) up to the mark which will admit of their meat 'taking the salt,' or we 
must look out for some other process by which the nutriment contained in their flesh may be made available for export.

II.

So great is the importance of the utilisation of our beef, both to this country and others, that new projects are constantly started, new theories propounded, and numerous experiments made.

Among others, a new process is now in operation: that of salting the whole carcass entire, by injecting salt into the veins by the force of gravitation, or by forcepumps (Dr. Morgan's plan). It may seem presumptuous to criticise any new and unproved plan; but I cannot see that this system can make any material difference in the issue. It is not the system or process that will primarily determine failure or success, but the medium and the condition of the meat.

I consider that the effect of the process of injection will be to impregnate completely the whole of the meat with salt-brine; and that, consequently, no portion of the flesh will escape its full deliquescent action. Under these conditions it is natural to suppose that both the antiseptic and solvent effects will be in relation to the impregnation-ergo, that the meat will be very salt; that a very large portion of the nutriment will be dissolved out; and that to produce a good article, it will be requisite-1st, that the animal should be in a better condition, with firmer flesh, than is needed for other processes; and, 2nd, that there should be unusual facilities for the rapid drying of the meat. I may venture to express the opinion, all circumstances considered, that with equal condition of the lean of meat, that process 
which is worked the driest, i.e. with the driest and cleanest salt, and by which the flesh is the most speedily dried, affording the smallest relative opportunity for the draining away of the juices, must be per se the best; that is, it will retain the most nutriment.

If the flesh of an animal killed when in a perfect state of rest, and in a perfectly healthy condition, the flesh firm, and packed with nutritive matter, be salted in favourable drying weather, and speedily and thoroughly dried without getting any taint in any portion of it, as fair an article will probably be produced as is practicable by salting.

For salting and packing with pickle in barrels a higher condition, well-fed meat, is absolutely requisite. A certain maturity or age in the animal is another essential condition for successful curing. The habit of the cattle of the country is the reverse of early maturity, owing to the nature and precarionsness of their food. As a rule, the meat of animals that have not passed the age of three or four years cannot be used advantageously for salting. Probably the most suitable age for the purpose will be found to be from four to six years; but this again is influenced by the nature and supply of pasturage, water, \&e.

The cattle destined for slaughter should feed descansado, and well, up to within twelve hours of the time of killing. During these twelve hours they should remain in perfect quietude; and at the expiration of that time slaughtered humanely and expeditiously. The bleeding should be complete, so that there shall remain only that which has been converted into the 'fibrine' of flesh.

It is with a view to this also that they should rest without food for the twelve hours before being slaughtered, allowing time for the complete assimilation of the food, 
so that there may be as little matter in the body in a state of 'transition' as possible, as that which is unformed, as well as that which is in a state of abnormal waste, is prone to decomposition, and will not take the salt, nor be preserved by it. The carcass should be cold, not only before it is salted, but also before it is cut up. There can be no doubt that it would be materially benefited by being 'hung' to bleed and cool before butchering.

The usual process here is to cut up or 'butcher' the animal immediately it is killed and flayed. When the flesh is supposed to be cold, it is cast into brine-tanks, and goes through two or three courses of washing and soaking in brine, being transferred from one brine-tank to another, and pressed, as it is stated, with the view of extracting or forcing out all the blood. It is, in fact, ' lixiviated ' before being dried or packed, as the case may be. Under such a process it may be easily enough understood, from the explanation given in this paper of the effects of salt-brine and lixiviation, how little nutritious matter remains in the meat when the process is completed.

Some of the older cattle fed on the 'strong' pastures which are found in districts in Buenos Ayres, in the Banda Oriental, in Santa Fé, \&c. and on the 'alfalfares' of San Luis, resist to a certain extent this process; and if driving is avoided, and the animals carefully killed, \&c. a sound article can be obtained, containing always a certain amount, more or less, of nutriment. There are two or three parties working on this principle near to the feedinggrounds of the cattle. They have produced an article certainly much superior to others; and if they can so arrange as to diminish to the lowest point the waste from travelling and excitement, and be more particular in killing and butchering, they may still further improve the quality of their production. 
It strikes me that in the absence of any thoroughly efficient method of preserving our beef in its solid form, so as to retain the greater part of its nutriment, we might advantageously look to those materials and appliances which are the direct causes of depriving the solid substance of its nutriment, to furnish us, in a concentrated form, with the nutriment they so readily dissolve out of the flesh.

I have spoken of the action of the acid of salt-muriatic acid - in extracting the food properties from the meat.

For many years, to my own knowledge (and I have suggested its use to many persons with much benefit), there has been what is called the 'cold soup of beef' used in hospitals in Europe, and by many eminent physicians, who have found it to be in the highest degree nutritious, and unequalled in tonic or vivifying powers. This preparation is simply the lean of beef perfectly fresh (and the sooner after killing the better), cut up into small pieces, and put, with rather more than twice its weight of cold water, into a vessel, a few drops of muriatic acid being added at the rate of eight drops to a pound of meat, and a little salt. In an hour's time the whole of the nutriment will be extracted from the flesh, and there only remains to strain it carefully, and the soup is ready for use. This soup is taken cold; if heated, it forms a deposit, coagulum, and it would be less easy of digestion.

Again, I learned from the same authority-the eminent chemist before named-that by simply placing chopped lean of beef or mutton (all fat, gelatine, or tendons being carefully removed*) in a vessel with a little cold water,

* The theory of nutriment existing in gelatinous or tendonous substances is completely exploded in scientific and professional circles, and those which are in contact with them. Nerertheless, there are many who still entertain such an iden, whose opportunitics have not been such as to lead to a better understanding. 
and lixiviating, the whole strength of the meat is extracted. The result is a brown, thickish liquid, about the consistency of treacle-the pure extract of meat and the indigestible, innutritious fibre.

If the liquid extract of meat is subjected to heat at a temperature of $133^{\circ}$ Fahr. a partial coagulation of the albumen takes place, and at $158^{\circ}$ the whole; and the colouring matter of the blood is coagulated. Evaporated at a lower temperature, the extract can be reduced to any required consistence without coagulation, and is soluble in hot water.

The extract retains not only all the nutriment of the meat from which it is prepared, but also its flavour. The quantity of the nutritious extract is just the amount contained in the animal; that quantity being dependent on its condition, size, and age. In an old animal there is very little nutriment_probably not more than 1 or 2 per cent.; whereas in a young but mature one there may be from 12 to 14 per cent.

These preparations of the juices of meat are invaluable. Their portability is likewise a great advantage, as is also their ready conversion into the most strengthening soup.

For hospital purposes; as part of the commissariat for an army ; for use in private families; and, if they can be produced at a price that will admit of it, for a whole population, they will prove useful and beneficial in the highest degree.

The soup made from the juices of meat extracted by means of the muriatic acid, and used cold, is found to be the most easily digested food that can be given to patients in the lowest degree of debility. It requires little or no digestive action, and is in a state to be at once assimilated with the system; but it is not in a portable form, and requires to be used fresh; whereas the other preparation 
can be packed in the smallest possible compass, will keep for years, and a very small quantity mixed with hot water makes a highly nutritious and palatable soup, to which vegetables and farinaceous matters can be added.

I am informed that there is an establishment forming, or formed, in the Banda Oriental for the manufacture of extract of meat; and I have no doubt that, if such is the case, the principle adopted in its preparation will be that propounded by Liebig,* which has for many years been practised in Europe; but as the meat is there dear, and the extract cannot be produeed at a cost less than that of the meat itself, it is only manufactured for special purposes and limited consumption. If Buenos Ayres can supply this extract at a price within reach of the mass, it will prove very beneficial to the producers as well as to the consumers.

There is no secret in the principle, $\uparrow$ but there are doubtless many details which it would be necessary for any party undertaking to prepare the extract to be well informed of, and which the discoverer will have perfected.

A fair field, if not a most extensive one, is here open to capitalists. It is one method, at least, of utilising our beef to the very best possible advantage, as no particle of nutriment contained in the flesh is lost; whereas in all other known processes the loss is excessive, and is, moreover, greatly augmented by the necessary operations of washing, steeping, and cooking salted meats-the best way of eooking which is to stew them with vegetables, rice, farina, \&c. as in that way such nutriment as they

* Since writing this, I have learned that my supposition was correct; that the party in charge of the establishment received his instructions concerning the process from Baron Liebig; and that the extract bears his name, and is a decided success.

$\dagger$ See Liebig's Letters on Chemistry (4th edition), Letter XXXII, and Appendix, p. 525. 
contain is retained in the dish, which is made more palatable by the addition of raisins, olives, \&c.

It must be borne in mind, however, with the aim before us of the most 'advantageous utilisation of 'our beef,' and of acquiring for this product the highest possible value, that the amount of nutriment contained in the carcass flesh represents its value, for whatsoever purpose or process it is destined; and that by no process can we give it a value it does not intrinsically possess. The process of forming the extract of meat will give us, in an available form, all the nutritive matter contained in the flesh of an animal, and no more; but we have seen (page 123) that this all is extremely various in quantity-it may be 1 per cent. or it may be 14 per cent.; and condition as well as age determines the percentage.

The influence of excitement and travelling affects the quantity of extract yielded, as well as, under other processes, it affects the nutritive value of the solid meat; and, cateris paribus, it is the food the animal consumes which determines its relative value. We shall never get good value for our cattle until they are domesticated, and better kept and fed. This, like everything else, must have a beginning on a small scale, and gradually extend itself. It is obviously the interest of all that this beginning should be made, and it behoves the wealthy and enterprising to lead the way. As regards the various processes, that is unquestionably the best which renders available the greatest value-that is, the greatest amount of nutritive matter from a given quantity of meat of equal condition, and that will enable it to be transported to distant parts in the condition of sound, wholesome food. 


\section{III.}

There are considerations in connection with the condition of our cattle, the travelling and slaughter of the same, and the supply of meat in the markets, which stand apart from the mere commercial question, and directly affect the population of our cities and the surrounding districts. These considerations are of a very serious and important character, bearing on no less a matter than the general health and mortality.

Year by year, the consequences of the condition of our meat supply are becoming more marked and more grave. The rapid increase of the city population, the larger supply of meat required, and, by reason of the gradual driving back to greater distance of the cattle establishments, the close feeding of the camps, and, consequently, the inferior condition of the animals, the exhausted state in which they reach the killing-grounds, and the long period of hunger and thirst which they often experience on the way, and in the pens (corrales) of the killinggrounds, and in the bare paddocks to which they are driven day after day, to return again and again to the corrales until sold to the butcher-all these circumstances contribute to affect our meat supply, to render it inferior, and, in the majority of cases, absolutely unwholesome.

I have shown, in the course of these papers, that the flesh of animals killed under the conditions above represented is in a state of decomposition. The waste of substance and nutritious matter is far in excess of the reconstruction or organisation capable of being effected by the quantity of food taken by the animal. A given amount of food, in the requisite constituent properties, 
represents a corresponding amount of force; and so long as an equilibrium is maintained between the food taken and the effort made or force expended within the reasonable capacity of the animal, organisation is perfect, and a sort of statu quo is maintained in the state of the system. If a moderate excess of food is taken (over and above the force expended) and digested, the substance of the bodyperfectly organised substance-is augmented; and in either case the meat is sound and wholesome; but in the latter instance the nutritive matter in the flesh bears a higher relative proportion to the fibrous portion of the meat, and the quality of the meat, as food, is better.

In the case of an excess of effort or expenditure of power or force over the food taken, existing-previously effected-organism is destroyed; that is, decomposition of organised matter takes place. It is notorious that from this cause the meat supplied to the markets grows bad, as a rule, in a few hours, and cannot be used on the second day. I have frequently known it unapproachable in eight or twelve hours, whereas I have killed my own meat, in good condition-descansado-in the country at midsummer, and have eaten it on the fifth day perfectly good-better, indeed, than on the first day-with the thermometer in the corridor outside of the dining-room standing at $100^{\circ}$ Fahr.

I have stated that meat in the state of decomposition is not fit to enter into the human organism. Meat, the organism of which is in part destroyed or decomposed, taken as food is prejudicial to health. Absorbed into the blood, it contaminates it, its oxidation becomes imperfect, and fevers and other disorders are the result. When poor and unwholesome diets are more or less general, low and putrescent fevers prevail, and epidemics are common; and from food, vegetable or animal, that is imperfectly 
organised and wanting in the due proportion of constituents, parasitical diseases are generated. All diseases are traceable to functional derangement; in fact funetional derangement constitutes disease, and all 'function' is dependent primarily on food and its assimilation.

It cannot have escaped the notice of even the least observant, that fevers, pestilential disorders, and epidemics are becoming more and more common amongst us, and that the mortality from these causes is very great. There can be no question that the chief cause of this lies in the unwholesome meat supply, and is further increased by atmospheric impurities resulting from defective sanitary arrangements and accumulations of foul matters. Indeed, it is a rarity to find even a moderately good piece of beef on any table in the cities of the Rio de la Plata; lean, wasted, and tasteless stuff, only rendered passable in many instances by means of condiments, is the general character of the beef supplied to the cities.

It will not be uninteresting to take a glance at our culinary processes. It will be found that prevailing culinary practices have a direct reference to, and are an almost infallible index of, the qualities and properties of the meats cooked. The art of the cook is brought to bear on, and answer to, the palate of the consumer of the food, and this palate, taste, or craving is the expression of the demand of nature for certain aliments or constituents of food. The beef in these countries is almost universally, if roasted (baked) in the oven or fried, cooked with a large quantity of grease. The lean quality of the beef, the absence of layering or veining of fat in the flesh, renders this necessary, to supply the needful proportions of heat-giving substance or carbon on the one hand, and on the other to check the drawing away of the albuminous matters from the substance of the beef in the 
cooking process. When meat is boiled, 'puchero' is the dish usually made from it; that is, meat boiled with vegetables of various descriptions, and rice, the vegetables, \&c. supplying the deficient starchy or carbonaceons matters, and taking up the albuminous juices so readily parted with by ill-fed beef. In all stews and 'made dishes' the beef is found to be hard, almost horny, and perfectly tasteless. It is the mere fibre of flesh; such nutritious matter as it contained, as in the case of salting, has drained away from it. To compensate for the deficiencies of nutritious and carbonaceous matters, and to absorb the juices that drain from the flesh, a variety of fruits and vegetables are cooked with it. Pumpkins, maize, raisins, olives, apples, pears, peaches, \&c. \&c. supplying saccharine matters-alkalies, vegetable acids, \&c. -compensating to a certain extent for deficiencies in nutrient matters, or adjusting the proportions of the food elements. These things are not only desired by the palate, but are absolutely requisite to constitute food, and as correctives; much in the same way as raisins, limes, \&c. are necessary with a salt meat diet.

The country cookery - that of the pastoral farms or estancias-rude and simple as it is, is equally an index of the state of the meat. The cattle are killed on the farm where they feed, there is therefore no exhaustion or fatigue from travelling, and no decomposition or wastc of the meat juices or fatty matter. The meat is pierced by an iron spit or 'asador,' which is stuck in the ground in close proximity, and leaning towards a fire made of thistle-stalks, bones, or wood, in the open air or in the centre of a hut, which serves as kitchen. The heat of the fire speedily roasts or coagulates the albuminous matter on the surface of the meat, where it forms a coating, preventing any escape or draining away of the 
albuminous juices within the meat; it is consequently full of gravy or juice, and of good flavour, and constitutes a 'dish' which can be eaten daily from year's end to year's end without exciting any repugnance, a quality indicative of its wholesomeness and fitness to meet the requirements of the human organism.

If the animals killed are in good condition, all the constituents-albuminous and fatty-are in such proportions as suffice for all the requirements of the system, and no other food matters are necessary. Hence the country people live almost entirely on beef so cooked, using only a little salt, and occasionally a biscuit. 'Maté' ('yerba' infused in a small gourd, or ' maté,' with boiling water, and imbibed through a tube) is taken in the morning and during the day. This is the tea of the country, and is very sustaining, containing a principle allied to theine, caffene, and the principles of cocoa, the karab nut, \&c.

The festal dish of the camps is ' carne con cuero,' or meat roasted in the hide. The animal is cut up with the hide on (on some great occasions when there are many to feed on it, the animal is roasted whole with the hide), a large piece is put on the spit and the inner side presented to the fire, as in the case of the usual ' asado' or roast; the red embers are then spread and the meat laid on them, the side with the hide on resting on them. In this way the whole of the juices are retained in the meat, and it is particularly rich and satisfying.

The contrast in flavour, appearance, and nutritious properties which the meats of the country present to that procurable in the cities is very marked, and clearly shows a cause and effect in the long travelling and sufferings of the animals driven to slaughter for city consumption. The necessity for the feeding of cattle near the towns for 
town consumption is unquestionable, and in the face of the serious - consequences to the public health arising from the consumption of ill-conditioned and more or less 'tined' meat, it is high time for some popular or authoritative movement to secure a supply of good-conditioned wholesome beef.

\section{Note.}

\section{The Utilisation of the Beef of the River Plate.}

There has reached me from England the announcement of a new, or a modification of a known, process of preserving raw meat, in a perfectly fresh state, in tins, from which the air has been exhausted and 'nitrogen' substituted. Also there have arrived in Buenos Ayres, two gentlemen, Messrs. Sloper and Paris, to experiment on a process of the former, which has likewise the object of preserving the meat in a perfectly fresh and raw state.

These gentlemen have brought out samples of English-fed beef preserved on the plan of Mr. Sloper, which manifests a perfect preservation; in appearance, odour, and flavour identical with fresh-killed meat.

I conceive that the results of the working of their processes, or any others that may be invented, must be subject to the general law, and dependent relatively on the condition of the animals slaughtered; hence the question evolves, Can the flesh of the grass-fed animals of South America be preserved by any process so as to reach Europe as sound, palatable, and nutritious food?

I think that there can be little doubt that it can be so preserved, provided always that the conditions I have set forth in the course of this work are observed, and the grasses which are to constitute the food of the animals, allowed to attain a certain completeness of organism, a certain maturity before they are 
fed down in the ordinary course; this could only be looked for in certain seasons of the year, when the natural grasses are nearly all annuals; but these indigenous grasses can be supplemented with artificial grasses, aided by a system of paddockfeeding, as indicated in the treatise on Agriculture, and it is probable that only in such way could complete success be attained and an uniform quality of meat supplied. 


\section{PART VI.}

A GRIC U L T U R E

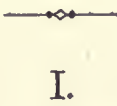

SheEP-Farming, sheep-breeding, cattle-breeding and feed- . ing (and the consequent utilisation of our beef) in progressive stages, must necessarily be dependent on agriculture. There is a mutual dependence, and there must be a mutual aid, or neither probably will or can be brought to any degree of perfection, and certainly not to a lasting one.

This is so important a truth, that thinking men of these countries should give it their earnest attention; indeed the conviction of this truth should dwell on the minds of the enlightened, and no opportunity should be lost for propagating it, and educating the minds of the masses to a right understanding of it.

Agriculture ever goes hand in hand with civilisation; and the most civilised nations are those with whom the science of agriculture is placed on the highest pedestal.

The decline and fall of more than one great nation has its connecting link with the absence of agricultural knowledge and agricultural practice; and the comparatively sterile lands, which exist in several countries as a consequence of an 'exhausting' system of farming, stand as impediments to their regeneration as nations. Able 
historians and philosophers have pointed this out as a warning to present and future generations.

Pastoral pursuits are those of nomadic tribes and, unconnected with agriculture, of nations in their infancy, when population is scanty, and wants easily supplied; but for a populous, or moderately populated country to exist and progress without agriculture, is a physical impossibility.

There is a prevalent opinion that these countries of the Rio de la Plata are unsuited for agricultural pursuits by reason of their climate, \&c. This popular error cannot be too soon discarded; indeed, to hold such an opinion, is to presuppose the impossibility of these countries producing great and prosperous nations.

The prevalence of this opinion arose from the monopoly of pastoral pursuits under circumstances particularly favourable to them on a primitive system, the small necessity there was for the practice of husbandry, and the very limited consumption of agricultural products but a few years ago-the bulk of the population living almost exclusively on flesh meat, like the wild huntsmen of forest and plain ; the almost total ignorance on the part of the native population of the elementary principles or practice of husbandry; an almost equal absence of knowledge of these subjects on the part of the foreign settlers and commercial men of those days; the rude attempts made with rude implements, and the consequent precariousness, and comparatively small yield of crops. Men who know not, and do not profess to know, how or why a plant grows, or under what influences different plants thrive, cannot possibly form a judgment of the capabilities of a country for agriculture. Furthermore, the man who has sown oats in England, Ireland, or Scotland-where the mean temperature is many degrees lower than here, and the 
rainfall altogether different in quantity and distributionand reaped abundantly under the combination of circumstances presented to him in those countries, certainly can have no just ground for assuming that these countries are unsuited for agriculture because the like cannot be done here. On equal grounds, the farmer who sows and reaps maize here, might assume that Scotland was unfit for husbandry because maize will not ripen there! Yet, from such data as this have conclusions been drawn.

Every few degrees of latitude, every few hundred feet of elevation, marks a difference of agricultural products, and determines the more or less favourable conditions of their culture.

There are certain laws which govern these things. These laws are universal, but their application (as demonstrated by those same laws) is various-infinitely various. The science of Agriculture is the embodiment of these laws, and their just application.

The possession of a rich soil by any country marks it infallibly as suitable for agriculture; as the very existence of a rich loamy soil, presupposes, and is the result of, a prior rich vegetation. The science of Agriculture teaches how this can be made available for reproduction in higher classes. The laws of tillage and its effects are everywhere the same; each plant, however, requires special conditions for its full development, and the business of the agriculturist is to select the plants for cultivation suitable to the conditions at his command; or by his art provide artificial conditions, or modify existing ones. When moisture is deficient, irrigate; when in excess, drain; when the food elements of plants are wanting, supply them to the soil ; if land is cold, raise its tempcrature by breaking it up to a considerable depth, and thereby clevate the surface, subdividing its substance 
by diligent tillage, and by heat generating applications, such as quicklime, or decomposing vegetable matter, as manure, \&c. \&c.

There are conditions, however, which cannot be provided or supplemented; for instance, plants which can only be grown at a very low temperature cannot well be produced in a warm climate; as vegetation will not grow without sunlight, and from that heat is inseparable; therefore in the warm or hot elimates of the tropics, both agriculturist and horticulturist must fail in the attempt to raise the plants of the frozen zone or cold latitudes; whereas the vegetation of warm climates can be grown in cold ones by means of artificial heat.

Agriculture comprises the cultivation of the mandioca, tobacco, sugar, rice, \&c. \&c., as well as oats, wheat, maize, turnips, \&c. \&c. On this broad basis it must be understood, and selection of plants made best suited to the climate, requirements of the country, and other conditions.

Our climate, however, at least, in the southern provinces, does not present any great disparity of feature with that of parts of Europe; and even for the main products of the British Isles it offers congenial conditions; and some that are wanting, or are precarious, can and will, in many districts, be provided by art, as necessities become greater, and knowledge of the science more general. Meauwhile, we have ample compensation in those plants which find more favourable conditions here than there, and these primarily claim attention.

Again, certain conditions which may be supposed generally wanting, probably from the circumstance of their not having been found in one or other locality or tract of land, will undoubtedly be found in other situations or other varieties of soil, of which many varieties 
exist in every square league of land. These conditions the agriculturist (it must be understood that there is a marked difference between the 'agriculturist' and the mere ' tiller of the soil') can readily detect and appreciate. Other conditions which are not at present so favourable as is desirable, will be modified by the extension of tillage and planting; the rainfall, for instance, will be more to be depended upon, and the absorption of moisture into the soil greater, both from rain and dew, so that the recurrence of drought (seca) may be less frequent or less felt.

II.

I have stated that pastoral pursuits, unassociated with agriculture, are incompatible with a stage of material progression, certain limits having been reached.

I believe that these limits have been attained within a certain radius of Buenos Ayres and other cities; and that that interest must inevitably decline in point of standing, if, from this time forward, there is not an union of the two to a certain extent formed.

I have shown in previous papers that marked augmentation of the value of stock cannot be expected without feeding both sheep and cattle; that the lands as they are in many districts, are incapable of supporting the stock now on them, and hence heavy losses and degeneration must be expected. Allied with tillage as an auxiliary, of only to an extent to meet pressing necessities, the pastoral interest is capable of very considerable development and increase of value. Incalculable national and individual wealth must be the result of the combination. There is no surer way, indeed there is no other way, to national 
greatness; and it is especially the 'porvenir' of these countries, and in none to a greater degree than Buenos Ayres, Santa Fé, Entre Rios, and the Banda Oriental. On the alluvial plains of some of these there is certainly no other source of wealth; they are, as it were, designed by the Almighty for agricultural and pastoral pursuits.

Men on all sides are asking, what is to be done? How are we to give increased value to, or utilise to greater advantage, this or that stock? The answer lies undoubtedly in what I have said. Ponder and speculate as we may, there is no other answer, and I assert this truth emphatically. The wisest heads need not be ashamed to make a permanent guest of this 'little truth,' and bend their best intellects to the solution of the problem it gives rise to. Our live stock is the sole source of wealth in the country. We must increase its value by feeding, care, and improved breeding, or all 'property' in the country will stand at a low level-a level commensurate with the value of stock.

\section{III.}

To practice to a maximum advantage any of the arts which have their roots in physical science, it is necessary to have a knowledge of the theory of the science with which such arts are connected; and I purpose explaining briefly the fundamental principles of the same, which, as I have just stated, I believe to be the essential element in the development of the resources of this country.

The object of tillage is to destroy an existing vegetation so as to supply its place with a better one; i.e. with higher class varieties, and to produce more largely from an equal space, to multiply the surface of the soil as it 
were, so as to maintain on it 'millions' where otherwise ' thousands' could not exist, that marvellously wise dispensation of Providence in the Creator's gift of the soil to man, to the end that he might multiply and live-_ live by the sweat of his brow.'

The science of Agriculture teaches us how to make the best use of this gift, how to till, sow, and multiply products; and the sciences of Chemistry, Physiology, and others in relation with agriculture, demonstrate the physical connexion of all matter, the identity of matter in all composite things living or growing; as also its indestructibility.

We learn, by means of these, that from the soil and the atmosphere, all things that grow and live have a common origin; what their composition is ; as also the course of construction or organisation.

We know, from these, the composition of plants and of all living things or beings, and the conditions under which they live and thrive; we learn from these the composition of soil, the properties which it possesses in relation to vegetation, and, by consequence, what increases or diminishes its productiveness; also the atmospheric and cosmic influences which are agents in formation, life, growth, and their operation.

Let us trace, as briefly as possible, the connexions of some of these things, and the origin of others.

The action of the 'waters of the earth' is that of a constant disintegration, and the atmosphere, the winds, rains, fire, and frost, labour to the same end.* Rocks of every variety are formed from substances that have had

* The detailed processes of ocean deposits, volcanic action, the avalanche, the iceberg, the formation of different strata of rock, the accumulations of Molluscr, \&c. \&c.; vegetable, animal, and mineral deposits and formations-lime, coal, salt, and metals-belong to other branches of 
a prior existence; and the particles of these, disintegrated by the washing of waters and the action of the atmosphere, form fresh deposits in the seas, the ocean, and on the low lands of the earth. Waters recede, or the land is raised, and the conglomeration of the various atoms in these deposits constitute soil. Soil is various in its class, according to the nature of the rocks from which it has been disintegrated.

All soil, however, contains certain elements, although in different proportions; these elements are identical with those existing in and forming everything that grows or lives; accordingly, the proportion of those elements which are essential for the growth of vegetation, contained in a soil, constitutes a soil fertile or sterile. Some of these elements are only found in small proportions, even in the most fertile soils, and, among those of the smallest proportions, are counted, in an agricultural sense, the most important.

\section{IV.}

The action of the component parts of all soils, in relation to the growth of plants, may be classified in two main divisions; one mainly mechanical, the other che. mical. To the former division by far the larger mass of matter constituting soil belongs, leaving, indeed, but a comparatively small percentage for the latter.

The mechanical action or condition with which the mass is invested consists in holding, distributed through

science, and although interesting to the agriculturist, are only in ultimate connexion with his science; and to attempt to explain them would be to go beyond the sphere of this paper, and would render it unnecessarily complex. 
its substance, the mineral elements which constitute the food of plants; with the power of absorbing, in greater or less degree, the gaseous elements needful for their growth ; of absorbing and retaining moisture, of absorbing and radiating heat, in their capacity of subdivision and cohesion; and in their furnishing the wherewithal for the rooting of plants.

The chief substances which, as a rule, comprise what may be called the mechanically acting portion of the soil, are clay (insoluble silica), sand, and chalk or lime. Soils are classified according to the relative proportions which they contain of these substances, with other subdivisions determined by the proportion of organic matters (vegetable substances) which are mixed through them, and are denominated respectively clayey, sandy, calcareous, medium; also clayey loam, sandy or calcareous loam, \&c. \&c. The physical or mechanical conditions of these different soils can be and are modified to an almost unlimited extent by tillage, by which the most compact and impervious of soils can be rendered friable.

The process of disintegration, under the action of the atmosphere, the winds, the waters, and the light and heat of the sun, by which soils were formed, is repeated on the soil, and prepares its elements for the use of plants; chemical changes are effected, and new and soluble combinations are formed, and the minerals, alkalies, and earths yield to this action their substance, which assumes forms available for the use of plants; these become diffused through the mass of the soil, and are retained in it by its inherent power of attraction.

Plants are composed of two principal parts- the underground, or roots, and the overground, or leaves and stems. The organic construction of these two parts fits them for the different offices they have to perform. The roots 
alone possess the power of taking up the minerals, alkalies, and earths-the inorganic elements which enter into the organism of the plant-and they do this by contact with the soil through which these elements have been distributed in an available form; being endowed with a power of attraction and abstraction superior to that of the soil, which yields up to them the matters or food which is required for the formation of the stems and leaves, and extension of the roots.

The food absorbed by an individual plant is in proportion of the root surface in contact with the soil containing that food, and the development of plants is in proportion to the quantity of these food matters existing in an available form, or due supply of moisture, heat, and sunlight, and the extent of feeding ground provided for them by means of the subdivision of the soil, so as to admit freely of the extension of the roots.

The soil, and the roots of plants in it, require the permeation of the atmosphere to prepare the mineral food, and facilitate its assimilation with the plant. This circulation, or permeation of the plant, is in greater or less degree, as there is more or less cohesion in the soil.

Moisture is absolutely requisite for the growth of plants; it is an essential agent in the preparation of this food in the soil, and it enters into the plant, is a material agent in its organisation, and a large constituent of it. An excess of moisture, however, is detrimental; wet stagnating in the soil obstructs the air channels, and, so to speak, suspends the respiration. A continuous process of respiration, or circulation of the atmosphere through the soil, and of absorption of moisture and its evaporation in unison, is as essential in the soil as in plants and living beings.

As a consequence of efficient tillage, the cohesion of the soil is broken, its atoms are separated, and an infinity 
of surfaces is presented, on which the atmosphere, the rains, and the dews percolating and permeating freely through it, act chemically, rendering soluble, and diffusing through it these mineral food constituents.

The change of position in the mass of the soil and its individual atoms, effected by repeated tillage operations, throws out fresh surfaces to the action of the atmosphere and the sunlight, thereby rendering available a larger quantity and a larger surface of soil saturated with available food.

From contact with the atmosphere, in circulation through its substance, the soil derives ammonia, carbonic acid, and oxygen - the solvents of mineral and the decomposers of organic substances. From rain and dew it derives also ammonia and nitric acid; and the evaporation of moisture (water) from any substance, generates ammonia from the nitrogen of the atmosphere; and in the case of this evaporation from the soil, the latter has the property of fixing or appropriating the ammonia thus generated. Ammonia and carbonic acid are essential to the formation, life, and growth of vegetation.

The absorption of heat by the soil during the day is counterbalanced by its radiation, or cooling, at night, and this 'respiration of caloric' is essential. In hard compact soil the radiation is very slow ; in subdivided or tilled soil, it is much more rapid, and dew, the result of radiation, is deposited on the soil and the vegetation, and is absorbed by them.

When land is deeply tilled all these influences are extended in proportion to the depth tilled; the rainfall penetrates, and forms a store of moisture in the substrata, rises, by capillary attraction, to supply the wants of surface vegetation, without stagnating in the soil or obstructing its air passages. 
The mode and detail of tillage varies, however, with the class of soil and the nature of the subsoil. There are, as I have already stated, clayey soils-stiff clay, siliceous clay, clay loams, sandy loams, vegetable loams, peaty soil, sandy soil, \&c. All these varieties of soils, differing in physical conditions, have different powers of absorbing moisture, heat, and food elements, and their cohesive powers and tendencies are different. While in the clayey soils the most laborious tillage, the most thorough disintegration and subdivision of atoms is needful, the tillage of sandy soils embraces the compression of its particles, so as to increase its power of retaining the moisture and food elements which it absorbs; and it is frequently found requisite, when the subsoil is of a more compact nature, to bring up a portion of it to incorporate with the lighter surface soil, be it sandy or peaty. Sandy soils absorb heat rapidly, and part with it readily. Clay soils absorb heat slowly, and retain it with tenacity; hence, vegetation is parched or chilled, dwarfed or luxuriant on them respectively, under different weather conditions.

Extremes in soils are the most difficult to treat, medium soils, loams of fair consistence, the easiest ; the presence of organic matter effecting changes in the soil mechanically and chemically in the same direction as those brought about by tillage.

On the higher and sloping lands whence the rainfall rapidly drains off, a deep tillage is essential, as thereby the rainfall penetrates more readily and in greater quantity, forming a deposit or reserve of moisture which as the surface dries, rises by capillary attraction as previously (page 118) explained.

On low lands a deep tillage is equally desirable, as the greater the mass of soil moved, the more the land is raised, and the deeper and more readily the water pene- 
trates, and the greater the extent of its diffusion. This class of land therefore, so tilled, is not so readily 'saturated;' the water does not stagnate on the surface so as to stop the circulation of the air and the diffusion of heat through the soil, which are so essential to the life and growth of plants.

On very low lands, in addition to deep tillage, it is requisite to facilitate the exit of the water by deep furrows, open drains, and ditches.

I do not enter on the very important and highly interesting subject of regular draining, as being from its costliness out of the reach of the infant husbandry of the country. I may, however, remark that it is nothing more than an advanced system of realising ends which I have just pointed out, viz. the leading down of the rainfall waters to a greater depth in the soil, and the carrying off any excess which would otherwise stagnate in it.

\section{$\nabla$.}

As the mechanical and physical action of soil is resident in and in relation to its general composite mass, so its chemical action has relation to certain elementary substances, or minerals, intermixed in its substance, each of which possess certain affinities for others in greater or less degree, governed and determined by special physical conditions and influences. Under these influences there is a dissolution of certain chemical combinations and the formation of others. In the laboratory of the mass of the soil, all those changes, solutions, and combinations are effected which dispose and prepare the inorganic or mineral elements forming part of its substance to enter on functions which form part of the cycle of organism or 
life. These elements constitute the mineral base of every thing that has life, development, and organism: from the humblest plant to the masterpiece of organism, man, there can be nothing without them. It is the combination of these organic mineral substances with gaseous elements which forms organic or living things; and this combination is effected under a 'power' which is arbitrarily styled 'vital force,' or 'vital action,' and which comprehends every defined and undefined power from sunlight to electricity, culminating in the 'will' of the Creator.

These minerals are of two main divisions, or, more properly speaking, three-acid, alkali, and metallicand consist of phosphoric acid, sulphuric acid, carbonic acid, potash, soda, lime, magnesia, silica, and iron. The presence in the soil of all these is absolutely requisite, otherwise vegetation could not exist on it. Vegetation is more or less luxuriant or scanty according as there is less or more of these in the soil in an available form, and the character or class of natural herbage is determined by the relative proportions in which they exist. This is exemplified by the growth of rushes and sedgy herbage on low wet silicious clay, or clay lands in which there is always present a large quantity of free silicic acid, so considerable a quantity of which (silica) enters into the composition of sedgy herbage, and by the permanence of sainfoin, clovers, and the like, on soils containing much lime; this element being a large constituent of the many varieties of this class or order of plants. 


\section{VI.}

The growth of crops on, and their removal from, the land, and the pasturing of sheep, cattle, \&c. and their removal or slaughter, withdraws from the soil certain proportions of its fertilising or mineral matters; and each succeeding crop grown and removed diminishes the power of the soil for reproduction, in a definite proportion according to the crop. The same result follows from the continuous rearing and removal of animals, as they carry away with them in their flesh, blood, wool, hair, and bones, mineral constituents derived from the herbage on which they feed, which in its turn derived them from the soil.

This is made perfectly manifest by a comparison of the analyses of soils, vegetation, and animal matters. A single series or table of these will suffice to make this clear.

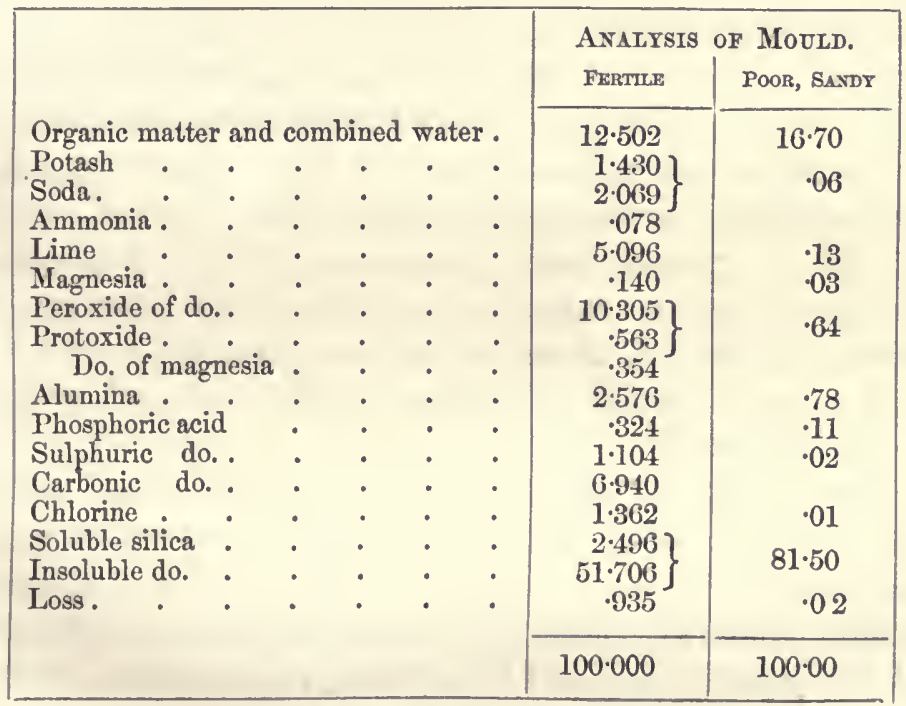




\begin{tabular}{|c|c|c|c|c|c|}
\hline \multirow{12}{*}{$\begin{array}{l}\text { Potash } \\
\text { Soda } \\
\text { Magnesia : } \\
\text { Lime } \\
\text { Phosphoric acid } \\
\text { Sulphuric do. } \\
\text { Silica } \\
\text { Peroxide of iron } \\
\text { Chloride of soda }\end{array}$} & \multirow{12}{*}{$\begin{array}{l}\dot{.} \\
\dot{.} \\
\dot{.} \\
\dot{.} \\
\dot{.} \\
\dot{.}\end{array}$} & \multirow{12}{*}{$\begin{array}{l}\dot{ } \dot{ } \\
\dot{5} \\
\dot{5} \\
\dot{5} \\
\dot{5} \\
\text {. }\end{array}$} & \multirow{12}{*}{$\begin{array}{l}\dot{ } \dot{.} \\
\dot{.} \\
\dot{.} \\
\dot{.} \\
\dot{.}\end{array}$} & \multicolumn{2}{|c|}{ ANALYSIS OF } \\
\hline & & & & WHEAT & Wheat Straw \\
\hline & & & & $29 \cdot 97$ & $12 \cdot 14$ \\
\hline & & & & 3.90 & .64 \\
\hline & & & & $12 \cdot 30$ & $2 \cdot 74$ \\
\hline & & & & $3 \cdot 40$ & $6 \cdot 23$ \\
\hline & & & & $46 \cdot 00$ & $5 \cdot 43$ \\
\hline & & & & .33 & $3 \cdot 88$ \\
\hline & & & & $3 \cdot 22$ & $67 \cdot 88$ \\
\hline & & & & .79 & $\cdot 74$ \\
\hline & & & & $\cdot 09$ & $\cdot 22$ \\
\hline & & & & $100 \cdot 00$ & $100 \cdot 00$ \\
\hline
\end{tabular}

For analyses of grasses, clovers, flesh, blood, bones, \&c. see 'Treatise on Sheep-breeding.'

The constant diminution in the produce of land continuously under crop is thus accounted for, where there is no sufficient restoration made in the form of manure, as is also the deterioration of pasture lands from which gradually, under a system of excessive stocking especially, the more suitable and nutritious grasses disappear. In pasture lands this, however, is not the only cause in operation to precipitate the result. On overstocked lands on which the best and most palatable grasses are closely eaten down, there is no sufficient opportunity for such better grasses to seed and reproduce themselves; so that ultimately the weeds and inferior grasses usurp possession. This is a process which is going on extensively on the sheep estancias of Buenos Ayres, and if certain limits are not put to it very serious consequences will accrue to the land and stockowners' interests.

The perpetual fertility of a soil is maintained by a sufficient restoration to it of the minerals abstracted from it by the crops ; moreover, this fertility or power of production can be increased by mechanical operations (tillage) efficiently performed, and through the improvement of the 
'climate' of the soil by drainage, \&c. as explained in another part of this paper.

What we understand as 'manures' are matters which contain the elements that constitute the food of plants, which have served the purpose of one or more organism, and having undergone combustion or decay, are in a condition to yield up these elements for assimilation with other organisms, when, being restored to the soil, they mect with those conditions-mechanical, chemical, and cosmic - essential to the realisation to that end.

Associated with efficient tillage, there is no law of the agricultural code more clearly defined, or more pointedly insisted on as of primary necessity, than that of the restoration to the soil of the matters abstracted from it by crops, \&c.; that is, of manuring the land when there is any sign of diminution of crops. The combination of the pastoral and agricultural is eminently favourable for the full compliance with this law.

It is convenient for the complete understanding of this to give analyses of manures. The most generally useful and efficient manure is that of the excrements of men and the inferior animals, which contain in their liquid and solid forms all the elements of the food on which they feed; and it follows that the higher the feeding, the richer the manure.

As it is not my intention to overcharge this treatise with technical and scientific details, but simply to direct attention to fundamental principles and draw practical conclusions, I confine myself to quoting only such analyses as will suffice to demonstrate these principles, and having, in this paper and in that on 'Sheep-farming,' given the analyses of soils, fodder, grain, and flesh, it will not be necessary to do more than quote that of the ash of an arerage sample of farmyard manure. 


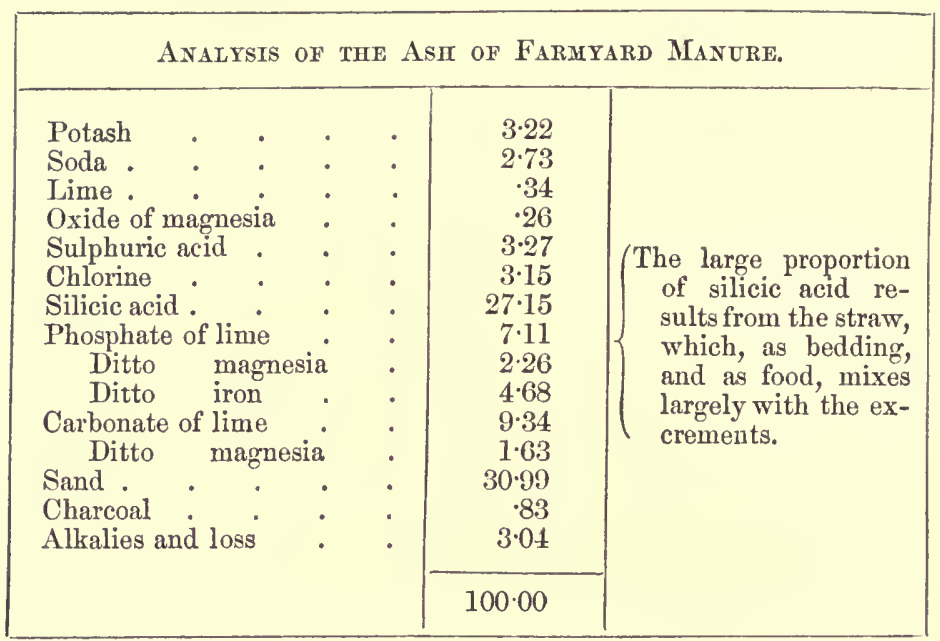

It is evident from this that, by applying to the land from which the food of the animals has been reaped, the excrements of the animals, such land is restored to more or less the same state of productiveness as before the crops were grown ; and if to this be added a little bone manure -crushed bones or bone ash-on old pasture lands, paddocks, or 'potreros,' on which numbers of animals have grown and lived, and generation after generation sold off, the productiveness of these fields will be restored, as that which was removed in the bones will be thus returned to the soil, and the result will be that these lands will again, if not overstocked, produce the good nutritious grasses which in part or wholly had disappeared from them.

Comparatively sterile soils can be made highly productive by efficient tillage and liberal manuring, as thereby their physical as well as chemical conditions will be materially modified or wholly changed.

The assertion made at the commencement of this treatise, of the necessity of a combination of the pastoral and 
agricultural which is comprehended in the term 'farming,' will derive point from the view presented by the foregoing facts. The consequence of feeding animals on a 'farm,' is the furnishing the farmer on the spot with, in the excrements, the means of maintaining the fertility or productiveness of his land; and the result of efficient tillage and manuring is to augment many fold the yield of the land, and, by consequence, enable the farmer to maintain a much greater number of animals on a given space, and to maintain them better, rear them of a better class, and render their products of greater value.

The tillage destroys an inferior vegetation, and leads to the production of a better, more abundant, and richer one; and better food produces greater development, better flesh, better wool, and more of them.

\section{VII.}

The agriculture of Buenos Ayres and the sister states is, as a rule, limited and rude, and, with very few exceptions, improvident. The crops comprise a few cereals, two of which alone are grown to any extent, and these year after year on the same land. Maize and wheat are the chief grain crops; barley is also grown, but to a less extent.

In the immediate vicinity of the cities, the usual course on the farms (chacras) is to take consecutive crops of these cereals until the soil to the depth to which their roots penetrate, having yielded up to them such a proportion of its available mineral food, ceases to produce sufficiently abundant crops to render their cultivation profitable. Potatoes, pumpkins, and the like, occupy but a very small extent of land. Recourse is then had to a deeper-rooted plant, and the land is laid down with 
lucerne (alfalfa), which is mown for 'soiling' or hay year after year until it is worn out. During all this time it is but rarely that there is any restoration to the soil of the fertilising matter abstracted from it in the crops. The extent to which the land is impoverished by this course in a few years, say the duration of the alfalfa, is very great, this being a plant which exhausts the soil probably to a degree unequalled by any other. Alfalfa hay taking more or less 12 per cent. of its weight of the mineral food of plants from the soil, the result is, that on the majority of lands on which this plant has been grown, it will not again thrive, and there is no other crop grown here that will as profitably replace it. These lands are, therefore, thrown out of cultivation, and fresh land must be had recourse to, or the farmer has to content himself with less remunerative crops.

When cereals alone have been grown, the usual tillage for which is shallow, a new surface can be provided by a deeper tillage, and a renewal of fertility is brought about for a time. On the other hand, alfalfa is an exceedingly deep-rooting plant, and impoverishes the soil to a corresponding depth. It has been explained that the means of maintaining the fertility of a soil consist of the restoration to it of the matters abstracted from it in the crops, in the form of manure. Now this is next to an impossibility on the majority of farms (chacras) as at present managed.

On very few chacras are there any more animals kept than suffice to do the work of tillage, so that almost the whole of the crops are removed from the land, and the elements of reproduction with them; and there is no means of obtaining manure except at a cost in labour and carriage out of all proportion to the value of the crops themselves. 
Changes of system and practice are always of slow growth in a country where the tillage and the pastoral establishments have ever been and are distinct, both rude, as also so disproportioned to each other in extent; and when the value of animals-horned cattle and sheep-is so small individually, the change of the agricultural system and its amalgamation with the pastoral must be especially difficult to introduce.

It is not, however, less the duty of a writer on these subjects to point to the only course which can ultimately raise the agriculture of the nation to anything like a rational and permanent system. This course is unquestionably the rearing and feeding of stock on farms for the city markets, the excrements of which, used as manure, will suffice to keep the land 'in heart,' that is, maintain its fertility; and, on the other hand, the rearing and feeding of improved breeds of stock constitutes the opening of a new outlet for agricultural products and consequent extension of agriculture.

The rearing and feeding of stock is desirable on other grounds than that of restoration. The continuous growth of the same crops on the same land has a highly prejudicial effect on its productiveness, as also on the crops, superinducing diseased conditions of a parasitical description, causing blight and partial or total failure. Variety and a certain rotation or change of cropping, added to efficient tillage and sufficient manuring, is that which agricultural experience teaches to be the most profitable, as well as the most advantageous, course for the land. This variety is rendered practicable and necessary when stock is kept on the farms, as forage crops can, and of necessity must, alternate with cereals and pasture. The more suitable forage crops will be discovered in practice, and the seasons best suited for their sowing and rise to 
meet the exigencies or conditions of the climate, will become known. The bean, the vetch, the melilot, the turnip, beetroot, carrot and cabbage, the sargo and bromus, \&c. \&c. may all be found desirable.

On all farms, too, where animals are not kept, there must necessarily be much waste. Much that is grown may not be marketable, owing to injury from weather, and other causes and contingencies which every farmer is subject to, or which arise out of the nature of the crops themselves. All this can be utilised when there is stock, so that no part of the farmer's labour is lost to him.

These things, in fact, constitute the economics arising out of 'mutual aid' and 'mutual dependence,' which lead to, and determine, in their completeness, the maximum good in all rural concerns and all nature.

As we have to bring animals to the tillage farms in the chacra radius, to effect their rapid extension and increase, and perpetuate their productiveness and value, so we must carry agriculture to our sheep-farms, and to the cattle establishments also, on which the owners rear high-caste cattle.

On the sheep-farms it is already a crying necessity everywhere, and propably this is the most urgent and important call and necessity for that union of the pastoral and agricultural which I have indicated as the life-blood of a nation's prosperity.

\section{VIII.}

It has been demonstrated, and the fact is patent, that no material progression can be looked for, in either sheep or cattle-breeding, without the aid of more nourishing food, and a more constant supply of it than is provided 
by nature under her varying influences, and the present general practice. It is an absolute necessity, therefore, to grow auxiliary food, and to dispose of and use the pasture lands under a system which will admit of their yielding more abundantly and more continuously, as also preserve the better class of grasses thereon. The ways and means of effecting this is the problem which presents itself for solution to every landowner and stockowner, who desires to keep pace with the times and the material progression which is everywhere in operation.

It must be a bold pen, indeed, that would presume to lay down a definite law for universal practice in the very dawn of a new phase in the heavings of progression in a great national industry; but in an humble and pious spirit it may be permitted us to endeavour to throw some light on so important a subject, one which is to work out the wellbeing and 'life' of the land we live in.

There is an infinite variety of individual circumstances, of conditions and situations of land, a considerable range of climate and climatic influences, great differences of vegetation, \&c. to complicate the subject.

Let us take into consideration, in the first place, our natural pastures. We find them teeming with luxuriant vegetation and bare and arid by turns. We find alternate tracts of wet and cold, rich and dry lands. Each in its turn serves a purpose or entails a prejudice, supplies more or less food according to the season, and the weather during the different seasons of the year, and producing different classes of herbage-poor and scant, strong and coarse, sedgy and of little nourishment, rich, succulent, and luxuriant, or fine, tender, and nutritious.

The higher, warmer, and richer lands yielding, with an average fall of rain, abundance of palatable grasses and clover during the autumn, winter, and spring, but many 
of them utterly devoid of green herbage during the heats of summer and early autumn, more especially in a season of less than the average rainfall. On the other hand, the lower lands, thinner in vegetable mould, and more clayey, are under water after heavy rains, and wet and puddly after every medium rainfall, and at such times the vegetation is by consequence deficient in alkalies and saccharine matter, poor in nutriment constituents, and tending to scour; but when the rainfall is scant and insufficient for the higher grounds, more especially during early summer, these low lands are clothed with nutritious and palatable herbage and sweet grasses, in many instances intermingled with two or three varieties of the melilot.

The most remarkable peculiarity of the medium and higher lands is the full possession taken of immense tracts at certain seasons by the variegated thistle, which overshadowing every other herbage, chokes it and causes almost every vestige of it to disappear. Other tracts are held possession of by the hard perennial thistle (wild artichoke) intermingled with the plants, which in the lower stages of its growth is the very best of grasses, but in the months of its maximum growth it covers the ground completely, bidding defiance to the entry of almost any animal into its prickly domain.

With few exceptions, the grasses, clovers, and various kinds of palatable herbage are annuals, and these constitute two distinct series, growing and seeding in different seasons of the year, and making no sign whatever at other periods.

One series of these grasses does not make its appearance until after the heats of the summer, and the first autumn showers cause them to spring into life. They develop, seed, die down, and disappear with the autumn, and are succeeded by the other series, comprising both grasses and 
clovers, which springing in the early part of winter (or late in autumn), maintain a low state of development during the.winter, and spread out luxuriantly with the genial spring weather.

On the uplands and medium lands carrying considerable stock, in the spring season the trefolium (medick clover) prevails over the graminaceous grasses; its predominance is in proportion to the stock kept on the ground, more particularly in the case of sheep, whose close feeding allows little chance of the grasses seeding, and being annuals they necessarily die out of the land, whereas the trailing habit of the medick clover, its abundant seed, produced on every shoot however short it may be eaten, causes it to dominate. Succulent and nutritious as this trefoil is, its excessive predominance is a great evil, and is a sure sign of overstocking. It is an early plant, and seeds and dies down early in the summer; the stems and trailers being of a soft and succulent nature are extremely light and substanceless when dry, completely withering in the summer heats, and leaving the ground on which it has grown most luxuriantly, perfectly bare. On the other hand, the more solid stems of the true and graminaceous grasses, when they have a chance to grow-and the stronger and closer packing of the roots present much greater resistance-they also, falling over, protect the land from the action of the sun, checking the evaporation of moisture, and encouraging the germination of the fallen seed and the intermingling of a young and tender grass with the faded.

Did every sheep-walk comprise the varieties of soil, elevation, and herbage which I have here described, it would be an easy matter to ensure a continuous and sufficient pasturage for flocks of sheep duly proportioned to the land; but, as the rule, probably a flock of 2,000 
sheep, or two or three such flocks, will have the 'run' of but one variety of land, high or low, as it may be, it becomes a very nice matter to dispose the grazing and calculate the amount of stock that can, with safety and advantage, be put on a given track of land.

This disposition of the pasturage, so as to give opportunity for the seeding of the good grasses, and the holding in reserve, for certain seasons, of a portion of the land well clothed with grasses that are less perishable than the trefolia, could be systematically managed, were it practicable for the landowner to 'fence.' Such an undertaking as general fencing and subdividing the sheep-walks or establishments, gigantic and costly as it would be, is in but rare instances practicable; first, by reason of the want of capital, secondly, the insufficiency of labourers, and thirdly, the small comparative value of the sheep. Doubtless this will ultimately be done, and the means will be made forthcoming through the improvement of the sheep increasing the weight of their fleece and carcass, so as to give them individual value.

The removal of the sheep from one subdivision to another (supposing the land to be fenced), according to the state of the herbage, to allow of the growth of the graminaceous grasses, when they would otherwise be deficient, and the accumulation of stock on land on which there is an excess of coarse herbage at a season when such herbage was still tender, so as to eat it down and 'fine it,' are practices of the highest importance, and require intelligent management. Failing the fencing, it is unquestionably to the interest of the landowner (for if through injudicious management, by insufficient or excessive grazing of the land, the herbage is allowed to deteriorate, he, de facto, loses a portion of his capital invested in the land, as that land not being able to carry its due 
proportion of stock, by reason of such deteriorated herbage, is of less positive or-actual value) to arrange the grazing of the flocks on certain portions of his ' run' at certain periods of the year, in as near an approximation as possible to the system he would adopt, supposing it to be fenced.

A careful examination and study of the herbage of lands, the period of its growth and ripening, is necessary to a correct estimate of its capabilities for carrying stock; and it is not too much to say that on this the greater or less profitableness of sheep-farming is dependent.

The stocking of land must necessarily be regulated with regard to season contingencies, as well as to the nature of the soil and its grasses. The openness of the country, without wood or hill, exposes it to a very unequal rainfall, and long and occasionally severe droughts occur. An effective and rational method to avoid the consequences of such recurring evils is that of always maintaining an extent of tillage land proportioned to the whole stock and its probable requirements in exceptional seasons, and as an auxiliary in others, on which to grow deeprooting artificial grasses and other fodder plants, and to stock a portion of the same as a reserve. This, like the ' fencing,' can only be done when the 'stock' is of a value commensurate with the necessary labour and expense, i.e. when the stock is worth taking care of, or can be made so.

Probably the most effective step towards a complete system would be the lessening of the extent of the establishments or estancias, when the capital is not in proportion to the extent. A man who has half a dozen or a dozen leagues of land (or even much less), with means disproportionate to it, must necessarily be overwhelmed by the magnitude of the work that would be required to place the whole property and stock on a proper footing; 
and such men must either reduce their stock and holdings, or devote a fractional part of them to the initiation of an improvement which, in course of time, they may make general; and there can be no question whatever that there must be tillage land on every well-regulated establishment, or material improvement cannot be hoped for.

\section{IX.}

THe 'THistle,' 'SEPO CABALLO,' 'ABRoJo,' AND POISONOUS IIERBS.

The former of these has its advocates, who believe it to be not only a proof of good ' campo,' but advantageous in itself. Sheep, cattle, and horses feed on it at certain stages of its growth, and its seeds furnish a certain quota of highly nutritious and oleaginous food; and it is notorious that, at the season of the fall of the seed, all stock get into good condition. The thistle seed and the seed of the medick clover are eaten from off the ground on which probably not so much as a blade of grass is to be found; but I do not hesitate to say that it is an unquestionable and an incalculable plague. The large spreading leaves and dense growth usurp the space which would be occupied by infinitely better fodder, and of nutritious quality tenfold that furnished by the thistle. At a certain period of its growth, its early stage, it is unquestionably a debilitating and unwholesome food, producing hove and scour-and at that period of the year all stock are lean and weak where the thistle prevails; and there is little doubt that, even at the period of the seed fall, a very much greater number of animals could be maintained in equal condition on the ripe grasses which would 
occupy the land, were it not for its overshadowing. Its extirpation, however, is an impossibility on estancias, and all that can be done for generations to come will be to clear fractional tracts, by cutting it down with thistlemowers, year by year, so as to admit of the growth of grasses and their seeding, and consequent re-stocking of the land with them. To effect this, the cutting should be at two periods-early in the spring, and at the time of flowering.

On the lower lands there is little or no thistle. It cannot exist on what are called the 'bañado,' or bathed lands; but there are certain plants of an extremely prejudicial character, bearing abundant seed-pods of oval form, densely covered with serrated prickles, which are apt to infest them, and which if not eradicated spread rapidly, and render the camps comparatively useless, or worse than useless. Of these the abrojo, or large burr, and the sepo caballo are the worst. The seed-pods fasten into the hair of the legs, manes, and tails of horses and cattle, are carried about by them, and ultimately bursting, scatter the seeds, which vegetate in any soil or land, high or low, although flourishing with greater strength on the lower.

In the wool of sheep they are known as the worst of banes. The 'cutter' that has been lately invented for the thistle answers well for these plants ; and so great a prejudice are they, that it is a public duty to eradicate them.

Lesser evils, at the same time by no means small ones, are the biznaga and wild camomile, which spread extensively on lands somewhat bare of good herbage. Poisonous tall-growing plants, such as the 'siente,' hemlock, and others, require to be carefully eradicated, as many animals are lost by feeding on them. All these, being either annuals or biennials, are to be got rid of by cutting at the time of flower. 
It would not be easy to over-estimate the benefits - the actual profit that would accrue to sheep-farmers and other estancieros by a practical application of the foregoing suggestions in respect of the judicious 'stocking' and systematic depasturing of estancia lands. Only a detailed study and observation will reveal the full importance that is attached to these matters. Their default is felt everywhere, but felt without a recognition of cause and effect in connexion with such default. Inevitable consequences, arising out of natural causes, are set down as 'Epidemia.' The wilfully blind shrug their shoulders when they look upon dwarfed sheep or their carcases strewing the camps; and still the rising consciousness of reproach for the greed for numbers, and the disinclination to take the requisite trouble and make the necessary outlay to attain better results, by the cry of 'Epidemia!' as though this was a something impalpable, borne on the breeze, and disseminating degeneracy and death; whereas, in ninety-nine cases cut of one hundred, starration is the active cause of nearly all the evils that, from time to time, visit the improvident sheep-farmer.

$\mathrm{X}$.

In proceeding to treat of tillage or arable farming on estancias, I wish it clearly to be understood that I am not suggesting any vast or impracticable scheme for putting the whole country under tillage, or anything more than a very limited accessory to the great pastoro-agricultural economy, or management, of grass or grazing lands. Nerertheless it is an extremely important adjunct, and no estancia henceforth can be considered to rank in the file of progress without it. 
The object is to supplement the indigenous herbage, and constitute a reserve to meet exceptional and unforeseen necessities, as before stated, and to provide a superior class of food for that portion of the stock which is destined to raise the standard of the whole, and stamp on it its type.

On estancias the means of enriching the land under tillage, and producing from a small surface enormous proportionate produce, are unbounded. A deep and thorough tillage and ample manuring, as fully explained in this treatise, are the means. A superabundance of fertilizing matter supplied by the corrals and rodeos, is at the command of the estanciero, and a free use of it will result in a great economy of labour; as through its instrumentality an amount of produce will be obtained from a given surface, equal to that which would otherwise be obtained from double that surface.

For the better conveyance of my views I will describe an establishment and its working, such as will probably meet the requirements of most.

On an estancia of any given extent and number of improving stock-say, sheep-a central agricultural farm, of an extent corresponding to circumstances and the necessities of the system proposed to be carried out, should be formed on well-selected ground, both as regards its quality and convenient position in respect of the various 'stations,' or 'puestos.' From this farm all the important regulations must be directed, and on it must be kept the whole of the ' sires,' which, through their superior vigour, class, and type, are looked to, to stamp their characteristics on, and engender uniformity in, the general stock. Such farm must necessarily be under the immediate direction of the owner of the establishment, or a thoroughly competent manager. 
It has been laid down as an absolute rule, not only that the rams (if any material improvement is to be effected) be separated from the flocks, well kept, and told off' to the flocks at fixed periods, and for a limited time; but that the borregas must be separated from the flocks before the rams are introduced, and that capones (wethers) and old ewes should likewise be parted out and formed into a flock or flocks apart, until opportunity offers for disposing of them, or they can be steamed down. There will therefore be required, on every estancia of any size, one or more 'puestos' for capones and old ewes, placed in potreros that will least incommode the ewe flocks. Also a puesto, with fenced or unfenced run for the borregas, which would have to be either redistributed to the flocks, after the rams are taken out, or formed into permanent flocks, and supplied with rams when of proper age.

On the central farm a sufficient extent of land would have to be laid out, fenced, and subdirided with conrenient paddocks (potreros); together with the like for tillage of alfalfa, maize, and other artificial grasses ; conveniently situated with respect to corrals, sheds, wells, drinking-troughs, and other conveniences, erected on it for the rams.

Assuming that the flocks of the estancia have attained to different degrees of improved quality, it might be convenient to keep the rams corresponding in quality to such flocks, in separate lots, two or three, as may be; each 'lot' having its own potreros, sheds, and corral; and probably the most convenient arrangement would be to have these potreros alternating with the 'alfalfares;' which latter, when not standing for mowing, and the ground being dry, would serve for occasional grazing, to relieve the grass potreros. 
I may state, incidentally, that a complete system of management necessitates the whole of the stock being under the absolute control of the estanciero. Either all his shepherds would have to be on a fixed wage, or those who had the charge of the ewe flocks (composed wholly of ewes), might be on a capitation wage, receiving a sum of money for every lamb counted out of these flocks, by which means they would be interested in the preservation of the lambs, and would earn an extra wage by extra care.

The following is a draft of a central farm, which might in many cases prove a convenient arrangement, and at all events will serve the purpose of facilitating explanation.

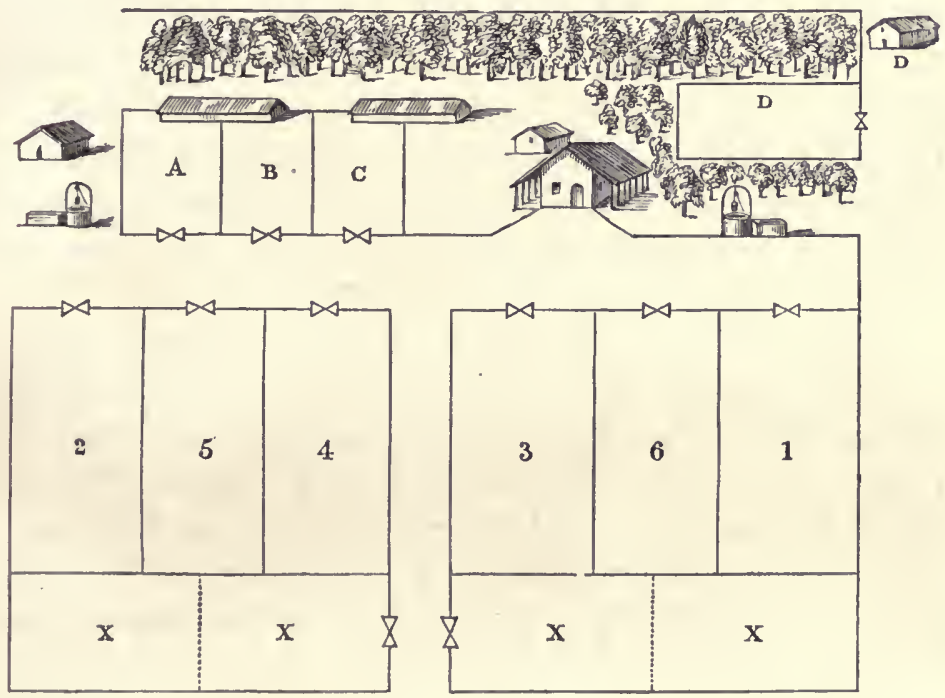

In this draft I place the ram, corrals, and sheds in a position sheltered from the south and west by the house and montes; in front of these, with a wide, well-levelled, and cleared road intervening, $I$ indicate convenient 
arrangement of potreros, alfalferes, and tillage lands under fence. Nos. 5, 3, and 1 represent grass potreros, of dimensions proportioned to the number of rams proposed to be kept in them. To render these productive of rich mutritious grasses, a good top dressing of corral manure should be given, and thistles and other weeds cut down or 'spudded' out. If the 'soft' thistle, it should be cut early, and the cutting repeated so as to admit of the growth of grasses, which they would otherwise choke off; if the 'hard' thistle it would require to be 'spudded' out, and so with other weeds, according as they are of annual or perennial growth. This treatment (manuring and cleaning) will abundantly repay the outlay. Nos. 2, 4 , and 6 represent alfalfares. One of these, or a portion of one, should be used for the supply of green alfalfa, to be given to the rams in the evening, in the sheds or corrals (in racks), during the spring, summer, and autumn; the others could be cut for hay for morning and evening feed of the rams, and as a reserve for any ease of need for the flocks, and to supply the ewes with a little dry nibbling for a week or two before lambing.

These alfalfares would be made enormously productive if a heavy manuring were given the land before ploughing for sowing. In addition to this manuring, the deeper the tillage the better ; as the result of deep tillage will be the infinitely more rapid and luxuriant growth of the plant : and moreover, it will be much less influenced and prejudiced by drought. Under such a preparation and treatment, the yield of one square of land would equal that of at least two squares ummanured and of shallow tillage. The economic position would be this;- - half the land, half (or one third) of the seed (four and athalf or five arrobas to the square would be ample), more or less half the labour, and half the fencing; against sixty or 
seventy cart-loads of manure on the spot, and only requiring to be spread, and a little more horse or ox-power to draw the ploughs some three inches deeper in the soil.

The land most advantageous in the average of seasons is that which is neither very high nor very low, with a good depth of black loam, vegetable loam, on the surface; and where there is a choice of sites, such an one should be selected.

Divisions marked XXXX could be used for grain-producing, and any other crops that might be useful. If one or two of these spaces sufficed for the supply of grain, the others could stand as extra potreros until required for tillage. On the same land corn could be sown for a couple of seasons, or perhaps three, without material diminution of yield, if well tilled. and well cleaned. It would then amply repay to manure (the cleanings of the sheds and corrals finding here a convenient and profitable outlet, instead of being left to accumulate about the place, and causing dirt and disorder), after which a further succession of full crops could be obtained. Should by that time more potrero room be required, this corn land could most advantageously be laid down in perennial grasses, such as form the permanent meadows and pastures in Europe, and which I know, from experience, form in this country an admirable and productive sward.

A.B.C. represent corrals for three ' lots' of rams, each with a shed, long, narrow (11 to 12 feet), and not too high ; a shed, open in the front and partially closed only at the back, so as to have thorough ventilation; and, by reason of their narrowness, affording every facility for drying. Wide sheds can scarcely ever dry, and are consequently inconvenient, dirty, and unwholesome.

At the end of the shed $\mathrm{C}$, it would be convenient to place a granary and store-room for all useful items and 
remedies that would be required. D would probably be a convenient locality on some establishments for the corrals of the borregas.

Divisional or interior fences, with five wires, render ditches unnecessary, except when, from the nature of the land, it would be advisable to carry off the water by means of open drains. The size of the potreros would depend on the number of rams intended to be kept in them ; and again, on the quality of the land, and the facilities provided for relieving or supplementing the natural pasture.

One of the most interesting considerations in connexion with the union of agriculture and pasturage is the adaptation of forage plants and artificial grasses to fill the blanks which the seasons leave in the supply of natural or indigenous herbage.

Alfalfa (lucerne), on lands of good quality and situation, is one of the most productive and permanent of the 'leguminose' varieties, and, in connexion with the species beans, peas, vetches, porotos, clover, lupines, \&c., is of a high nutritive value. It is probably unsurpassed in durability and product on suitable land, for mowing, for soiling, or hay, when liberally and carefully treated; but it is not so well suited, and dies out much sooner, if depastured, especially by sheep, whose close biting injures the crown of the plant, and canses it to rot. Moreover, it cannot be kept clean as a pasture ; trefolinm, grasses, chickweed, and various strong weeds, quickly appear in it, and hasten its decay and disappearance.

It likewise requires time for the preparation of the ground and growth before it becomes productive. Only in the third year after breaking up the land, supposing it to have proper tillage, eleaning, and general treatment, can an alfalfa be considered productive. For these rea- 
sons it is very desirable that other artificial true grasses should be introduced, not by any means to the exclusion of alfalfa, but to meet requirements when the alfalfa is at fault in degree.

The 'Bromus schraderii' is an exceedingly productive grass, both in herbage and seed, and suitable for dry climates, - a cut-and-come-again plant, that can be mown and grazed alternately during a season. Sown in the autumn, or early in the spring, it matures in a few months, and is of such strong growth, that scarcely any other plant or weed can hold its way with it. It is relished by all animals-cattle, horses, or sheep-and, in all likelihood, will be found very useful on our farms. It is very easily 'saved' as hay, as it dries rapidly, and is not liable to injure or mould, as is alfalfa,-matters of considerable importance in 'campo' farms. The cultivation or tillage of the land is simply that of any other crop. Plough, cross-plough, and harrow fine, and cover in the seed with harrows and brush. It is a sub-perennial, from its abundant seeding, readily reproducing itself, if allowed to ripen one set of seed-shoots in the year.

I have already made reference to permanent grass pastures of perennial varieties. I am grazing a paddock laid down with a mixture of grass-seeds commonly used in laying down grass on good loams in the British Islands'fescues,' meadow grasses, cocksfoot, perennial rye-grass, timothy, \&c.-which gives me the highest satisfaction, yielding a large amount of feed, and growing and spreading under conditions, and at seasons when the indigenous annual grasses fail; covering the ground with a sward absorbent of moisture, and protecting the soil from the sun. Sown early in the autumn, with a little barley, they can be cut for soiling (green fodder) in spring, and depastured in the autumn, and will, undoubtedly, prove 
invaluable as potreros or meadows on the tillage-farms, for fine stock.

In the suggestions I have made will probably be found all the requisites to meet the necessities for the highest development in sheep-rearing attainable for many years to come. The more laborious tillage operations, and cultivation of forage crops, such as turnips and the like for sheep, is a stage perliaps yet far removed, even on the most advanced establishments, and need not therefore be treated of here.

\section{XI.}

It may, on first thoughts, be considered premature to treat of agriculture in comnexion with cattle-feeding; but, as I have already remarked, it is becoming a pressing necessity to produce good beef for the town consumption, and for salting for foreign markets. The benefits accruing from the higher-bred animals - shorthorns and Herefords - that exist and are augmenting in a few hands, camnot be realized without a system of at least partial fatting; and we can never have wholesome beef in the city, nor a trade in salt beef, until farms in the vicinity of the cities, convenient to ports or along lines of railway, are in part devoted to this very important branch of industry. 'Cattle-feeding' is a term which conveys the idea of an European system, with all its appliances; but, we have, by no means, reached that stage, and there would be no likelihood of such a system paying in the present generation. Cattle-feeding, however, can be adapted to circumstances, and determined in its details, by the circumstances of climate, products, and possible appliances, and the cost of the same; a fair returu on the 
capital employed; the market value of the fodder consumed; a fair rent for the land, with return of expenses, as the case may be ; is all that can or ought to be looked for. The contingent profit that can be reasonably looked for is that of the doubling the produce of the land, through the instrumentality of the animals fed on the farm.

It is an industry that has to be created, and the ways and means of its economic conduct have yet to be unfolded by practice; and there is, undoubtedly, a crying necessity for the initiation of some simple and practical system of preparing wholesome meat for the consumption of our city populations.

That which is required to put animals into sufficiently good and firm condition for all purposes of beef, is that they should be domesticated, and that they should have a sufficient and never-failing supply of fodder, or food of a quality sufficiently nutritious-strong feed-grasses that are neither too young to have collected nutrient elements, and which have reached a stage of organization sufficient to render them 'fatting food,'-nor so old or over-ripe as to have parted with their nutritious properties. The food best calculated to answer the purpose (it need not be turnips and oil-cake) is that which can be produced in the greatest quantity and nutrient quality from a given space or extent of ground at the least comparative cost, and which can be provided or produced in the most suitable feeding state at the different seasons of the year. That determined, consumers must of necessity pay for beef a price equivalent to the value of such food converted into beef.

There is no help for it ; it is a law of economies that it must be so; and, there is no question, that good, nutritious beef, at five times the cost per given weight, is 
cheaper, per se, than bad beef from which the greater part of its alimentary properties have been drained or wasted. The science and practice of agriculture must indicate the ways and means; and the more advanced this science and practice are, and the more efficient the mechanical means brought into play, the more economical will be the conversion of forage into beef.

It is of the highest importance just now that this problem of beef-producing should have a practical solution. The cattle plague in Europe is reported to have made such ravages in the herds, that some years may probably elapse before the losses are replaced; and this, coupled with the slaughtering of a large number of breeding stock-cows, dried off in the great city dairies,-and, above all, the increasing necessity for flesh food, consequent on the high-pressure existence, mental and bodily, engendered in this age of steam, of rapid and perpetual thought, of constant contact and friction, of sharp wits, and of accelerated movement, which require food of the highest 'azotized' description to maintain,-renders it more than probable that a large market will be open to fed meat from the plains of South America.

I am of opinion that isolated attempts on small farms cannot lead to this 'solution.' As a sequence, the feeding of cattle will naturally extend to farmers generally. But, in the meanwhile, establishments of sufficient magnitude, fattening a number of animals, to make an impression on the home consumption, or to supply a curing undertaking for export, will have to be set on foot; and these must be in connexion with either such curing business, or butchers' stalls, where the meat is properly killed and cut up, as in Europe.

An ample supply of food and water, regularly given to domesticated animals of cross breed for English stock, 
is, as I have said, an essential. To provide this is the problem.

In this, as in the caring of rams, a series of potreros is a necessary first step; and these must either be in direct or easy communication with permanent water, pure and wholesome, or have regularly supplied water-troughs. These potreros must be depastured in turn, allowing the grass to attain nutrient consistence before the animals are allowed to graze on them. From the nature of our indigenous grasses and climate-influences, paddocks of artificial grasses, alfalfa, and others, would be requisite to fill the blanks of the natural ones, as also to yield a larger quantity on a giren space. It would also be necessary to have lands sown with fodder and forage crops, from wlich to supply soiling (cut fodder), \&c., for the same purpose. Lucerne, 'sorgo,' bromus, meadow grasses, and broadcastsown maize, as well as many others to cut green, are available; also for the provision of dry food, such as hay, for the seasons when the green fodder has not sufficient consistence or fatting quality. For the same purpose, ' chala' (maize straw) might prove a useful auxiliary, and the grain would be available either for sale or consumption.

Borrowing the idea of one of the oldest of British agricultural writers, I may say that, in all the farmer does in this matter, in all his arrangements, and with all the seed he sows, he must mix one other little seed, which will assuredly bear him good fruit, and bring home good store. This little seed is called 'Discretion,' or, as we now-a-days express it, intelligence and judgment must guide every step.

Shed-feeding is, and will be, for a long time to come, out of the question; but large strongly-fenced yards, or small paddocks, would be practicable conveniences for 
night feeding, more especially for such animals as have attained an advanced stage of fatting, and require to be ' finished off,' or hardened, for slaughter. It will be clear to practical minds that essential elements of success consist in procuring a never-failing supply of pasture-feed in the most nutritious stage of its growth and productive yield; over and above this, stored feed to meet all requirements, and in the economic arrangements of gathering it and supplying it without waste, in quantities sufficient and not in excess, and in dispositions which will admit of the feeding being effected with the least amount of labour consistent with efficiency and regularity. The sowing of the little seed, 'discretion,' with these matters, or its omission, may, in most instances, make the difference of a profit or a loss_-success or failure. There is no branch in the agricultural sphere which requires higher practical powers, or more complete knowledge of climate conditions, soils, products, and mechanical detail, than the embryo business of bringing the staple commodity of the country into a realizable condition ; and it is earnestly to be hopecl that the conduct of the first movement in this direction may fall into the hands of earnest and thoughtful, as well as practical parties, and that such parties may be fortunate, as well as deserving, in the selection of a course of practice. There being no landmarks, it is hardly possible that we should not owe much to the 'genius of fortune,' inspiration, or induction. 


\section{P A R T VII.}

THE RIVER PLATE AS A FIELD FOR THE EMPLOYMENT OF CAPITAL AND LABOUR.

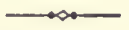

I.

Trre intimate commercial relations existing between Great Britain and the Rio de la Plata, and the very great number of British resident in these South American States as commercial men, owners of property of every description-sheep, cattle, and general farmers, tradesmen, mechanics, professional men, and labouring classes ; the wide field for enterprise in commercial and banking undertakings, railways, lands, canalization, colonization, steam navigation, \&c., and the cordial reception given to settlers, as well as the favourable terms or guarantees accorded by the Legislature to joint-stock company enterprises, coupled with the rapid development of the national wealth, indicate them as eminently calculated to afford most favourable opportunities for the employment of British capital-collective capital-in joint-stock undertakings, individual capitals, large and small, and for the immigration of the industrial classes of all denominations, without respect to creed-a perfect, proclaimed, and practical religious freedom existing.

There are already realized, and on foot, undertakings in 
railway and banking companies, sheep-farming associations, mining companies, land speculations, canalization of rivers, \&c., representing many millions sterling, and year by year the rapid development of the resources of the country throws out additional opportunities and creates fresh necessities. There is a virgin richness and corresponding energy of production, which only requires the magic touch of capital to call forth abundant returns.

The extent to which the rich pasture and fertile lands have passed, and are daily-I might almost say hourlypassing into the hands of the British settlers, marks beyond question the congeniality of climate and occupation, as well as testifies to the advantages that have resulted, and are resulting, from their investments in land and in stockbreeding.

The great industries of the country, as stated in other parts of this work, are sheep and cattle-farming, as also agricultural farms and mechanical trades.

The comparatively small money value of land, its absohute availability for immediate and profitable use, the low price of stock and the wide margin for its improvement, present advantages which are not surpassed, perhaps, in any part of the world.

Large capitals, whether of individuals or companies, have ample scope and opening in stock and land, and camnot fail in producing profitable results under ordinarily intelligent management.

Sinaller capitals, even to the smallest_of a few hundred pounds-coupled with industry, find relatively equal acvantages employed in lands and stock, or in stock alone, and nowhere is there a wider or more certain field for accumulative profit than is here afforded through the improvement of the stock, and by consequence also, of the increased value of the land. 
To make good my proposition, I have only to set before my readers a fair statement of the actual ; and in so doing I may probably dispel many erroneous ideas as to the ways and means of acquiring property and accumulating wealth.

So easy was it a few years ago to acquire property in land at a nominal cost of $500 l$. to $800 l$. per square league; so trifling the price of sheep with which to stock it- $8 d$. to $1 s$. each; so wide the extent of land for them to increase over; so little the trouble or cost in minding them-as a rule, there was no direct outlay in so doing, an interest being given to all comers in lieu of paymentthat men, to use a figure of speech, went to sleep and became rich by the natural accumulation of their stock. But in addition to this, so rapid and great was the increase in value of land and stock, that in eight or ten years, through the increase and growing importance of the produce of the stock, lands rose in value tenfold; stock likewise rose manyfold in value. It will appear as a consequence that, through the accumulative increase of the stock, its improved value, and the tenfold augmentation of the value of land, the parties who entered early into the sheep-farming business had a concurrence of extraordinarily advantageous circumstances, which made their fortunes without any effort on their parts. This did not alone extend to the land and stock-owners, but the shepherds, who were paid their services by a half-share in the increase of the flocks and half the wool, rapidly acquired property, and many were enabled to purchase land while it was yet at a low figure.

The report of these extraordinary successes naturally creates, at a distance especially, the impression that the like is to be achieved now, that property can be acquired without capital, and that the industrial classes can become 
proprietors of land and stock by simply rounding a flock of sheep. Numbers arrive in this country, particularly those from Ireland, with this idea, much to their own prejudice; many able-bodied fellows, when good situations and good wages are offered them in industrial occupations, answer that they did not come out here to work, but to be proprietors and flock-masters, and seeking in vain their 'Eldorado,' become loafers in the 'campo,' addicted to caña (rum) drinking.

A right understanding of the state of things and what is required here, would lead to the advantage of newcomers and established residents. There is an unquestionable 'Eldorado' in the Rio de la Plata, but it is for the industrious, the intelligent, the practical, and the enterprising.

Notwithstanding that lands have increased so much in value, they are yet, as I have said, at a low figure, and have many stages of equally important augmentation of value to go through. Stock, though of very much greater value than a few years ago, is still low in figure.

This industry has simply passed through one stage of its progress and now enters upon another, requiring merely the employment of more capital and more intelligent industry to yield again what it has already yieldedviz. : large and accumulative profits.

\section{II.}

The value of estancia land, as a matter of course, varies according to its quality and position; its greater or less adaptability for stock-farmingin general, and sheep-farming in particular, as the branch of rural industry which is 
steadily driving back to greater distances the cattle estancias.

The land in the province of Buenos Ayres being for the most part better adapted for sheep-grazing than that in other parts of the Republic, is rated at a higher value, at least in those districts which are considered within the sheep-farming radius, that is in those districts where the depasturing of cattle has 'fined' the grasses, and may be stated to range between 2,500l. and 5,000l. per square league. There are, however, some favoured tracts which have been sold as high as $8,000 l$. and 10,000l. per league. The price of public or 'state lands' on the frontier, as fixed by law, is $200,000 \$$ (paper dollars), or about $1,600 l$., and $400,000 \$$ for lands well within the frontier. There is, however, an agitation on foot which will induce a modification in the price of the frontier lands, as also in the manner of disposing of them.

Owing to the difficulties and cost of transit to and from these lands, the more or less risk from Indian raids, and the disadvantages incidental to virgin 'camps' in the comparatively coarse and dense herbage which covers the greater part of them, rendering them, for the time being, less suited for sheep than those which have been 'fed off' by cattle, the government price of $200,000 \$$ is considered too high to induce parties to purchase and settle on them in any number.

In the Banda Oriental (or Uruguay) the sales of lands have been equivalent to from $1,500 l$. to $3,500 l$ : One or two unusually good and favourably situated estancias have been sold as high as 5,000l. per square league. The lands of this Republic are sold by the 'suerte,' which is, more or less, three-quarters of a league.

The Banda Oriental ' campos' will not, as a rule, carry so many head of sheep per league as those of the Province N 2 
of Buenos Ayres. The grasses are stronger and coarser, and a considerable extent of woodland, which is more or less general through the country, reduces the grazing area; also on the higher lands the rock is near to the surface and crops out in many parts, and there are numerous boulders, all of which reduce the grazing surface. On the other hand, the numerous streams afford a rarely, and in many parts a never-failing supply of water, and the wood, a grateful shade for sheep and cattle, and both thrive well and increase rapidly. Of late years, very many estancias have passed into the hands of foreigners, more especially those in the vicinity of Colonia, along the course, or within comparatively easy reach of the river Uruguay, and on the banks of the Rio Negro.

In the province of Entre Rios, there are extensive tracts of low land, frequently under water after heary rains, and bearing coarse, hard, and rush-like grasses ; and there are also extensive woods. In some parts also, there is so much of the Flechilla, or arrow-grass, that sheep suffer severely, owing to its seed-sheaths penetrating through the wool and into the skin and flesh. In the northern parts of this province, this plague, coupled with the high temperature of the summer season, which superinduces fly-blow or maggot in the injured parts, causes many losses, and to a certain extent renders the sheepindustry undesirable. Hence the extent of good sheeppasture does not bear so large a relative proportion to the whole area of this province as in Buenos Ayres, or even the Banda Oriental. 'There exist, howerer, tracts of land, more especially in the district of Gualeguaychú, which leave nothing to be desired, and which are equal, perhaps, to anything in the Republic for sheep-farming; and the very best of these are in the hands of British proprietors, and were purchased years back at mere nonimal figures. 
Cattle thrive very well in Entre Rios, and attain a good size and yield a good hide.

The lands of the southern districts of the province of Santa Fé are similar to those of the north of Buenos Ayres, to which they are contiguous. With the exception of those in the more immediate vicinity of the town of Rosario, they are, however, still crude and abounding in strong, hard grasses, requiring feeding down before they become really good sheep-pastures. The sheep-industry is, however, spreading, and numerous estancias are owned by foreigners. The strong grass-camps of this province produce and feed some of the best cattle of the country, and when carefully herded, and not over-driven, yield a very fair to good ' mess beef.'

So luxuriant are the strong grasses in parts, that they attain the height of the cattle; and the thistle, which abounds in the camps of finer herbage, cannot find a footing. The more northern parts of this province are, as yet, unfitted for sheep-industry, owing to the nature of the herbage; and in part, too, they are at a disadvantage, owing to the high temperature.

Sales of land in the more suitable districts have been effected at from $1,500 l$. to $3,000 l$.

The province of San Luis contains very fertile land of the same character, and on the slopes of the hill-ranges and adjoining valleys there are, as in San Juan and Mendoza, large tracts of cultivated artificial grass, i.e. lucerne or alfalfa, which are regularly irrigated, and on which cattle are reared and fattened.

Lands in the province of Cordoba are offering at a mere nominal figure. Many of them on the 'Grand Chaco' frontier are represented as well-suited for sheep of a strong, hardy class; the grasses are luxuriant, but as yet strong and hard. The passage of the Central Argentine 
Railway will give access to these lands, and many agricultural and sheep-farming colonies will be formed on tracts granted for the purpose.

\section{III.}

The estimated capacity of a square league of land for carrying sheep is from 10,000 to 20,000 head ; few, however, could be safely counted on to carry over 16,000 sheep, unless fenced in and trespassing cattle and horses excluded.

The value of sheep generally offered for sale is to-day much lower than the quotation of a year or two ago, by reason of the necessity there exists of relieving a large number of establishments which have become overstocked, and the expediency of weeding out inferior and aged animals and improving the remainder, The quotations for fair to good average cross-bred sheep are 258 to $35 \$ \$$ per head, or, say, $3 s .10 d$. to $5 s .6 d$. as they run; the better classes bear a proportionately higher value. After shearing, they can be had proportionably less, and average sheep have been sold at $18 \$$ to $20 \$$.

The average yield of wool from this class of sheep is $31 \mathrm{lbs}$. per fleece, and its value from $70 \$ \$$ to $80 \$$ per $25 \mathrm{lbs}$., according to present market rates-say $5 \frac{1}{4} d$. to $6 \frac{1}{2} d$. per pound. The deductions for carriage to market are graduated by distance. The wool of a few very superior highcaste flocks is worth from 20 to 50 per cent. higher.

The usual calculation of increase under the general system of management is, that a flock will double itself in three years; and this is accumulative so long as there is room on the land to receive and feed the increase. Thus, 2,000 sheep in three years would reach 4,000, and 
in three years more--in all, six years-8,000, and so on. Flocks composed entirely of breeding ewes would increase much more rapidly, as will be hereafter shown. The expenses of management are usually estimated at about one-fourth or one-third; this, however, depends on the value of the stock, and applies to stock of average class.

As an investment of a considerable capital by a company, or more limited capitals by individuals, there are sources of profit open to judicious management, apart from the direct returns in wool and average increase in the numbers of the sheep-viz., the increase in the value of land; the wide scope for improvement in the class of sheep ; augmentation of the yield of wool, and improvement of its quality; greater product of carcass, skin, and grease ; and the larger increase of numbers from a given proportion of stock kept. These are results certainly attainable through a more liberal employment of capital and more careful management than has been generally practised.

It is quite practicable, as I know from experience, to treble in a few years the returns from wool; and, by consequence, the value of the sheep as wool-producers, and more than double the product in carcass, skin, and grease ; but assuming an estimate considerably under this, there is assurance of a highly satisfactory return for money invested.

The estimated increase from cattle is more or less the same as in sheep, that is, they double themselves in three years. The annual sources of revenue from sheep are the wool, the wethers, and the surplus and aged ewes. From cattle, the 'steers,' or 'neats' (Novillos), and surplus cows.

The expediency of having cattle on a large establishment only partially stocked with shcep, and on which 
the herbage or pasture is strong and somewhat coarse, is undoubted. A clirect profitable return will be obtained from the cattle, and by a judicious disposition in grazing them, they will eat down the coarser herbage, and bring the land into better state for sheep.

This constitutes a by no means unimportant economy in the management of lands which, from their present conditions as strong grass-producing, and being a little outside of the present sheep-walk radius, can be purchased at half the price of lands of finer herbage, and which have merely had the advantage of having been so depastured as to bring them into that better condition.

It will have been observed that I treat the cattlebreeding as subordinate to the brceding of sheep. In the first place, there is not yet introduced the practice of improving the cattle, and there is not yet determined, in practice, a course of treatment which will bring into play the most important item of eattle products, viz. the beef. The land that is in good state will maintain, on a given area, a very much greater value in sheep than in native cattle, under the ordinary course of treatment. Sheep, too, make an annual return in wool, in addition to the increase; also, to the generality of Europeans, the sheepindustry is more congenial. Working among semi-wild cattle is a speciality of the borseman of the plain, and the management of a cattle establishment requires some experience in the country and a knowledge of the language.

Where small capitals are employed, and the parties are new in the country, this branch of rural industry is not, at present, a desirable undertaking. Where larger capitals are invested, efficient managers are obtainable; and in the more distant and cruder lands of Buenos Ayres, and on estancias in the Banda Oriental, Entre 
Rios, \&c., as I have explained above, cattle are very desirable, as they materially accelerate the improvement and preparation of the lands to receive sheep advantageously.

Although land is higher in value in Buenos Ayres than in other parts of the River Plate States, sheep, as the rule, are lower by reason of the greater number existing and disposable in that province.

It is convenient to submit an estimate of the capital required to purchase and stock land. We will take, as a basis, a single square league :-

Say one square league, of mean value . . . . . $£ 3,500$ to $£ 4,000$ 5,000 sheep, at $\$ 30$ each . . . . . . . . . . . . . . 1,250

Which, divided into four flocks, would require four stations, the huts or houses for which would cost from $£ 15$ to $£ 25$ each, according to their solidity; say $£ 25$. . . . . . . . . .

(If of brick and lime and with azotea roof, they would cost more.) Corrals or pens, say $£ 15$ each flock

It will depend on the determination of the proprietor or purchaser as to the degree of refining he will pursue with his stock, what the cost of his rams may be. As 'time is money,' there can be no question that the introduction into his flocks of rams of superior class, yielding heavy fleeces and long, sound, stapled wool, is the best course ; and at lenst in one or more of his flocks, rains of high class should be used. Rams, in any required quantity, can be had at from $\$ 200$ to $\$ 500$ each; but there can be no question that, if there is the capital, an average cost of at least $\$ 1,000$ (say $£ 8$ ) for large, vigorous rams of the right sort, would be true economy; the more costly ones, which might cost from $\$ 3,000$ to $\$ 6,000$, going into the best flock. Say, 80 rams at $£ 8$. . . . Such rams as these are worthy of every care, and should be housed and looked after as I have explained in other papers; the 'plant' requisite for which may be set down at . . . . . . . .

1,500l: laid out in rams would be well-employed capital; in fact, the better and higher class the rams, the more rapid and greater the improvement and consequent profit. 
The sheep I have put down at $\$ 30$. This is by the ' eut;' but the invester would do well to purchase, instead of $5,000,6,500,7,500$, or more, and select from these 5,000 of the best young ewes and ewe lambs, selling the remainder for what he eould get, or killing them for the skin and grease.

Say that in so doing he raises the cost of his flocks by one-fourth, or even more, which, with feneing and sowing of alfalfa and corn, will bring up the cost of land, plant, and stock, placed on the most advantageous working footing, to $6,500 l$. or $7,000 l$. for every square league.

The wages of shepherds, for four flocks, would amount to about $15 l$. per month, or $180 l$. per annum, and care of rams $45 l$. to $50 l$.

The first year's clip would yield, probably, somewhat over 600 arrobas of wool, value $380 l$. If the flocks are composed, as I have recommended, of all ewes, and the rams be sound and vigorous, an increase of 80 per eent. of breeding ewes may be fairly calculated on ; so that in two years the number of, more or less, 12,000 head may be counted, of which some 3,500 may be males, which will be realisable - those from the less high-easte rams, - if the establishment be within reach of a market, will be saleable as wethers; if out of the reach of a market they will be available for steaming, and those from the select flocks and best rams, as sires for use or sale. It will not be too much to estimate these 3,500 , at the age of 18 months, to be worth, one with another, something like $10 \mathrm{~s}$. each, equal to $1,750 \mathrm{l}$. There will remain as breeding stock, of ewes and ewe lambs, 8,500, which, from the improved quality of the 3,500 , should yield a clip of nearly 1,200 arrobas of wool, in value about $750 l$.

Up to this point, no material inerease of eharge for herding (i.e. for shepherds) will have been required. 
Taking stock at this point, allowing for the better quality and class of the young stock, we may assume :-

$$
\begin{aligned}
& \text { 8,500 Females, representing . . . . . } £ 3,300 \\
& 3,500 \text { Males, representing at 10s. each . . . 1,750 } \\
& \text { (1,000 rams and } 2,500 \text { wethers). } \quad \frac{1,750}{5,050} \\
& \text { Rams . . . . } 640 \\
& £ 5,690 \\
& \text { Wool sold, say } £ 1,130 \text {. }
\end{aligned}
$$

There will now be required additional stations or puestos, and additional rams, yearly - some of highcaste-purchased, others taken from the best-bred on the establishment.

It is in the succeeding period, or 'term,' that the accumulative increase tells; and it is quite within bounds of fair calculation to say that, in the three years of the second period, the wool sales will average $2,000 l$. to $2,500 l$. per annum; that the stock existing and realized in wethers, rams, and old ewes sold, or steamed down, will represent a value equal to 14,000l. at the end of this second period; and that the land and plant will represent a marketable value of $6,500 l$. to $7,000 l$.

To elucidate the progress of increase $I$ give the following table, from which it will be seen that the foregoing estimates of probable returns are within the mark.

Assuming that the stock commenced with consists of 5,000 head, say in January, 1865, and that these comprise- 
1866.

4,000 Ewes drop . . . . . . 1,600 Male lambs. $1,600^{*}$ Ewe lambs.

Original stock . . . . $5,000^{*}$

(Lambed in April \& May.)

$$
8,200
$$

1867.

5,000 Ewes lamb . . . . . . 2,000 Males.

2,000 Ewe lambs.

Previous year's stock . . . 8,200

12,200 head.

1868.

6,600 Ewes (5,000,* and 1,600*) lamb . . 2,600 Males.

2,600 Ewe lambs.

Previous year's stock . . . 12,200

17,400

1869.

8,600 Ewes $(5,000,1,600$, and 2,000) lamb . 3,440 Males.

3,440 Ewe lambs.

Previous year's stock . . 17,400

24,280

1870.

11,200 Ewes (5,000, 1,600, 2,000, 2,600) lamb4,480 Males.

4,480 Erve lambs.

Previous year's stock . . . 24,280

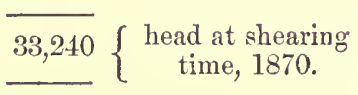

It will be observed that I have retained the full number of ewes throughout, and calculated the increase at 80 per cent. of the same. Such an increase presupposes the management of the flocks and the care of the rams, on the system $I$ have recommended in the treatises on Sheep-farming and Agriculture. 
I have made no deductions for deaths, or for sale or slaughter of the old ewes. I believe, judging from my own experience, that, under very careful management and good average seasons, the losses (deaths) will be replaced by the increase in excess of the 80 per cent. I have calculated. A fair allowance, however, may be made to cover losses, or weeding out, of the inferior and elder ewes, and deducted from the sum total as contingencies.

It is not to be supposed that these 33,240 head, or, say, 30,000 , allowing the 3,240 against losses, would exist on one league of land. All the wethers, we will presume, have been sold or killed, and all rams bred from the best flocks, sold ; say, more or less, 9,000 males clisposed of as they attain saleable age; leaving ewes and lambs, 21,000 .

The rams, we will assume, have been such as I have recommended; in consequence, the sheep and their yield of wool will have greatly improved and augmented. Excluding the old ewes of the original stock, or assuming that they have, for the most part, died or been drafted, it cannot fail to be, that if the right class of rams have been used, the average of the wool-yield per sheep will have been doubled, and that a number of the males bred and retained as rams, for sale or otherwise, will have been worth from $\$ 200$ to $\$ 500$ each, and that it will be within the mark to estimate the whole of the stock that has existed-existing or been disposed of up to shearing time, 1870 - to represent a value of $10 \mathrm{~s}$. or $12 \mathrm{~s}$. each.

The augmentation of the weight of fleece per sheep will be manifested chiefly in the third, fourth, and fifth years' clip; and it is more than probable that an average of over 6lbs. per fleece may be obtained in the fifth year, with a considerable increase of relative value. Under 
such circumstances, it is within fair calculation to estimate the clip of 1870 at a value of over 3,000l., assuming 16,000 sheep shorn.

On the usual system of management with rams of low value, say $200 \$$ to $500 \$$ each, the calculation under good average circumstances is, as I have said, that flocks double themselves in three years. Thus, 5,000 sheep would give 10,000 in three years, and 20,000 in six years, with the weight of fleece and value of wool stationary.

The facilities for the sale of wethers for the butcher depend altogether on the situation of the estancia. Distant establishments, and most of those in the Banda Oriental and Entre Rios are at a disadvantage in this particular, and this circumstance undoubtedly affects in some degree the prices of land in these parts.

The relative cost of management, shepherds, \&c. is affected by the value of the stock. It costs more per head to take greater care than that usually bestowed on flocks, as it does also to carry out a better and more complete system; but this is more than compensated by the smaller direct loss in the sheep; the per centage of costs and charges are relatively much higher on sheep of comparatively small value. The amount of management charges is also affected by the residence or non-residence of the owner on an establishment, rendering necessary or otherwise the employment of a manager, the extent of the estancia, number of flocks, and the staff required to overlook large concerns.

There are, as a matter of course, certain items which it is needless to enlarge upon, as they apply to all businesses and are well understood by business men.

I have in another part of this work indicated the great advantages derivable from fencing or enclosing estancia lands. The difficulty of doing this arises from the want 
of eapital and enterprise of the majority of the sheepfarmers. There is no doubt, however, of its advisability ; and I do not hesitate to say that so doing would more than double the capacity of the land for carrying stock, thereby amply, abundantly recompensing the outlay, and I earnestly recommend the practice.

The Government or public land question is one that is at present much discussed. The traditional 'clinging' of the governing powers to the public lands in the expectation of obtaining high prices at some future date, and the putting of a minimum price on these lands which they offer in the market, is one of the great errors of legislative and political economy which restricts enterprise and national development; but it must be admitted that the question is one which presents difficulties in its solution. There is a wide field for ' jobbing' involved in it, and the Legislature is naturally jealous of innovation which might give rise to such a result.

Public opinion is fairly awakened and is passing through the usual 'throes' preparatory to its definitively pronouncing itself and resolving into action. As I write this the Government has met with failure in an attempt to auction lands, fixing a minimum price considered to be above the market value. Distant unsettled lands, as involving risk and some considerable outlay in 'settling' and stocking them, must go for low figures to induce settlers to take them; and some of the frontier lands would, as far as the public interest is concerned, be advantageously disposed of if given away with exemptions from taxes, military service (other than guarding the possessions themselves), on the condition of ' settling' them ; and I am led to believe that the Legislature would be disposed to give lands, situated at different points of the frontier, for the purpose of colonization, to individuals or 
companies with sufficient capital to put a minimum number of families with flocks, herds, and horses on the same. Several 'projects of law,' that is, 'measures,' are prepared for introduction into the Chambers, and will probably have been published before this work reaches the public, the tenor of which is the granting in fee-simple of frontier lands. It would perhaps not be correct to criticise embryo projects which have come to my knowledge by the favour of the projectors, but I may say that their practical working, supposing any of them to become law, depends mainly on the exemption from trammel of detail. Granting land on more or less exposed frontiers, would be ineffectual unless the proposed grants were of sufficient extent to admit of a strong and comparatively concentrated settlement, and made to parties or companies with means sufficient to settle and stock them on the principle of colonies; the settlers acquiring a right in fee-simple to a portion, say half the land occupied by them, and to have half the increase of stock under agreement with the 'grantees;' the settlers, if foreiguers, to retain their rights as such, and be subject to no other service than that of mutual protection under direction of the resident representative of the grantees; and if natives, to be exempt from all military service other than that of the protection of the colony for a term of years. These settlements once fairly established and stocked, the surrounding lands would assume a value, however small at first, which it would be the interest of the country to sell at any price that a public market might establish.

Frontier grants, and subsequently the adjoining lands, would be advantageous investments for enterprising capitalists, and would afford good opportunities to hardy and adventurous settler's, who would acquire say half a leágue 
of land in fee-simple and sufficient stock for the same in the course of perhaps four or five years.

Lands already settled and well within frontier lines can, as I have stated, be obtained in the Banda Oriental, Entre Rios, Santa Fé, and Buenos Ayres, at a range in value from $1,500 l$. to $5,000 l$, and these are arailable for investments of individual or joint-stock capitals to the extent of from half a league to ten or twenty leagues, or any extent, in one or more establishments; and such investments, with an efficient agency or direction, as I have shown, are certain to afford profitable results.

There is ample room and opportunity for settlers of every extent of capital; for instance, parties desirous of settling in these countries, and not possessing sufficient capital to purchase and stock one or more leagues of land on the basis I have thrown out in calculation, can find lands and stock of less cost.

Practical and enterprising young men of small means, sons of country gentlemen, farmers, professional men, any men indeed of industrious habits, and resolved to work their way, could most advantageously combine to purchase a tract of land, stock it, and themselves occupy the stations (puestos), and take care of their respective flocks, and thus effect an important saving on small capitals. Others of less means, again, could purchase stock and rent land, which they can do at rents from $25 l$. to $60 l$. per annum for a 'run' capable of maintaining, more or less, 2,000 sheep. Land is obtainable on rent per 'run' or 'runs,' or per half league, or one or more leagues. Parties of still smaller means can purchase half a flock and arrange with owners of land to join such half flock to an equal number furnished by the owner of the land, and take charge of the same on the land, such charge or care being taken as an equivalent and in lieu of rent. Numbers 
of young gentlemen, as well as small farmers, have settled in the country on these terms; mercantile clerks and men of the industrial class who have saved out of their earnings, are constantly abandoning the desk or their trades to enter into arrangements of this class, or to purchase sheep and rent land, and with ordinary care and constancy do very well.

\section{IV.}

The river Plate not only affords bright prospects to the possessors of eapital, but likewise to the industrial classes of all grades: no man need want employment for a day who can work; and working, he will earn good wages in every class of labour and every trade. Moreover, good conduct and constancy lead to advancement, and constancy and labour at high wages, and small or no expense in living, enable a man to save considerable sums, with which he can enter into some trade, or stockbreeding. I have already said that in every branch of working trade, there are numbers of our countrymen thriving, well to do, and with realised fortunes. In almost, indeed, I may say in every instance, these parties have come to this country as journeymen, and from the high wages obtained, have soon been able to save sulficent to furnish workshops for themselves. In like manner, for agricultural labourers, as well as any man who can handle a spade or a pick, wheel a barrow, drive a cart, or herd a flock of sheep, employment is never wanting, and the supply of labour is very far short of the demand.

I will enumerate the classes, or some of them, for which as 'settlers' there are unfailing and increasing openings and work at good wages.

Gentlemen with from medium to considerable capitals, 
possessing some knowledge of, or at least a taste for, country pursuits.

Enterprising young gentlemen, farmers, farmers' sons, having an industrial training, and possessing small capitals.

Skilled agricultural labourers, ploughmen, reapers, mowers, and men who can use agricultural instruments of modern construction; hardy, sober, and industrious young men, handy and intelligent.

Such men readily obtain work at good wages, with every prospect of increase of wage and advancement to situations as under farm bailiffs and bailiffs.

The wages of an agricultural labourer of this class are from $350 \$$ to $400 \$$ per month, with board and lodging, equal to about $2 l$. $15 s$. to $3 l$. $5 s$. per month, which, with board and lodging found them, makes the wage amount to from $4 l$. to $5 l$. per month. Ordinary labourers $300 \$$ per month.

Shepherds._There are many openings for intelligent and skilled shepherds, equal in wage to skilled agricultural labourers, with excellent prospects of advancement as over-lookers, \&c.

Shepherds and flock-tenders.-Any man of sober habits, accustomed to country work, can easily obtain a situation as flock-tender, at a wage more or less equal to that of ordinary farm labourers, with lodging and flesh meat found him.

As I have previously stated, in years past this class of men easily obtained sheep on shares-half increase and half wool-as, owing to the then extremely small value of sheep, this was considered equivalent to a wage of $200 \$$ to $250 \$$ per month, and freed the flock-masters from cash outlay. Subsequently, and as sheep became of greater value, this interest was reduced to a third, then to a 
quarter, and, ultimately, to a quarter without wool ; but now the majority of flock-masters decline to give any, especially when the flocks are of better than average quality, and when a system of refining or improvement is followed; as in such cases it is absolutely requisite for the flock-master to have the full control of his stock. Every year, therefore, the system of a fixed wage in cash will become more general.

This is likewise, under present circumstances, more to the advantage of the flock-tender than an interest in the sheep. Land not being obtainable for the once nominal sum, either to purchase or rent, the flock-tender who has had an interest in the sheep finds that his two, three, or four hundred sheep at the expiry of his contract term are a clog to him, and he has perhaps no option but to sell them at a sacrifice.

On distant establishments approaching the frontier lines, or large newly-formed sheep-farms, large cattlefarms that are undergoing the transition process from cattle to sheep (on which probably the sheep at first introduced may not be of particularly good quality), with ample, superabundant extent of land for the increase, shares will probably be given, as it may answer both parties. On such establishments, young men with small capitals sufficient to purchase half a flock, would find a location to their advantage. I know some establishments where small 'colonies' of young men, six, eight, or ten, have settled down on adjoining 'runs,' much to their moral, intellectual, and material advantage.

Artisans of all trades, from the cobbler to the iron ship and engine builder, from the tinker to the watchmaker; blacksmiths, joiners, carpenters, builders, \&c. \&c. are much wanted, and would find immediate employment at from $1 l .15 s$. to $2 l .10 s$. per week.

Domestic servants, male and female, are another class 
of desirable immigrants, and could find employment immediately at wages of $2 l .10 s$. to $3 l$. $10 s$. per month.

I believe that many educated young men have come to this country under the impression that to get a puesto with a small interest in a flock of sheep is an easy matter, and at the same time a somewhat brilliant opportunity. I think it only a duty to young gentlemen who may think of settling in these countries to correct any such impression. To serve as a peon or flock-tender in a solitary hut without other means than what he may derive from his quarter interest is not the life for a young gentleman with brains or aspirations after social position. To live alone, to be his own cook and everything else, to have no surrounding-I will not say 'comforts,' but common necessaries of his position-a stretcher his bed, a deal table or no table at all, and a bench, stool, or chair his furniture; to have to pick up a few thistle stalks, or take the dung from the sheep corral for his fuel, and cook his bit of meat on a fire made of these in the middle of his hut, is not a mode of life calculated to elevate, and almost inevitably leads to the reverse; especially so if neighbouring flock-tenders are men who can neither read nor write, and are addicted to spirit-drinking. On the other hand, a young gentleman who has means sufficient to purchase a flock or half a flock of good sheep, and to surround himself with some of the comforts of civilised life, located with other young men of his own social standing, can do well for himself, and it will be his own fault if he does not hold his moral and social position.

I have stated in this work that sheep-farming has entered or is about to enter on a new phase, and this will present opportunities for young gentlemen with a knowledge of the management of this class of stock and its accompaniments. Possessing a fair practical knowledge of these matters learned on British or German or other 
European or Australian stock farms, he will readily adapt his knowledge, after a little experience out here, to the requirements of this country, and will be eligible for situations of trust in the management of establishments. Capable assistants, sub-managers, \&c. will undoubtedly be at a preminm, and young men after filling such situations will after a time be competent to fill the higher situations of local managers. Good conduct, industry, and intelligence in their business will ensure their promotion, and ultimately, in many cases, an interest, which is the customary practice with able managers and directors. It is highly probable also that establishments will be formed for feeding cattle up to a point that will make their flesh available for preserving and curing, and such inclustry would present openings for competent hands.

\section{V.}

It is not alone on the plains of the Litoral provinces of the Argentine Republic and their pastoro-agricultural industries that favourable opportunities are afforded for the employment of capital and labour. The interior provinces-Salta, Jujuy, Rioja, Catamarca,* Cordora, San Juan, \&c.-with their great mountain ranges of igneous rock, are rich in minerals-lead, silver, copper, gold, iron, \&c.-and await but the clirection of capital and labour to yield their mineral wealth in vastly greater quantities than they now do; and in addition to this, every variety of tropical and semi-tropical products are cultivated in greater or less quantity - coffee, sugar, tea, tobacco, indigo, cotton, spices, fruits, and wines. Most valuable hard-

* Several exceedingly rich copper mines are now rorking in Catamarca and Cordora, in which the percentage of both copper and silver is very high. 
woods, dyes, and medicinal vegetation abound. Many of the hardwoods and timbers are marvellously durable, and very valuable for house and ship-building purposes. Nor are animal products wanting. The mountain slopes and valleys give us, and are admirably adapted to the breeding of, the alpaca, vicuna, llama, guanaco, and the native goat crossed with the angora, also sheep of long wool available for material improvement by crosses of the English long wools and others; also cattle, on the slopes and plains. Already many British and other foreigners are dedicating themselves to the goat and sheep industries in the province of Cordova, the lands on the hill slopes and on the southern plains being remarkably well adapted for them. The indigenous sheep of Cordova, Santiago, Tucuman, and other adjoining provinces, crossed with the large-framed English long wools will, as already stated, form a breed of great promise, and well suited not only to the slopes of the hill ranges, but to the somewhat strong pastures of the southern plains of this province and the adjoining lands of Santa Fé and San Luis. There have been several considerable purchases of land recently made at Frayle Muerto and establishments formed on them, by a number of enterprising English gentlemen, in adjoining lots of various extent from four to nine square leagues; some sixty or eighty more square leagues are taken up at that place, and were purchased at prices ranging between 800 and 2,000 Bolivian dollars, equal to 120l. to $300 l$. per square league. These are frontier lands, and are of course somewhat exposed, though in reality there is little risk.

These great 'alfalfa' or lucerne irrigated meadows on or near the slopes of San Luis, San Juan, and Mendoza, where cattle are fatted for the Chilian market on the other side of the Cordilleras,-as these provinces are brought nearer to a market and seaport on the east coast 
of South America by the railway in course of construction, and protected, will contribute their products of cattle and of sheep to the trade of the river Plate, and present opportunities for settlers. That wonderfully fertile province, Tucuman, will become easily accessible to capital and enterprise; and its sugar, coffee, tobaceo, indigo, \&c. \&c. will swell the trade of the Rio de la Plata.

In the fertile Catamarca, as in San Juan, Mendoza, \&c. immense crops of artificial grasses and cereals are produced under irrigation, which is easily effected by means of the numerous rivers and streams which flow from the mountain and hill ranges; and their capacity for the production of wine, spirits, and dried fruits is unlimited. The innumerable islands in, and the lowlands on the banks of, the Paraná, produce delicious finits, excellent potatoes and vegetables, and many of them are well suited for the production of rice; and the yerba tea plantations of Corrientes and Misiones are of great promise.

There are, indeed, marvellous riches, mineral, vegetable, and animal, in these more distant provinces, which only require the whistle of the steam-engine to give them vent and hand them over to the capitalist and to inclustry. And this is at hand. The Great Central Argentine Railway now in course of construction from Rosario on the Paraná, through the provinces of Santa Fé and Cordova to the city of the latter name, will be a main artery from which there will be many branches. The canalisation of the Rio Salado, in course of operation, will open water communication with the most distant provinces; and in the wake of the steamel and the locomotive follow enterprise and industry, capital and civilisation. peace and prosperity. 


\section{GENERAL LIST OF WORKS \\ PCBLISIUA $\mathbf{B Y}$}

\section{Messrs. LONGMANS, GREEN, READER, and DYER.}

Arts, Manufactures, \&c.............. 11

Astronony, Meteorology, Poptlar

Geography, \&c. ......................

Atrases, Geveral and Schoor ...... 19

Brography and Meyorrs ..............

Chemistry, Medicine, Surgery, and

the Arlund Sctances .................

Commerce, Navigation, and Mercai-

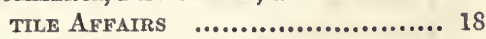

Crittcisy, Philoloay, \&c............... 4

Fne Arts and Illustrated Editions 10

Historical Works...................... 1

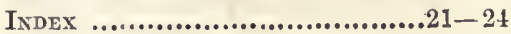

KNowledge for the Yound ........... 20

Miscellaneous and Popular MetaPHYSICAL Works...................... 6

Natural History and Popular

Scrence.............................. 7

Periodicax Publications ............... 20

Poetry and The Drama................ 17

ReLigious WorKs ....................... 12

RurAL Sports, \&c.................... 17

Tratels, Voyages, \&c. ................ 15

Works of Fiction ..................... 16

Works of UTHITY and GeNERAL INFORMATION

\section{Historical Works.}

Lord Macaulay's Works. Complete and nniform Library Edition. Edited by his Sister, Lady Treveryar. 8 vols. 8 vo. with Portrait, price $£ 55 s$. cloth, or $£ 88$ s. bound in tree-calf by Rivière.

\section{The History of England from} the Fall of Wolsey to the Death of Elizabeth. By James Anthory Froude, M.A. late Fellow of Exeter College, Oxford.

VoLs. I. to IV. the Reign of Henry VIII. Third Rdition, $54 s$.

Vols. V. and VI. the Reigns of Edward VI. and Mary. Second Edition, 28s.

Vous. VII. \& VIII. the Reign of Elizabeth, Vous. I. \& II. Third Edition, 28 s.

\section{The History of Fngland from} the Accession of James II. By Lord Macaulay.

Library Edition, 5 vols. 8 vo. $£ 4$.

Cabinet Enition, 8 vols. post $8 \mathrm{ro} .48 \mathrm{~s}$.

People's Edition, 4 vols, crown 8vo. 16 s.

\section{Revolutions in English History.}

By Robert Vatailan, D.D. 3 vols. 8vo. $45 \mathrm{~s}$.

Vou. I. Revolutions of Race, $15 \mathrm{~s}$.

Vor. II. Revolutions in Religion, $15 s$.

Vot, III. Revolutions in Government, $15 \mathrm{~s}$.
An Essay on the History of the English Government and Constitution, from the Reign of Henry VII. to the Present Time. By John Earl Russel.. Third Edition, revised. Crown 8vo. 6s.

The History of England during the Reign of George the Third. By the Right Hon. W. N. Masser. Cabinet Edition, 4 vols. post 8 ro. 24s.

The Constitutional History of England, since the Accession of George III. 1760-1860. By Thomis Enskine MaY, C.B. Second Edition. 2 vols. 8vo. 33s.

Brodie's Constitutional History of the British Empire from the Accession of Charles I. to the Restoration. Second Edition. 3 vols. 8 ro. $36 s$.

Historical Studies. I. On Precursors of the French Revolution; II. Studies from the IIistory of the Seventeenth Century; III. Leisure Hours of a Tourist. By Herman Merivale, M.A. 8vo, 12s. G.t.

Lectures on the History of England. By William Losomax. Vol. I. from the Earliest Times to the Death of King Edward II. with $6 \mathrm{Maps}$, a coloured Plate, and 53 Woodcuts. 8vo. $15 \mathrm{~s}$. 


\section{History of Civilization. By Henry}

THonas Buckle. 2 vols. $£ 117$ s.

VoL. I. England and France, Fourth Edition, 21s.

VoL. II. Spain and Scotland, Second Edition, I6s.

Democracy in America. By Axexis De Tocqueville. Translated by Henry ReEve, with an Introductory Notice by the Translator. 2 rols. 8 ro. $21 s$.

\section{The Spanish Conquest in} America, and its Relation to the History of Slavery and to the Government of Colonies. By Arthur Helps. 4 vols. 8vo. £3. VoLs. I. \& II. 28s. VoLs. III. \& IV. 168. each.

\section{History of the Reformation in} Europe in the Time of Calvin. By J. H. Merle D'Aubigné, D.D. Vols. I. and II. 8vo. 28s, and VoL. III. 12s. VoL. IV. nearly ready.

Library History of France, in 5 vols. 8vo. By Eyre Evans Crowe. VOL. I. 14s. VoL. II. 15s. VoL. III. I8s. VoL. IV. nearly ready.

Lectures on the History of France. By the late Sir Jayes Stephen, LL.D. 2 vols. 8 vo. $24 s$.

The History of Greece. By C.THIRLwaLl, D.D. Lord Bishop of St. David's. 8 vols. 8 vo. £3; or in 8 vols. fep. 288.

The Tale of the Great Persian War, from the Histories of Herodotus. By Georae W. Cox, M.A. late Scholar of Trin. Coll. Oxon. Fcp. $7 s, 6 d$.

\section{Greek History from Themistocles} to Alexander, in a Series of Lives from Plutarch. Revised and arranged by A. H. Clovar. Fcp. with 44 Woodcuts, $6 s$.

\section{Critical History of the Lan-} guage and Literature of Ancient Greece. By William Mure, of Caldwell. 5 vols. 8vo. £3 9s.

\section{History of the Literature of} Ancient Greece. By Professor K. O. M üLLER. Translated by the Right Hon. Sir George Cornewall Lewis, Bart. and by J. W. Donaldoson, D.D. 3 vols. 8 vo. $36 s$.

\section{History of the City of Rome from} its Foundation to the Sixteentls Century of the Christian Era. By Tromas II. DYer, LL.D. 8vo. witl 2 Maps, 15 s.
History of the Romans under the Empire. By Crarles Merivale, B.D. Chaplain to the Speaker. Cabinet Edition, with Maps, complete in 8 vols. post 8 vo. $48 s$.

The Fall of the Roman Republic : a Short History of the Last Century of the Commonwealth. By the same Author. 12mo. 7 s. $6 d$.

The Conversion of the Roman Empire; the Boyle Lectures for the year 1864, delivered at the Chapel Royal, Whitehall. By the same. 2nd Edition. 8vo. 8s.6d.

\section{The Conversion of the Northern} Nations; the Boyle Lectures for 1865. By the same. 8 vo. $8 s .6 d$.

Critical and Historical Essays contributed to the Edinburgh Review. By the Riglit Hon. Lord MACAULAY.

Library EDition, 3 vols. 8vo. 36 s.

Traveller's Eidition, in I vol. 21 s.

Cabinet Editron, 3 vols. fcp. 218.

People's Edition, 2 vols. crown 8 vo. $8 s$.

Historical and Philosophical Essays. By Nassau W. Senior. 2 vols. post 8ro. $16 s$.

History of the Rise and Influence of the Spirit of Rationalism in Europe. By W. E. H. LECKY, M.A. Second Edition. 2 vols. 8 vo. $25 s$.

The History of Philosophy, from Thales to the Present Day. By Georaz Henry Lewes. Third Edition, partly rewritten and greatly enlarged. In 2 vols. Vou. I. Ancient Philosophy: VoL. II. Modern Philosophy.

[Ncarly ready.

\section{History of the Inductive Sciences.}

By William Wieweld, D.D. F.R.S. late Master of Trin. Coll. Cantab. Third Edition. 3 vols. crown 8 vo. 24 s.

History of Scientific Ideas; being the First Part of the Philosoply of the Inductive Sciences. By the same Author. Third Edition. 2 vols. crown 8 vo. 14s.

Egypt's Place in Universal History ; an Historical Investigation. By C. C. J. Bussen, D.D. Translated by C. H. Cотtrell, M.A. With many lllustrations. 4 vols. 8 vo. £5 8s. VoL. V. is nearly ready, completing the work.

MIaunder's Historical Treasury ; comprising a General Introductory Outline of Universal History, and a Series of Separate Histories. Fep. 10s. 
Historical and Chronological Encyclopædis, presenting in a brief and convenient form Chronological Notices of all the Great Events of Universal History. By B. B. Woodward, F.S.A. Librarian to the Queen.

[In the press.

\section{History of the Christian Church,} from the Ascension of Christ to the Conversion of Constantine. By E. Burton, D.D. late Regius Prof. of Divinity in the University of Oxford. Eighth Edition. Fcp. 3s.6d.

\section{Lectureson the History of Modern} Music, delivered at the Royal Institution. By Johr Hochan. First Course, with Chronological Tables, post 8vo. 6s. 6d. Secoxd Course, the Transition Period, with 26 Specimens, 8 vo. $16 s$.
History of the Early Church, from the First Preaching of the Gospel to the Council of Nicra, A.D. 325. By the Author of 'Amy Herbert.' Fcp. 4s. $6 d$.

The English Reformation. By F. C. Massing Berd, M.A. Chancellor of Lincoln. Fourth Edition, revised. Fcp. 8vo. [Nearly ready.

\section{History of Wesleyan Methodism.}

By George Sutru, F.A.S Fourth Edition, with numerous Portraits. 3 vols. crown 8ro. 78. each.

Sketch of the History of the Church of England to the Revolution of 1688. By the Right Rev. T. V. ShorT, D.D. Lord Bishop of St. Asaph. Seventh Edition. Crown 8ro. 10s.6d.

\section{Biography and Memoirs.}

Extracts of the Journals and Correspondence of Miss Berry, from the Year 1783 to 1852. Edited by Lady Theresa Lewis. Second Edition, with 3 Portraits. 3 vols. 8 vo. 42 s.

The Diary of the Right Hon. William Windham, M.P. From 1783 to 1809. Edited by Mrs. H. BariNg. 8vo, 18s.

Iife of the Duke of Wellington. By the Rev. G. R. GLerG, M.A. Popular Edition, carefully revised; with copious Additions. Crown 8vo. with Portrait, 5s.

Life of the Duke of Wellington, partly from M. BRIALMONT, partly from Original Documents (Intermediate Edition). By Rev. G. R. Gleig, M.A. 8vo. with Portrait, $15 s$.

Brialmont and Gleig's Life of the Duke of Wellington (the Parent Work). 4 vols. 8vo. with Illustrations, $£ 214 s$.

History of my Religious Opinions. By J. H. Newmax, D.D. Being the Substance of Apologia pro Vitâ Suâ. Post 8 vo. $6 s$.

Father Mathow: a Biography. By Jomn Francis Maguire, M.P. Popular Edition, with Portrait. Crown 8vo. 3s. 6d.

Rome; its Rulers and its Institutions. By the same Author. New Edition in preparation.

Letters and Lifo of Francis Bacon, including all his Occasional Works. Collected and edited, with a Commentary, by J. Spending, Trin. Coll. Cantab. Vols. I. and II. $8 \mathrm{ro}, 24 s$ :
Lifo of Amelia Wilhelmina Sieveking, from the German. Edited, with the Author's sanction, by Catrerise Wiskworth. Post 8 vo. with Portrait, $12 s$.

Mozart's Letters (1769-1791), translated from the Collection of Dr. Ludivig Norr by Lady Wallace. 2 vols. post 8 vo. with Portrait and Facsimile, 18s.

Beethoven's Ietters (1790-1826), from the Two Collections of Drs. NoHz and Vos KöcHeL. Translated by Lady Waltace. 2 vols, post 8vo. with Portrait.

\section{Felix Mendelssohn's Letters from} Italy and Switzerland, and Letters from 1833 to 1847 , translated by Lady WALLACE. With Portrait. 2 vols. crown 8 vo. 58, each.

\section{Recollections of the late William} Wilberforce, M.P. for the County of York during nearly 30 Years. By J. S. HARFOrd, F.R.S. Second Edition. Post 8 vo. $7 \mathrm{~s}$.

Memoirs of Sir Henry Havelock, K.C.B. By John Crark Marsmung. Second Edition. 8vo. with Portrait, 12s.6d.

Thomas Moore's Memoirs, Journal, and Correspondence. Edited and abridged from the First Edition by Earl RuSSEIJ. Square crown 8 ro. with 8 Portraits, 12a. 6d.

Memoir of the Rev. Sydney Smith. By his Daughter, Lady Hollusid. With a Selection from his Letters, edited by Mrs. Austin. 2 vols. 8vo. $28 s$. 
Essays in Ecclesiastical Biography. By the Right Hon. Sir J. STEPHEN, LL.D. Fourth Edition. 8vo. 14s.

Biographies of Distinguished Scientific Men. By François Arago. Translated by Admiral W. H. SнYтu, F.R.S. the Rev. B. Poweld, M.A. and R. Grant, M.A. 8 vo. $18 s$.
Vicissitudes of Families. By Sir Bernard Burke, Ulster King of Arms. First, Second, and Third Series. 3 vols. crown 8 vo. $12 s .6 d$. each.

Maunder's Biographical Treasury : Memoirs, Sketches, and Bric $f$ Notices of above 12,000 Eminent Persins of All Ages and Nations. Fep. 8vo. 10s.

\section{Criticism, Philosophy, Polity, \&c.}

The Institutes of Justinian; with English Introduction, Translation, and Notes. By T. C. Sandars, M.A. Barristerat-Law, late Fellow of Oriel Coll. Oxon. Third Edition. 8vo. $15 s$.

The Ethics of Aristotle. Illustrated with Essays and Notes. By Sir A. Grant, Bart. M.A. LL.D. Director of Public Instruction in the Bombay Presidency. Second Edition, revised and completed. 2 vols. 8 vo.

\section{On Representative Government.} By John Stuart Mill, M.P. Third Edition. 8vo. $9 s$. crown 8vo. $2 s$.

On Liberty. By the same Author. Third Edition. Post 8vo, 7s, 6d. crown 8vo. 1s. $4 d$,

Principles of Political Economy. By the same. Sixth Edition. 2 vols. 8 vo. 30 s. or in 1 vol. crown 8 vo. $5 s$.

A System of Logic, Ratiocinative and Inductive. By the same. Sixth Edition. 2 vols. 8 vo. $25 s$.

Utilitarianism. By the same. 2d Edit. 8vo.5s.

Dissertations and Discussions. By the same Author. 2 vols. 8 vo. $24 s$.

Examination of Sir W. Hamilton's Philosophy, and of the Principal Philosophical Questions discussed in his Writings. By the same Author. Second Edition. 8vo. 14s.

\section{Lord Bacon's Works, collected} and edited byR. L. Eulis, M.A. J. Spkdping, M.A. and D. D. HeATh. Vols. I. to V. Philosophical Works, 5 vols. 8vo. $£ 46 s$. Vols. VI. and VII. Literary and Professional Works, 2 vols. $£ 116 s$.

\section{Bacon's Essays, with Annotations.} By R. Whately, D.D. late Archbishop of Dublin. Sixth Edition. 8vo. 10s. $6 d$.
Elements of Logic. By R. Whately, D.D. late Archbishop of Dublin. Nintl Edition. 8vo. 10s. 6d. crown 8vo. $4 s .6 d$.

Flements of Rhetoric. By the same Author. Seventh Edition. 8vo. 10s.6d. crown $8 \mathrm{vo}, 4 s .6 d$.

English Synonymes. Edited by Arcllbishop Wintely. 5th Edition. Fep. $3 s$.

\section{Miscellaneous Remains from the}

Common-place Book of Ricirard WhATELY, D.D. late Archbishop of Dublin. Edited by Miss E. J. Whately. Post 8vo. $7 s .6 d$.

Essays on the Administrations of Great Britain from 1783 to 1830 . By the Right INon.' Sir G. C. LEwis, Bart. Edited by the Right Hon. Sir E. HEAD, Bart. 8 ro. with Portrait, $15 s$.

\section{By the same Author.}

Inquiry into the Credibility of the Early Roman History, 2 vols. 30 s.

On the Methods of Observation and Reasoning in Politics, 2 vols. 28 s.

Irish Disturbances and Irish Church Question, 12s.

Remarks on the Use and Abuse of some Political Terms, $9 s$.

The Fables of Babrius, Greek Text with Latin Notes, Part I. 5s.6d. Part II. 3s. $6 d$.

An Outline of the Necessary Laws of Thought: a Treatise on Pure and Applied Logic. By the Most Rev. W. Thouson, D.D. Archbishop of York. Crown $8 \mathrm{ro} .5 s, 6 d$.

The Elements of Logic. By Troms Shedder, M.A. of St. Peter's Coll. Cantab. $12 \mathrm{mo} .4 s .6 d$. 
Analysis of Mr. Mill's System of Logic. By W. Stebring, M.A. Second Edition. $12 \mathrm{mo} .3 s .6 d$.

\section{The Election of Representatives,} Parliamentary and Municipal; a Treatise. By Tiromas Hare, Barrister-at-Law. Third Edition, with Additions. Crown 8 ro. $6 s$.

\section{Speeches of the Right Hon. Lord} MACAULAY, corrected by Himself. Library Edition, 8vo. 12s. People's Edition, crown 8 ro. 3s. 6d.

\section{Lord Macaulay's Speeches on} Parliamentary Reform in 1831 and 1832. $16 \mathrm{mo} .1 \mathrm{~s}$.

\section{A Dictionary of the English} Language. By- R. G. LATHA M, M.A. M.D. F.R.S. Founded on the Dictionary of Dr.S. Jorsson, as edited by the Rev. H. J. Tonn, with numerons Emendations and Additions. Publishing in 36 Parts, price 3s.6d. each, to form 2 vols. 4 to.

\section{Thesaurus of English Words and} Phrases, classified and arranged so as to facilitate the Expression of Ideas, and assist in Literary Composition. By P. M. RogeT, M.D. 18th Edition, crown 8vo. 10s. $6 d$.

\section{Lectures on the Science of Lan-} guage, delivered at the Royal Institution. By Max Müller, M.A. Taylorian Professor in the University of Oxford. First Series, Fourth Edition, 12s. Secoxd Series, 18s.

\section{Chapters on Language. By Fre-} DKRTC W. FArRAR, M.A. late Fellow of Trin. Coll. Cambridge. Curown 8ro. 8s. 6d.

The Debater; a Series of Complete Debates, Outlines of Debates, and Questions for Discussion. By F. Rowtox. Fep. 6s.

\section{A Courso of English Reading,} adapted to every taste and capacity; or, How and What to Read. By the Rer. J. Pycroft, B.A. Fourth Edition, fep. 5 s.

\section{Manual of English Literature,} Historical and Critical: with a Chapter on English Metres. By Thomas Arvold, B.A. Post 8v0. 10s. 6d.

Southey's Doctor, complete in One Volume. Edited by the Rev. J.W. WARTER, B.D. Square crown 8ro. 12s. $6 d$.
Historical and Critical Commentary on the Old Testament; with a New Translation. By M. ML. KaLIsci, Ph. D. Vor. I. Genesis, 8vo. 18s. or adapted for the General Reader, 12s. Vor. II. Exodus, 15s. or adapted for the General Reader, 12s.

A Hebrew Grammar, with Exercises. By the same. PArt l. Outlines with Exercises, 8vo. 12s. 6d. Key, 5s. PART II. Exceptional Forms and Constructions, 12 s. $6 d$.

A Latin-English Dictionary. By J. T. White, M.A. of Corpus Christi College, and J. E. RidpLE, M.A. of St. Edmund Hall, Oxford. Imp. 8vo. pp. 2,128, price 428.

A New Latin-English Dictionary, abridged from the larger work of White and Riddle (as above), by J. T. WH1TE, M.A. Joint-Author. 8vo. pp.1,048, price 18 s.

The Junior Scholar's Latin-English Dictionary, abridged from the larger works of White and Riddle (as above), by J. T. Wnite, II.A. surviving Joint-Author. Square $12 \mathrm{mo}$. pp. 662, price 7s. $6 d$.

An English-Greek Lexicon, containing all the Greek Words used by Writers of good anthority. By C. D. YovGE, B.A. Fifth Edition. 4to. $21 s$.

Mr. Yonge's New Lexicon, English and Greek, abridged from his larger work (as above). Square $12 \mathrm{mo} .8 \mathrm{~s} .6 d$.

A Greek-English Lexicon. Compiled by H. G. LidDeELL, D.D. Dean of Christ Church, and R. Scotr, D.D. Master of Balliol. Fifth Edition, crown 4to. 31s.6d.

A Lexicon, Greek and English, abridged from LIDDELL and ScoTT's GreekEnglish Lexicon. Eleventh Edition, square 12 mo. 7 s. $6 d$.

A Sanskrit-English Dictionary, The Sanskrit words printed both in the original Devanagari and in Roman letters; with References to the Best Editions of Sanskrit Authors, and with Etymologies and Comparisons of Cognate Words chiefly in Greek, Latin, Gothic, and Anglo-Saxon. Compiled by T. BeNFeY. 8 vo. 52s. $6 d$.

A Practical Dictionary of the French and English Languages. By L. Contanseav. 10th Edition, post8vo.108.6d.

Contansean's Pocket Dictionary, French and English, abridged from the above by the Author. 3d Edition. 18mo. 5s.

New Practical Dictionary of the German Language; German-English, and English-German. By the Rev. W. L. Blackley, M.A., and Dr. Carl Martix Friedlasder. Post 8vo. [Nearly ready. 


\section{Miscellaneous Works and Popular Metaphysics.}

\section{Recreations of a Country Parson.} By A. K. H. B. First Series, with 41 Woodcut 1llustrations from Designs by R. T. Pritchett. Crown 8vo. 12s. $6 d$.

Recreations of a Country Parson. Second Series. Crown 8vo. 3s.6d.

The Commonplace Philosopher in Town and Country. By the same Author. Crown 8vo. 3s. $6 d$.

Leisure Hours in Town; Essays Consolatory, Esthetical, Moral, Social, and Domestic. By the same. Crown 8vo. 3s.6d.

The Autumn Holidays of a Country Parson ; Essays contributed to Fraser's Magazine and to Good Words, by the same. Crown 8vo. 3s. $6 d$.

The Graver Thoughts of a Country Parson, Second Series. By the same. Crown 8vo. 3s. $6 d$.

Critical Essays of a Country Parson, selected from Essays contributed to Fraser's Magazine, by the same. Post 8vo. 9s.

A Campaigner at Home. By SHIRLEY, Author of 'Thalatta' and 'Nugæ Criticæ.' Post 8vo. with Vignette, 7s. $6 d$.

Studies in Parliament: a Series of Sketches of Leading Politicians. By R. H. Hutron. (Reprinted from the Pall Mall Gazette.) Crown 8vo. 4s. 6d.

\section{Lord Macaulay's Miscellaneous Writings.}

Lrbrary Edition, 2 vols. 8vo. Portrait, 21 .

People's Edition, 1 vol, crown 8vo. $4 s .6 d$.

The Rev. Sydney Smith's Miscellaneous Works; including his Contributions to the Edinburgh Review.

Library Edition, 3 vols. 8vo. $36 s$.

Trapeller's Edition, in 1 vol. 21s.

Cabinet Edition, 3 vols. fcp. $21 s$.

People's Edition, 2 vols. crown 8 vo. $8 s$.

Elementary Sketches of Moral Philosophy, delivered at the Royal Institution. By the same Author. Fep. $7 s$.

The Wit and Wisdom of the Rev. Sxdnex Smitr: a Selection of the most memorable Passages in his Writings and Conversation. $16 \mathrm{mo} .5 \mathrm{~s}$.
Epigrams, Ancient and Modern :

Humorous, Witty, Satirical, Moral, and Panegyrical. Edited by Rev. Jo11x BоotrI, B.A. Cambridge. Second Edition, revised and enlarged. Fcp. $7 s, 6 d$.

From Matter to Spirit: the Result of Ten Years' Experience in Spirit Manifestations. By Sorhia E. De Morgan. With a Preface by Professor DE Moroan. Post 8vo. 8s. 6d.

Essays selected from Contributions to the Edinburgh Review. By HeNRY Rogers. Second Edition. 3 vols. fep. 21 s. The Fclipse of Faith; or, a Visit to a Religious Sceptic. By the same Author. Eleventh Edition. Fcp. 5s.

Defence of the Fclipse of Faith, by its Author. Third Edition. Fcp. 3s.6d.

Selections from the Correspondence of R. E. H. Greyson. By the same Author. Third Edition. Crown 8vo. 7s.6d.

Fulleriana, or the Wisdom and Wit of Thomas Fuller, with Essay on his Life and Genius. By the same Author. 16mo. 2s.6d.

An Essay on Human Nature; showing the Necessity of a Divine Revelation for the Perfect Development of Man's Capacities. By Henry S. Bonse, M.D. F.R.S. and G.S. $8 \mathrm{ro} .12 s$.

The Philosophy of Nature; a Systematic 'Treatise on the Causes and Laws of Natural Phenomena. By the same Author. 8vo. 12s.

The Secret of Hegel: being the Hegelian System in Origin, Principle, Form, and Matter. By James Hetchison StirLING. 2 vols. 8 vo. $28 s$.

An Introduction to Mental Philosophy, on the Inductive Method. By J. D. Moreld, M.A. LL.D. 8vo. $12 s$.

Elements of Psychology, containing the Analysis of the Intellectual Powers. By the same Author. Post 8vo. $7 s, 6 d$.

Sight and Touch: an Attempt to Disprove the Received (or Berkeleian) Theory of Vision. By Tromas K. Аввотt, M.A. Fellow and Tutor of Trin. Coll. Dublin. 8vo. with 21 Woodcuts, $5 s, 6 d$. 
The Sonses and the Intellect. By Alexander Bais, M.A. Prof. of Logic in the Univ. of Aberdeen. Second Edition. 8 vo. $15 s$.

The Emotions and the Will, by the same Author. 8ro. 15s.

On the Study of Character, including an Estimate of Phrenology. By the samo Author. 8vo. 9s.

Time and Space: a Metaphysical Essay. By Shadwortir H. Hodeson. 8 vo. pp. 588, price 168 .

The Way to Rest: Results from a Life-search after Religious Truth. By R. VAuarisis, D.D.

[Nearly ready.
Hours with the Mystics: a Contribution to the History of Religious Opinion. By Robert Alfred Vaughav, B.A. Socond Edition. 2 vols. crown 8 vo. 128.

The Philosophy of Necessity; or, Natural Law as applicable to Mental, Moral, and Social Science. By Charlas Bray. Second Edition. 8vo. 9s.

The Education of the Feelings and Affections. By the same Author. Third Edition. 8vo. 3s. $6 d$.

Christianity and Common Sense. By Sir Willoughby Jones, Bart. M.A. Trin. Coll. Cantab. 8vo. $6 s$.

\section{Astronomy, Meteorology,}

Outlines of Astronomy. By Sir J. F. W. Herschri, Bart, M.A. ' Eighth Edition, revised; with Plates and Woodcuts. $8 \mathrm{ro} .18 \mathrm{~s}$.

\section{Arago's Popular Astronomy.} Translated by Admiral W. H. Sмyтh, F.R.S. and R. GRANT, MI.A. With 25 Plates and 358 Woodcuts. 2 vols. 8 vo. $225 s$.

Saturn and its System. By RichARD A. Proctor, B.A. late Scholar of St. John's Coll. Camb. and King's Coll. London. 8vo. with 14 Plates, $14 s$.

\section{Celestial Objects for Common} Telescopes. BY T. W. WEBB, M.A. F.R.A.S. With Map of the Moon, and Woodcuts. $16 \mathrm{mo} .78$.

\section{Physical Geography for Schools} and General Readers. By M. F. MAURY, LL.D. Fep. with 2 Charts, 28. $6 d$.

A General Dictionary of Geography, Descriptive, Physical, Statistical, and Historical ; forming a complete Gazetteer of the World. By A. KerTH JoHNstoN, F.R.S.E. 8 vo. 31s. $6 d$.
Popular Geography, \&c.

M'Culloch's Dictionary, Geographical, Statistical, and Historical, of the various Countries, Places, and principal Natural Objects in the World. Revised Edition, printed in a larger type, with Maps, and with the Statistical Information throughout brought up to the latest returns. By Frederick Martiv. 4 vols. 8vo. price 21s. each. VoL. I. now ready.

A Manual of Geography, Physical, Industrial, and Political. By W. Huenzs, F.R.G.S. Prof, of Geog. in King's Coll, and in Queen's Coll.Lond. With 6 Maps. Fcp.7s.6d.

The Geography of British History; a Geographical Description of the British Islands at Successive Periods. By the same Author. With 6 Maps. Fcp. 8s.6d.

Abridged Text-Book of British Geography. By the same. Fcp. 1s.6d.

Maunder's Treasury of Geography, Physical, Historical, Descriptive, and Political. Edited by W. HuGHes, F.R.G.S. With 7 Maps and 16 Plates. Fcp. 10s. 6d.

\section{Natural History and Popular Science.}

The Elements of Physics or Natural Philosophy. By NerL ARvotr, M.D. F.R.S. Physician Extraordinary to the Queen. Sixth Edition, rewritten and completed. 2 Parts, 8 ro. 21 s.
Volcanos, the Character of their Phenemena, their Share in the Structure and Composition of the Surface of the Globe, \&c. By G. Poulett Scrope, M.P. F.R.S. Second Edition. 8ro. with Illustrations, 15s. 
Heat Considered as a Mode of Motion. By Professor John Tyndal, F.R.S. LL.D. Second Edition, Crown 8vo. with Woodeuts, 12s. 6d.

A Treatise on Flectricity, in Theory and Practice. By A. DE LA RIVE, Prof. in the Academy of Genera. Translated by C. V. WALker, F.R.S. 3 vols. 8vo. with Woodcuts, £3 13s.

The Correlation of Physical Forces. By W. R. Grove, Q.C. V.P.R.S. Fourth Edition. 8vo. $7 s .6 d$.

Manual of Geology. By S. Havghtor, M.D. F.R.S. Fellow of Trin. Coll. and Prof. of Geol. in the Univ. of Dublin. Revised Edition, with 66 Woodcuts. Fcp. $6 s$.

A Guide to Geology. By J. Phillirs, M.A. Prof. of Geol. in the Univ, of Oxford. Fifth Edition. Fep. $4 s$.

A Glossary of Mineralogy. By H. W. Bristow, F.G.S. of the Geological Survey of Great Britain. With 486 Figures. Crown 8 vo. $12 s$.

\section{Phillips's Elementary Introduc-} tion to Mineralogy, re-edited by H. J. Brooke, F.R.S. and W. H. Miller, F.G.S. Post 8 vo. with Woodcuts, 18 s.

Van Der Hoeven's Handbook of Zoology. Translated from the Second Dutch Edition by the Rev. IV. Crark, M.D. F.R.S. 2 vols. 8 vo. with 24 Plates of Figures, 60 s.

The Comparative Anatomy and Physiology of the Vertebrate Animals. By Richard Owha, F.R.S. D.C.L. 3 vols. 8 vo. with upwards of 1,200 Voodcuts. Vors. I. and II. price 21s. each, now ready. VoI. III. in the Autumn.

Homes without Hands: a Description of the Habitations of Animals, classed according to their Principle of Construction. By Rev. J. G. Woon, M.A. F.L.S. With about 140 Vignettes on Wood (20 full size of page). Second Edition. 8vo. $21 s$.

The Harmonies of Nature and Unity of Creation. By Dr. G. HArtwig, 8 ro. with numerous Illustrations.

The Sea and its Living Wonders. By the same Author. Second (Englisli) Edition. 8vo, with many Illustrations, $18 s$.

The Tropical World. By the same Author. With 8 Chromoxylograplis and 1\%:2 Woodcuts. 8ro. $21 s$.
Manual of Corals and Sea JelliesBy J. R. Greene, B.A. Edited by J. A. Galbraith, M.A. and S. Haughtox, M.D. Fcp. with 39 Woodeuts, $5 s$.

Manual of Sponges and Animalculæ; with a Gencral Introduction on the Principles of Zoology. By the same Autlior and Editors. Fep. with 16 Woodcuts, $2 s$.

Manual of the Metalloids. By J. ApJoHs, M.D. F.R.S. and the same Editors. 2nd Edition. Fep. with 38 Woodcuts, $7 s .6 d$.

\section{Sketches of the Natural History} of Ceylon. By Sir J. Emerson Tennent, K.C.S. LL.D. With 82 Wood Engravings. Post 8vo. 12s.6d.

Ceylon. By the same Author. 5th Edition; with Maps, \&c. and 90 Wood lingravings. 2 vols. 8 vo. $£ 210$ s.

A Familiar History of Birds. By E. Staxlex, D.D. late Lord Bishop of Norwich. Fcp. with Woodeuts, 3s.6d.

Marvels and Mysteries of Instinct; or, Curiosities of Animal Life. By G. Garratr. 'Third Edition. Fep. $7 s$.

Home Walks and Holiday Rambles. By the Rev. C. A. Johss, B.A. F.L.S. Fep. with 10 Illustrations, $6 s$.

Trirby and Spence's Introduction to Entomology, or Nlements of the Natural History of Insects. Crown 8vo. 5 s.

Maunder's Treasury of Natural History, or Popular Dictionary of Zoology. Revised and corrected by T. S. CoвboLI, M.D. Fcp. with 900 Woodcuts, 10 s.

The Elements of Botany for Families and Schools. Tenth Edition, revised by Thomas Moore, F.L.S. Fcp with 154 Woodeuts, $2 s, 6 d$.

The Treasury of Botany, or Popular Dictionary of the Vegetable Kingdom; with which is incorporated a Glossary of Botanical Terms. Edited by J. Lindley, F.R.S. and T. Moore, F.L.S. assisted by eminent Contributors. Pp. 1,274, with 274 Woodcuts and 20 Steel Plates. 2 Parts, fep. 20 s.

The British Flora; eomprising the Phænogamous or Flowering Plants and the Ferns. By Sir W. J. Hooker, K.H. and G. A. Walker-ArNott, LL.D. $12 \mathrm{mo}$. with 12 Plates, 14s, or coloured, $21 s$. 
The Rose Amateur's Guide. By Thomas Rivers. New Edition. Fep. 4 s.

The Indoor Gardener. By Miss Malixg. Fcp. with Frontispiece, 5 s.

\section{Loudon'sEncyclopædia of Plants;} comprising the Specific Character, Description, Culture, History, \&c. of all the Plants found in Great Britain. With upwards of 12,000 Woodcuts. 8vo. $£ 3$ 13s. $6 d$.

Loudon's Encyclopædia of Trees and Shrubs; containing the Hardy Trees and Shrubs of Great Britain scientifically and popularly described. With 2,000 Woodcuts. 8 vo. 50 s.

Bryologia Britannica; containing the Mosses of Great Britain and Ireland, arranged and described. By W. Wirson. 8vo. with 61 Plates, 42s. or coloured, $£ 44 s$.
Maunder's Scientific and Litorary Treasury; a Popular Encyclopædia of Science, Literature, and Art. Fcp. 10 s.

A Dictionary of Science, Literature, and Art. Fourth Edition, re-edited by the late W. T. Bravor (the Author) and George W. Cox, M.A. assisted by gentlemen of eminent Scientific and Literary Acquirements. In 12 Parts, each containing 240 pages, price $5 s$. forming 3 vols. medium $8 v 0$. price $21 s$. each.

Essays on Scientific and other subjects, contributed to Reviews. By Sir H. Hollaxd, Bart. M.D. Second Edition. 8 vo. $14 s$.

Essays from the Edinburgh and Quarterly Reviews; with Addresses and other Pieces. By Sir J. F. W. Herscher, Bart. M.A. 8vo. 18s.

\section{Chemistry, Medicine, Surgery, and the Allied Sciences.}

\section{A Dictionary of Chemistry and} the Allied Branches of other Sciences. By Hexry WATts, F.C.S. assisted by eminent Contributors. 5 vols. medium $8 \mathrm{ro}$. in conrse of publication in Parts. Vou. $I$. 31s. 6d. Vor. II. 26s. and VoL. III. 31 s. $6 d$. are now ready.

\section{Handbook of Chemical Analysis,} adapted to the Unitary System of Notation: By F. T. Coxlugton, M.A. F.C.S. Post 8vo. 7s. 6d. - TABLes of Qualitative Aralysis adapted to tlie same, $2 s, 6 d$.

\section{A Handbook of Volumetrical} Analysis. By Robert H. Scotr, M.A. T.C.D. Post 8 vo. $4 s .6 d$.

Elements of Chemistry, Theoretical and Practical. By Willins A. Miller, M.D. LL.D. F.R.S. F.G.S. Professor of Chemistry, King's College, London. 3 vols. 8vo. £2 13s. PArt I. Cinvirat Puxsics, Third Edition, 12s, Part II. Inorganic Cilemistry, 21s. Par't III. Organic Chemistry, Second Edition, $20 \mathrm{~s}$.

\section{A Manual of Chemistry, De-} scriptive and Theoretical. By WrLliaM Odling, M.B. F.R.S. Part I. 8 ro. $9 s$.

A Course of Practical Chemistry, for the use of Medical Students. By the same Author. Second Edition, with 70 new Woodcuts. Crown 8vo. 7s.6d.

Lectures on Animal Chemistry Delivered at the Royal College of Physicians in 1865. By the sane Autlior. Crown 8ro. 4s. $6 d$.
The Toxicologist's Guide: a New Manual on Poisons, giving the Best Methods to be pursued for the Detection of Poisons. By J. Horsley, F.C.S. Analytical Chemist.

The Diagnosis and Treatment of the Diseases of Women; including the Diagnosis of Pregnancy. By GrarLy HEwitr, M.D. \&c. 8vo. $16 s$.

Lectures on the Diseases of Infancy and Childhood. By Charles West, M.D. \&c. 5th Edition, revised and enlarged. 8vo. $16 s$.

Exposition of the Signs and Symptoms of Pregnancy : with other Papers on subjects connected with Midwifery. By W. F. Montgomery, M.A. M.D. M.R.I.A. 8vo. with Illustrations, 25.

\section{A System of Surgery, Theoretical} and Practical, in Treatises by Various Authors. Edited by T. Hotmes, M.A. Cantab. Assistant-Surgeon to St. George's Hospital. 4 vols. 8vo. $£ 413 s$.

Vol. I. General Pathology, 21s.

Vol.II. Iocal Injuries: Gun-shot Wounds, Injuries of the Head, Back, Face, Neck, Chest, Abdomen, Pelvis, of the Upper and Lower Extremities, and Diseases of the Eye. 21s.

Vol. III. Operative Surgery. Diseases of the Urgans of Circulation, Locomotion, \&c. $21 s$.

Vol. IV. Diseases of the Organs of Digestion, of the Genito.Urinary System, and of the Breast, Thyroid Gland, and Skin ; with Appexdix and Gexerat Ixdex. 30 s. 
Lectures on the Principles and Practice of Physic. By Thomas Watson, M.D. Physician-Extraordinary to the Queen. Fourth Edition, 2 vols, 8vo. 34s.

\section{Lectures on Surgical Pathology.} By J. PAgEt, F.R.S. Surgeon-Extraordinary to the Queen. Edited by W.Turrer, M.B. 8vo. with 117 Woodcuts, 21 s.

\section{A Treatise on the Continued} Fevers of Great Britain. By C. Murchison, M.D. Senior Physician to the London Fever Hospital. 8vo. with coloured Plates, $18 s$.

\section{Anatomy, Descriptive and Sur-} gical. By Henry Gray, F.R.S. With 410 Wood Engravings from Dissections. Third Edition, by T. Holmes, M.A. Cantab. Royal 8vo. 28s.

\section{The Cyclopædia of Anatomy and} Physiology. Edited by the late R. B. ToDD, M.D. F.R.S. Assisted by nearly all the most eminent cultivators of Physiological Science of the present age. 5 vols. $8 \mathrm{vo}$. with 2,853 Woodcuts, $£ 66 s$.

Physiological Anatomy and Physiology of Man. By the late R. B. ToDD, M.D. F.R.S. and W. BowmaN, F.R.S. of King's College. With numerous Illustratịons. VoL. I1. $8 \mathrm{vo} .25 s$.

\section{A Dictionary of Practical Medi-} cine. By J. Copland, M.D. F.R.S. Abridged from the larger work by the Anthor, assisted by J.C. CopuaND, M.R.C.S. and throughout brought down to the present state of Medical Science. Pp. 1,560, in 8vo. price $36 \mathrm{~s}$.

Dr. Copland's Dictionary of Practical Medicine (the larger work). 3 vols. $8 \mathrm{vo}$. $£ 511$ s.
The Works of Sir B. C. Brodie, Bart. collected and arranged by CharLirs HawkIss, F.R.C.S.E. 3 vols. 8 vo. with Medallion and Facsimile, 48 s.

Autobiography of $\operatorname{Sir}$ B. C. Brodie, Bart. printed from the Author's materials left in MS. Second Edition. Fcp. $4 s, 6 d$.

A Manual of Materia Medica and Therapeutics, abridged from Dr. Pereira's Elements by F. J. Farre, M.D. assisted by R. BentueY, M.R.C.S. and by R. Warington, F.R.S. 1 vol. 870. with 90 Woodcuts, 21 s.

Dr. Pereira's Elements of Materia Medica and Therapeutics, Third Edition, by A. S. TAYlor, M.D. and G. O. REES, M.D. 3 vols. 8vo. with Woodcuts, £3 15s.

Thomson's Conspectus of the British Pharmacopœia. Twenty-fourth Edition, corrected and made conformable thronghout to the New Pharmacopœia of the General Council of Medical Education. By E. Lloxd Birketr, M.D. $18 \mathrm{mo} .5 s .6 d$.

Manual of the Domestic Practice of Medicine. By W. B. Kesteven, F.R.C.S.E. Second Edition, thoroughly revised, with Additions. Fcp. $5 s$.

The Restoration of Health; or, the Application of the Laws of Hygiene to the Recovery of Health: a Manual for the Invalid, and a Guide in the Sick Room. By W. Strange, M.D. Fcp. $6 s$.

Sea-Air and Sea-Bathing for Children and Invalids. By the same Author. Fcp. 3s.

Manual for the Classification, Training, and Education of the FeebleMinded, Imbecile, and Idiotic. By $\mathbf{P}$. Martin Duncax, M.B. and Wilutax Millard. Crown 8vo. 5s.

\section{The Fine Arts, and Illustrated Editions.}

\section{The Life of Man Symbolised by}

the Months of the Year in their Seasons and Phases; with Passages selected from Ancient and Modern Anthors. By Richard Proot. Accompanied by a Series of 25 full-page Illustrations and numerous Marginal Devices, Decorative Initial Letters, and Tailpieces, engraved on Wood from Original Designs by JoHs LEIGHTON, F.S.A. 4to. $42 s$.
The New Testament, illustrated with Wood Engravings after the Early Masters, chiefly of the Italian School. Crown 4to. $63 s$. cloth, gilt top; or $£ 55 s$. morocco.

Lyra Germanica; Hymns for the Sundays and Chief Festivals of the Christian Year. Translated by Catherive WinkwORTH; 125 Illustrations on Wood drawn by J. L.eignton, F.S.A. Fep. 4to. $21 s$. 
Cats' and Farlio's Moral Emblems; with Aphorisms, Adages, and Proverbs of all Nations : comprising 121 Illustrations on Wood by J. LFighton, F.S.A. with an appropriate Text by R. Pigor. Imperial 8vo, 31s. $6 d$.

Shakspeare's Sentiments and Similes printed in Black and Gold and illuminated in the Missal style by HeNrY NoEL HUMrPREYS. In massive covers, containing the Medallion and Cypher of Shakspeare. Square post 8 vo. 21 s.

Moore's Irish Melodies. Illustrated with 161 Original Designs by D. MAclise, R.A. Super-royal $8 \mathrm{vo} .31 s$. $6 d$. Imperial $16 \mathrm{mo} .10 \mathrm{~s}, 6 d$.
The History of Our Lord, as exemplified in Works of Art. By Mrs. J AMesox and Lady EAsTLAKE. Being the concluding Series of 'Sacred and Legendary Art.' Second Edition, with 13 Etchings and 281 Woodcnts. 2 vols. square crown 8 ro. $42 s$.

Mrs. Jameson's Legends of the Saints and Martyrs. Fourth Edition, with 19 Etchings and 187 Woodcuts. 2 vols. 31s. $6 d$.

Mrs. Jameson's Legends of the Monastic Orders. Third Edition, with 11 Etchings and 88 Woodcuts. 1 rol. $21 s$.

Mrs.Jameson's Legends of the Madonna, Third Edition, with 27 Etchings and 165 Woodcuts. 1 vol. 218.

\section{Arts, Manufactures, $\& c$.}

Drawing from Nature; a Series of Progressive Instructions in Sketching, from Elementary Studies to Finished Views, with Examples from Switzerland and the Pyrenees. By George Barixard, Professor of Drawing at Rngby School. With 18 Lithographic Plates and 108 Wood Engravings. Imp. 8vo. 25s.

\section{Encyclopædia of . Architecture,} Historical, Theoretical, and Practical. By JosepH GwiLt. With more than 1,000 Woodcuts. 8ro. $42 s$.

\section{Tuscan Sculptors, their Iives,} Works, and Times. With 45 Etchings and 28 Woodcuts from Original Drawings and Photographs. By Charies C. Perkins. 2 vols. imp. 8 vo. $63 s$.

The Grammar of Heraldry: containing a Description of all the Principal Charges used in Armory, the Signification of Heraldic Terms, and the Rules to be observed in Blazoning and Marshalling. By Jorn E. Cussass. Fep. with 196 Woodcuts, 4s. $6 d$.

The Engineer's Handbook; explaining the Principles which should guide the young Engineer in the Construction of Machinery. By C.S.Lowndes. Post 8vo.5s.

\section{The Elements of Mechanism.}

By T. M. Goodeve, M.A. Prof. of Mechanics at the R. M. Acad. Woolwich. Second Edition, with 217 Woodents. Post 8vo. 6s. 6d.
Ure's Dictionary of Arts, Manufactures, and Mines. Re-written and enlarged by RoBert HuNT, F.R.S., assisted by numerous gentlemen eminent in Science and the Arts. With 2,000 Woodcuts. 3 rols. 8vo. $£ 4$.

Encyclopædia of Civil Engineering, Historical, Theoretical, and Practical. By E. Cresy, C.E. With above 3,000 Woodcuts. 8vo. 42s.

Treatise on Mills and Millwork. By W. Fatrbaira, C.E. F.R.S. With 18 Plates and 322 Woodcuts. 2 vols. 8vo. 32s.

Useful Information for Engineers. By the same Author. First and SEcond Serres, with many Plates and Woodcuts. 2 vols. crown 8 ro. 10 s. $6 d$. each.

The Application of Cast and Wrought Iron to Building Purposes. By the same Anthor. Third Edition, with 6 Plates and 118 Woodcuts. 8vo. $16 s$.

Iron Ship Building, its History and Progress, as comprised in a Series of Experimental Researches on the Laws of Strain; the Strengths, Forms, and other conditions of the Material; and an Inquiry into the Present and Prospective State of the Navy, including the Experimental Results on the Resisting Powers of Armour Plates and Shot at High Velocities. By the same Author. With 4 Plates and 130 Woodcuts, 8 ro. 18 s.

The Practical Mechanic's Journal: An Illustrated Record of Mechanical and Engineering Science, and Epitome of Patent Inventions. 4to. price 1s, monthly. 
Tho Practical Draughtsman's Book of Industrial Design. By W. JoHvsos, Assoc. Inst. C.E. With many hundred Illustrations. 4to. $28 \mathrm{~s} .6 d$.

\section{The Patentee's Manual : a Treatise} on the Law and Practice of Letters Patent for the nse of Patentees and Inventors. By J. and J. H. Johnsos. Post 8vo. 7s. $6 d$.

\section{The Artisan Club's Treatise on} the Steam Engine, in its various Applications to Mines, Mills, Steam 'Navigation, Railways, and Agrieulture. By J. Bourne, C.E. Seventh Edition; with 37 Plates and 546 Woodcuts. 4to. $42 s$.

\section{A Treatise on the Screw Pro-} peller, Screw Vessels, and Screw Engines, as adapted for purposes of Peace and War; illustrated by many Plates and Woodents. By the same Author. New and enlarged Edition in course of publication in 24 Parts, royal 4to. 2s. 6d. each.

\section{Catechism of the Steam Engine,} in its various Applications to Mines, Mills, Steam Navigation, Railways, and Agriculture. By J. Bourne. C.E. With I99 Woodcuts. Fep.9s. The Intronvction of ' Recent Improvements' may be liad separately, with 110 Woodcuts, price $3 s .6 d$.

$\mathrm{H}_{\text {and }}$ book of the Steam Engine, by the same Anthor, forming a KEY to the Catechism of the Steam Engine, with 67 Woodcuts. Fcp. $9 s$.

The Theory of War Illustrated by numerous Examples from History. By Lient.-Col. P. L. MacDovgall. Third Edition, with 10 Plans. Post 8wo. 10s. 6d.
The Art of Perfumery ; the History and Theory of Odours, and the Metlods of Extracting the Aromas of Plants. By Dr. Piesse, F.C.S. Third Edition, with 53 Woodcuts. Crown 8vo. 10s. $6 d$.

Chemical, Natural, and Physical Magic, for Juveniles during the IIolidays. By the same Author. Third Edition, enlarged with $3 S$ Woodcuts. Fep. 6s.

Talpa; or, the Chronicles of a Clay Tarm. By C. W. Hoskyns, Esq. With 24 Woodcuts from Designs by G. CrurksIIANK. Sixth Edition. 16mo. 5s.6d.

Loudon's Encyclopædia of Agriculture: Comprising the Laying-out, Improvement, and Management of Landed Property, and the Cultivation and Economy of the Productions of Agricnlture. With 1,100 Woodcuts. 8vo, 31s. 6 d.

Loudon's Encyclopædia of Gardening : Comprising the Theory and Practice of Horticnlture, Floricultnre, Arboriculture, and Landscape Gardening. With 1,000 Woodeuts. 8vo. 31s. $6 d$.

Loudon's Encyclopædia of Cottage, Farm, and Villa Architecture and Furniture. With more than 2,000 Woodcuts. 8vo. $42 s$.

History of Windsor Great Park and Windsor Forest. By Wizlianr Mexzies, Resident Deputy Surveyor. With 2 Maps and 20 Photographs. Imp. folio, $f 88 s$.

Bayldon's Art of Valuing Rents and Tillages, and Claims of Tenants upon Quitting Farms, both at Michaelmas and Lady-Day. Eighth Edition, revised by J. C. Morton. 8vo. 10s.6d.

\section{Religious and Moral Works.}

\section{An Exposition of the 39 Articles,} Historical and Doctrinal. By E. HAROLD Browne, D.D. Lord Bishop of Ely. Seventh Edition. 8vo. 16s.

The Pentateuch and the Elohistic Psalms, in Reply to Bishop Colenso. By the same. Second Edition. 8vo. $2 s$.

Examination-Questions on Bishop Browne's Exposition of the Articles. By the Rev. J. Gorle, M.A. Fep. 3s.6d.

Five Tectures on the Character of St. Paul; being the IIulsean Lecturis for 1882. By the Rev. J. S. Howsov, D.D. Second Edition. 8ro. 9 s.
The Iife and Epistles of St. Paul. By W. J. Conyeeare, M.A. late Fellow of Trin. Coll. Cantab. and J. S. Howson, D.D. Principal of Liverpool Coll.

Library Edition, with all the Original Ilnstrations, Maps, Landscapes on Steel, Woodents, \&c. 2 rols. 4 to. 48 s.

INTermediate Edition, with a Selection of Maps, Plates, and Woodcuts. 2 rols. square crown 8 ro. $31 s .6 u$.

Prople's Edrtion, revised and condensed, with 46 Illustrations and Maps. 2 vols. crown 8 vo. $12 s$. 
The Voyage and Shipwreck of St. Paul; with Dissertations on the Ships and Navigation of the Ancients. By Jawes Sмrті, F.R.S. Crown 8vo. Charts, 8s. 6d.

Fasti Sacri, or a Key to the Chronology of the New Testament; comprising an Historical Harmony of the Four Gospels, and Chronological Tables generally from B.C. 70 to A.D. 70 : with a Preliminary Dissertation and other Aids. By Thomis LEwIs, M.A. F.S.A. Imp. $8 v 0.42 s$.

\section{A Critical and Grammatical Com-} mentary on St. Paul's Epistles. By C. J. Eluicotr, D.D. Lord Bishop of Gloucester and Bristol. 8 ro.

Galatians, Third Edition, 8s.6d.

Ephesians, Third Edition, 8s.6d.

Pastoral Epistles, Third Edition, 10s. $6 d$.

Philippians, Colossians, and Philemon, Third Edition, 10s, $6 d$.

Thessalonians, Second Edition, 7s. Gd.

Historical Iectures on the Iife of Our Lord Jesus Christ : being the Hulsean Lectures for 1859. By the same Author. Fourth Edition. 8vo. 10s.6d.

The Destiny of the Creature; and other Sermons preached before the University of Cambridge. By the same. Post 8vo. 5 s.

The Broad and the Narrow Way; Two Sermons preached before the University of Cambridge. By the same. Crown 8 ro. $2 s$.

Rev. T. H. Horne's Introduction to the Critical Study and Knowledge of the Holy Scriptures. Eleventh Edition, corrected, and extended under careful Editorial revision. With 4 Maps and 22 Woodcuts and Facsimiles. 4 vols. 8 vo. $£ 313$ s. $6 d$.

Rev. T. H. Horne's Compendious Introduction to the Study of the Bible, being an Analysis of the larger work by the same Author. Re-edited by the Rev. JoHx AYre, M.A. With Maps, \&c. Post 8vo.9s.

\section{The Treasury of Bible know-} ledge; being a Dictionary of the Books, Persons, Places, Events, and other Matters of which mention is made in Holy Scriptnre; intended to establish its Autlority and illustrate its Contents. By Rev. J. Arre, M.A. With Maps, 15 Plates, and numerous Woodcuts. Fcp. $10 s, 6 d$.

TheGreek Testament; with Notes, Grammatical and Exegetical. By the Rev. W. Webster, M.A. and the Rev. W. F. Wuikinsox, M.A. 2 vols. 8 ro. $£ 248$.;

Vor. I. the Gospels and Acts, $20 s$.

Vor. II. the Fpistles and Apocalypse, 24s.
Every-day Scripture Difficulties explained and illustrated. By J. E. Pres. CorT, M.A. VoL. I. Matthew and Mark; Vot. II. Luke and John. 2 vols. 8vo. 9s. each.

The Pentateuch and Book of Joshua Critically Examined. By the Right Rev. J. W. Colexso, D.D. Lord Bishop of Natal. People's Edition, in 1 rol. crown 8 ro. 6s. or in 5 Parts, 1 s. each.

The Pentateuch and Book of Joshua Critically Examined. By Prof. A. Kuevex, of Leyden. Translated from the Dutch, and edited with Notes, by the Right Rev. J. W. Colesso, D.D. Bishop of Natal. 8vo. 8s. $6 d$

The Church and the World: Essays on Questions of the Day. By various Writers. Edited by Rev. Orby Shipley, M.A. 8vo. _._: [Nearly ready.

The Formation of Christendom. Part I. By T. W. Allies. 8vo. $12 s$.

Christendom's Divisions; a Philosophical Sketch of the Divisions of the Christian Family in East and. West. By Ensurd S. Froulkes, formerly Fellow and Tutor of Jesus Coll. Oxford. Pust 8ro.7s.6d.

Christendom's Divisions, Part II. Greeks and Latins, being a History of their Dissentions and Overtures for Peace down to the Reformation. By the same Author.

[Nearly reudy.

The Iife of Christ, an Eclectic Gospel, from the Old and New Testaments, arranged on a New Principle, with Analytical Tables, \&c. By Cinanles De ra Pryme, M.A. Revised Edition. 8vo. 5s.

The Hidden Wisdom of Christ and the Key of Knowledge; or, History of the Apocrypha. By Ersest De Buxsex. 2 vols. $8 \mathrm{vo} .288$.

The Temporal Mission of the Holy Ghost; or, Reason and Revelation. By the Most Rev. Archbishop Masnivo. Second Edition. Crown 8vo. 8s. $6 d$.

Essays on Religion and Literature. Eulited by the Most Rev. Archbishop Mansixg. 8vo. 10s. $6 d$.

Essays and Reviows. By the Rev. IV. 'Nesiple, D.D. the Rev. R. Willians, B.D. the Rev. B. Powel, M.A. the Rev. H. B. Wilsos, B.D. C. W. Goodwis, M.A. the Rev. M. PAtrison, B.D. and the Rev. B.Jowet, M.A. 12th Edition. Fep. 5 s. 
Mosheim's Ecclesiastical History. Murdock and Soames's 'Translation and Notes, re-edited by the Rev. W. Stubis, M.A. 3 vols. 8 vo. 45 s.

\section{Bishop Jeremy Taylor's Entire} Works: With Life by Bishop HEBER. Revised and corrected by the Rev. C. P. EDen, 10 rols. $£ 55$ s.

\section{Passing Thoughts on Religion.} By the Author of 'Amy Herbert.' New Edition. Fcp. 5 s.

Thoughts for the Holy Week, for Young Persons. By the same Author. 3d Edit on. Fep. 8vo. 2s.

Night Lessons from Scripture. By the same Anthor. 2d Edition. 32mo. 3s.

Self-examination before Confirmation. By the same Author. $32 \mathrm{mo} .1 \mathrm{~s} .6 d$.

Readings for a Month Preparatory to Confirmation from Writers of the Early and English Church. By the same. Fcp. $4 s$.

Readings for Every Day in Lent, compiled from the Writings of Bishop JEREMY TAYLOR. By the same. Fep. $5 s$.

Preparation for the Holy Communion; the Devotions chiefly from the works of Jerkmy TaYlor. By the same. 32mo. $3 s$.

\section{Principles of Education drawn} from Nature and Revelation, and Applied

- to Female Education in the Upper Classes. By the same. 2 rols. fcp. $12 s .6 d$.

\section{Morning Clouds. Second Edition.} Fep. 5s.

The Wife's Manual ; or, Prayers, Thoughts, and Songs on Several Occasions of a Matron's Life. By the Rev. W. CALVERT, M.A. Crown 8vo. 10s. $6 d$.

\section{Spiritual Songs for the Sundays} and Holidays throughout the Year. By J. S. B. MoNselL, LL.D. Vicar of Egham. Fourth Edition. Fcp. $4 s .6 d$.

The Beatitudes: Abasement before God: Sorrow for Sin; Meekness of Spirit; Desire for Holiness; Gentleness; Purity of Heart ; the Peace-makers; Sufferings for Christ. By the same. 2nd Edition, fcp. 3s, $6 d$.

Lyra Domestica; Christian Songs for Domestic Edification. Translated from the Psaltery and Harp of C. J. P. SPITTA, and from other sources, by Richard Massie. First and Second Series, fcp. $4 s .6 d$.each.
Lyra Sacra; Hymns, Ancient and Modern, Odes, and Fragments of Sacred Poetry. Edited by the Rev. B.W. Savile, M.A. Third Edition, enlarged. Fcp. $5 s$.

Lyra Germanica, translated from the German by Miss C. Wrikwortir. First Series, Hymns for the Sundays and Chief Festivals; Second Series, the Christian Life. Fcp. 5s. each Series.

Hymns from Lyra Germanica, 18mo. 1s.

Lyra Eucharistica ; Hymns and Verses on the Holy Communion, Ancient and Modern; with other Poems. Edited by the Rev. Orby Shipley, M.A. Second Edition. Fep. 7 s. $6 d$.

Iyra Messianica; Hymns and Verses on the Life of Christ, Ancient and Modern; with other Poems. By the same Editor. Second Edition, enlarged. Fcp. 7s.6d.

Lyra Mystica; Hymns and Verses on Sacred Subjects, Ancient and Modern. By the same Editor. Fcp. 7s. $6 d$.

The Chorale Book for England; a complete Hymn-Book in accordance with the Services and Festivals of the Church of England : the Hymns translated by Miss C. WIsk worth; the Tunes arranged by Prof. W. S. Bennetr and Otto Goldscinmot. Fep. 4to. I2s. $6 d$.

Congregational Edition. Fep. $2 s$.

The Catholic Doctrine of the Atonement; an Historical Inquiry into its Development in the Church : with an Introduction on the Principle of Theological Developments. By H. N. Oxenhà, M.A. formerly Scholar of Balliol College, Oxford. 8 ro. $8 s .6 d$.

From Sunday to Sunday; an attempt to consider familiarly the Weekday Life and Labours of a Country Clergyman. By R. GeE, M.A. Fep. $5 s$.

First Sundays at Church; or, Familiar Conversations on the Morning and Evening Services of the Church of England. By J. E. Riddle, M.A. Fep. $2 s .6 d$.

The Judgment of Conscience, and other Sermons. By RiCHARD WhateLY, D.D. late Archbishop of Dublin. Crown 8vo. 4s. 6d.

Paley's Moral Philosophy, with Annotations. By Richiard Whately, D.D. late Archbishop of Dublin. 8vo. $7 s$. 


\section{Travels, Voyages, \&ंc.}

Outline Sketches of the High Alps of Dauphiné. By T. G. Bonsex, M.A. F.G.S. M.A.C. Fellow of St. John's Coll. Camb. With 13 Plates and a Coloured Map. Post 4to. 16 s.

\section{Ice Caves of Franco and Switzer-} land; a narrative of Subterranean Exploration. By the Rev. G. F. Browne, M.A. Fellow and Assistant-Tutor of St. Catherine's Coll. Cambridge, M.A.C. With 11 Woodcuts. Square crown 8vo. 12s. $6 d$.

Village Life in Switzerland. By Sophia D. Delmard. Post 8vo. 9s.6d.

How we Spent the Summer; or, a Voyage en Zigzag in Switzerland and Tyrol with some Members of the Al.PINE Cuub. From the Sketch-Book of one of the Party. Third Edition, re-drawn. In oblong 4to. with abont 300 Illustrations, 15 s.

Beaten Tracks; or, Pen and Pencil Sketches in Italy. By the Authoress of 'A Voyage en Zigzag.' With 42 Plates, containing about 200 Sketches from Drawings made on the Spot. 8vo. 16s.

Map of the Chain of Mont Blanc, from an actual Survey in 1863-1864. By A. Adams-Reilly, F.R.G.S. M.A.C. Published under the Authority of the Alpine Clab. In Chromolithography on extra stout drawing-paper 28in. $\times 17 \mathrm{in}$. price $10 \mathrm{~s}$. or mounted on canvas in a folding case, $12 s, 6 d$.

Transylvania,its Products and its People. By Charles Bonrr. With 5 Maps and 43 Illustrations on Wood and in Chromolithography. 870. 21s.

\section{Explorations in South-west} Africa, from Walvisch Bay to Lake Ngami and the Victoria Falls. By Thomas Barves, F.R.G.S. 870. with Maps and Illustrations, $21 s$.

\section{Vancouver Island and British} Columbia ; their History, Resources, and Prospects. By MATTHEw MACris, F.R.G.S. With Maps and Illustrations. 870. 18s.

\section{History of Discovery in our} Australasian Colonies, Australia, Tasmania, and New Zealand, from the Earliest Date to the Present Day. By Wrumiar Howrtr. With 3 Maps of the Recent Explorations from Official Sources. 2 vols. $8 \mathrm{vo} .28 \mathrm{~s}$.
The Capital of the Tycoon; a Narrative of a 3 Years' Residence in Japan. By Sir Rutherford Alcock, K.C.B. 2 vols. 8 vo. with numerous Illustrations, 42 s.

Iast Winter in Rome. By C. R. WeLD. With Portrait and Engravings on Wood. Post 8vo. 14s.

Autumn Rambles in North Africa. By Joun Ormsiy, of the Middle Temple. With 16 Illustrations. Post 8vo. 8s. $6 d$.

The Dolomite Mountains. Excursions through Tyrol, Carinthia, Carniola, and Friuli in 1861, 1862, and 1863. By J. Grubert and G. C. Churchils, F.R.G.S. With numerous Illustrations. Square crown 8ro. 21s.

A Summer Tour in the Grisons and Italian Valleys of the Bernina. By Mrs. Hentry Fresh Field. With 2 Coloured Maps and 4 Views. Post 8vo. 10s. $6 d$.

Alpine Byways; or, Light Learcs gathered in 1859 and 1860. By the same Anthoress. Post 8ro. with Illustrations, 10s. $6 d$.

\section{A Lady's Tour Round Monto Rosa;} inclnding Visits to the Italian Valleys. With Map and Illustrations. Post 8vo, 148.

Guide to the Pyrenees, for the use of Mountaineers. By Charles Packe. With Maps, \&c. and Appendix. Fcp.6s.

The Alpine Guide. By Jorn Ball, M.R.I.A. late President of the Alpine Club, Post 8 ro. with Maps and other Illustrations. Guide to the Eastern Alps. [Just ready.

Guide to the Western Alps, including Mont Blanc, Monte Rosa, Zermatt, \&c. price 7s. $6 d$.

Guide to the Oberland and all Switzerland, excepting the Neighbourhood of Monte Rosa and the Great St. Bernard; with Lombardy and the adjoining portion of Tyrol. 7s. $6 d$.

A Guide to Spain. By H. O'Shea. Post 8vo. with Travelling Map, 15s.

Christopher Columbus; his Life, Voyages, and Discoveries. Revised Edition, with 4 Woodcuts. $18 \mathrm{mo} .2 s, 6 d$.

Captain James Cook; his Life, Voyages, and Discoveries. Revisel Edition, with numerous Woodeuts. $18 \mathrm{mo} .2 s .6 d$. 
Humboldt's Travels and Discoveries in South America. Third Edition, with numerous Woodcuts. $18 \mathrm{mo} .2 s .6 d$.

Mungo Park's Life and Travels in Africa, with an Account of his Death and the Substance of Later Discoveries. Sixth Edition, with Woodcuts. $18 \mathrm{mo} .2 s .6 d$.

Narratives of Shipwrecks of the Royal Navy between 1793 and 1857, compiled from Official Documents in the Admiralty by W. O. S. GrLIY ; with a Preface by W. S. GILLY, D.D. $3 d$ Edition, fep. $5 s$.
A Week at the Land's End. By J. T. Burgrt ; assisted by E. H. RovD, R. Q. Coucr, and J. Ralfs. With Map and 96 Woodcuts. Fcp. 6s. $6 d$.

Visits to Remarkable Places : Old Halls, Battle-Ficlds, and Scenes illustrative of Striking Passages in English History and Poetry. By William HowitT. 2 vols. square crown 8vo. with Wood Engravings, $25 s$.

The Rural Life of England. By the same Author. With Woodcuts by Bewick and Williams. Medium 8vo. 12s. $6 d$.

\section{Works of Fiction.}

Atherstone Priory. By L. N. Comrs. 2 vols. post 8 vo. $21 s$.

Ellice: a Tale. By the same. Post 8 vo. 9 s. $6 d$.

\section{Stories and Tales by the Author} of 'Amy Herbert,' uniform Edition, each Tale or Story complete in a single volume.

Any Heriert, 2s.6d. Katifarine Ashton, Gertrude, 2s. $6 d$.

EARL'S DAUGHTER, $3 s .6 d$. $2 s .6 d$.

Margaret PerciVAL, $5 s$.

Experience of Life, Laxeton Parson$2 s .6 d$.

Clevye Hald, 3s. $6 d$.

Ivors, $3 s, 6 d$. $\triangle \mathrm{GE}, 4 s .6 d$. UrSUlA, 4s. $6 d$.

A Glimpse of the World. By the Author of 'Amy Herbert.' Fep. 7s. 6d.

\section{The Six Sisters of the Valleys:} an Historical Romance. By W. BrayleyMoore, M.A. Incumbent of Gerrard's Cross, Bucks. Third Edition, with 14 Illustrations. Crown 8vo. 5 s.

Icelandic Legends. Collected by Jon. Arnason. Selected and Translated from the Icelandic by GEORGE E.J. PoiveLL and E. Magnussox. Second Series, with Notes and an Introductory Essay on the Origin and Genius of the Icelandic Folk-Lore, and 3 Illustrations on Wood. Crown 8vo. $21 s$.

The Warden : a Novel. By AxthonY Trollope, Crown 8vo. $3 s .6 d$.

Barchester Towers: a Sequcl to "The Warden.' By the same Author. Crown 8 vo. $5 s$.
The Gladiator's : a Tale of Rome and Judæa. By G. J. Whyte Melville. Crown 8vo. 5 s.

Digby Grand, all Autobiography. By the same Author. 1 vol. $5 s$.

Kate Coventry, an Autobiography. By the same. 1 vol. $5 s$.

General Bounce, or the Lady and the Locusts. By the same. 1 vol. $5 s$.

Holmby House, a Tule of Old Northamptonshire. 1 vol. $5 s$.

Good for Nothing, or All Down Hill. By the same. 1 vol. $6 s$.

The Queen's Maries, a Romance of Holyrood. By the same. 1 vol. $6 s$.

The Interpreter, a Tale of the War, By the same Author. 1 rol. $5 s$.

Tales from Greek Mythology. By George W. Cox, MI.A. late Scholar of Trin. Coll. Oxon. Sec:ond Edition. Square $16 \mathrm{mo} .3 s .6 d$.

Tales of the Gods and Heroes. By the same Author. Second Edition. Fcp. 5̃s.

Tales of Thebes and Argos. By the same Author. Fep. 4s.6d.

Gallus; or, Roman Scenes of the Time of Augustus: with Notes and Excursuses illustrative of the Manners and Customs of the Ancient Romans. From the German of Prof. Becker. New Edition. [Nearly rendy.

Charicles; a 'Tale illustrative of Private Life among the Ancient Greeks : with Notcs and Excursuses. From the German of Prof. Becker. New Edition. [Nearly ready. 


\section{Poetry and The Drama.}

Goethe's Second Faust. Translated by Jonis Axster, LL.D. M.R.I.A. Regius Professor of Civil Law in the University of Dublin. Post 8ro. 15s.

\section{Tasso's Jerusalem Delivered,} translated into English Verse by Sir J. Kingston Jases, Kt. M.A. 2 vols. fcp. with Facsimile, 14s.

\section{Poetical Works of John Edmund}

Reade; with final Revision and Additions. 3 vols. fcp. 18 s. or each vol. separately, $6 s$.

Moore's Poetical Works, Cheapest Editions complete in $1 \mathrm{rol}$. including the Antobiographical Prefaces and Anthor's last Notes, which are still copyright. Crown 8 vo. ruby type, with Portrait, $6 s$. or People's Edition, in larger type, 12s. $6 d$.

Moore's Poetical Works, as above, Library Edition, medium 8vo. with Portrait and Vignette, 14s. or in 10 vols. fcp. $3 s .6 d$. each.

Moore's Lalla Rookh. 32mo. Plate, 1s. $16 \mathrm{mo}$. Vignette, $2 s .6 d$.

Tenniel's Edition of Moore's Lalla Rookh, with 68 Wood Engravings from Original Drawings and other Illustrations. Fcp. 4to. 218.

Moore's Irish Melodies. 32mo. Portrait, 1s. $16 \mathrm{mo}$. Vignette, $2 s .6 d$.

Maclise's Edition of Moore's Irish Melodies, with 161 Steel Plates from Original Drawings. Super-royal 8vo. 31s.6d.

Maclise's Edition of Moore's Irish Melodies, with all the Original Designs (as above) reduced by a New Process. Imp. 16mo. 10s. $6 d$.

Southey's Poetical Works, with the Author's last Corrections and copyright Additions. Library Edition, in 1 vol. medinm 8vo. with Portrait and Vignette, 143. or in 10 vols. fcp. $3 s, 6 d$. each.
Lays of Ancient Rome; with Ivry and the Armada. By the Right Hon. Lord Macaular. 16mo. 4s. $6 d$.

Lord Macaulay's Lays of Ancient Rome. With 90 Illustrations on Wood, Original and from the Antique, from Drawings by G. Scharr. Fcp. 4to. 21s.

Pooms. By Jeax Ixgelow. Tenth Edi. tion. Fcp. 8 vo. 5 s.

Poetical Works of Letitia Elizabeth Landon (L.E.L.) 2 vols. $16 \mathrm{mo} .10 \mathrm{~s}$.

Playtime with the Poets : a Selection of the best English Poetry for the use of Children. By a LADY. Crown 8vo. 5s:

\section{Bowdler's Family Shakspeare;} cheaper Genuine Edition, complete in 1 rol. large type, with 36 Woodcut Illustrations, price $14 s$. or, with the same Illustratioss, in 6 pocket vols. $3 s$. $6 d$. each.

Arundines Cami, sive Musarum Cantabrigiensinm Lusus Canori. Collegit atque edidit H. Drury, M.A. Editio Sexta, curavit H. J. Hodgsos, M.A. Crown 8 vo. price 7 s. $6 d$.

The Iliad of Homer Translated into Blank Verse. By ICma bod Crurles Wriant, M.A. late Fellow of Magdalen Coll. Oxon. 2 vols. crown 8 vo. 21 s.

The Iliad of Homer in English Hexameter Verse. By J. IIENry DART, M.A. of Exeter College, Oxford; Author of 'The Exile of St. Helena, Newdigate, 1838.' Square crown 8vo. price 21s. cloth.

Dante's Divine Comedy, translated in English Terza Rima by JoHx DAxMAx, M.A. [With the Italian Text, after Brunetti, interpaged.] 8vo.21s.

\section{Rural Sports, \&·c.}

Encyclopædia of Rural Sports; a Complete Account, Historical, Practical, and Descriptive, of Hunting, Shooting, Fishing, Racing, \&c. By D. P. Blatse. With above 600 Woodcuts (20 from Designs by JOHN LEECH). $8 \mathrm{vo} .42 s$.

Notes on Rifle Shooting. By Captain Heatos, Adjutant of the Third Manchester Rifle Volunteer Corps. Fcp. 28.6d.
Col. Hawker's Instructions to Young Sportsmen in all that relates to Guns and Shooting. Revised by the Author's Sos. Square crown $8 \mathrm{vo}$. with Illustrations, 18 s.

The Rifle, its Theory and Practice. By Artrur Walker (79th Highlanders), Staff. Hythe and Fleet wood Schools of Musketry. Second Edition. Crown 8vo. with 125 Woodcuts, $5 s$. 
The Dead Shot, or Sportsman's Complete Guide; a 'Treatise on the Use of the Gun, Dog-breaking, Pigeon-shooting, \&c. By Marksuan. Fep. with Plates, $5 s$.

Hints on Shooting, Fishing, \&c. both on Sea and Land and in the Fresh and Saltwater Lochs of Scotland. By C. IDLE, Esq. Second Edition. Fcp. 6s.

The F'ly-Fisher's Entomology. By Alfred Ronalds. With coloured Representations of the Natural and Artificial Insect. Sixth Edition; with 20 coloured Plates. 8vo. 14s.

Hand-book of Angling: Teaching Fly-fishing, Trolling, Bottom-fishing, Salmon-fishing; with the Natural History of River Fish, and the best modes of Catching the . By Ephesiera. Fcp. Woodcuts, 5s.

The Cricket Field; or, the History and the Science of the Game of Cricket. By es Pycroft, B.A. 4th Edition. Fcp. 5s.

The Cricket Tutor; a Treatise exclusively Practical. By the same. $18 \mathrm{mo} .1 s$.

Cricketana. By the same $\Lambda$ uthor. With 7 Portraits of Cricketers. Fcp. 5s.

Youatt on the Horse. Revised and enlarged by W. WATsor, M.R.C.V.S. 8vo. with numerons Woodcuts, $12 s .6 d$.

Youatt on the Dog. (By the same Author.) 8 vo. with linmerous Woodcuts, $6 s$.

The Horse-Trainer's and Sportsman's Guide: with Considerations on the Duties of Grooms, on Purchasing Blood Stock, and on Veterinary Examination. By Digby Collins. Post 8vo. 6s.
Blaine's Veterinary Art: a Treatise on the Anatomy, Physiology, and Curative Treatment of the Diseases of the Horse, Neat Cattle, and Sheep. Seventh Edition, revised and enlarged by C. STEEL, M.R.C.V.S.L. 8vo. with Plates and Woodcuts, $18 s$.

\section{The Horse's Foot, and how to keop} it Sound. By W. Mrles, Esq. 9th Edition, with Illustrations. Imp. 8vo. 12s. $6 d$.

A Plain Treatise on Horse-shoeing. By the same Author. Post 8vo. with Illustrations, $2 s .6 d$.

Stables and Stable Fittings. By the same. Imp. 8vo. with 13 Plates, $15 s$.

Remarks on Horses' Teeth, addressed to Purchasers. By the same. Post 8vo. 1s.6d.

On Drill and Manœuvres of Cavalry, combined with Horse Artillery. By Major-Gen. Michael W. Smith, C.B. Commanding the Poonah Division of the Bombay Army. 8vo. 12s. $6 d$.

\section{The Dog in Health and Disease.} By Stonenenge. With 70 Wood Engravings. Square crown 8vo. 15s.

The Greyhound. By the same Author. Revised Edition, with 24 Portraits of Grey* hounds. Square crown 8 vo. 218.

The Ox, his Diseases and their Treatment; with an Essay on Parturition in the Cow. By J.R. Dobson, M.R.C.V.S. Crown 8 vo. with Illustrations, $7 s .6 d$.

\section{Commerce, Navigation, and Mercantile Affairs.}

A Dictionary, Practical, Theoretical, and Historical, of Commerce and Commercial Navigation. By J. R. M'CuLLOCH. 8vo. with Maps and Plans, $50 s$.

Practical Guide for British Shipmiasters to United States Ports. By PicrREPont Euwards, Her Britannic Majesty's Vice-Consul at New York. Post 8vo. 8s. 6d.

A Manual for Naval Cadets. By J. M'NEIL BOYD, late Captain R.N. Third Edition; with 240 Woodcuts, and 11 coloured Plates. Post 8vo. 12s.6d.
The Law of Nations Considered as Independent Political Communities. By Travers Twiss, D.C.L. Regius Professor of Civil Law in the University of Oxford. 2 vols. 8 vo. 30 s. or separately, PArt I. Peace, 12s. Part II. War, 18 .

A Nautical Dictionary, deflning the Technical Language relative to the Building and Equipment of Sailing Vessels and Steamers, \&c. By Artiun Young. Second Edition ; with Plates and 150 Woodcuts. 8 vo. $18 s$. 


\section{Works of Utility and General Information.}

Modern Cookery for Private Families, reduced to a System of Easy Practice in a Series of carefully-tested Receipts. By Eluza Acton. Newly revised and enlarged; with 8 Plates, Figures, and 150 Woodcuts. Fep. 7s.6d.

The Handbook of Dining; or, Corpalency and Leanness seientifically considered. By Brillat-SAvariv, Author of 'Physiologie du Goût.' Translated by L. F. Simpsos. Revised Edition, with Additions. Fep. 3 s. $6 d$.

On Food and its Digestion; an Introduction to Dietetics. By W. BrINTON, M.D. Physician to St. Thomas's Hospital, 8cc. With 48 Woodcuts. Post 8vo. 12s.

\section{Wine, the Vine, and the Cellar.} By Thomas G. Shaw. Second Edition, revised and enlarged, with Frontispiece and 31 Illustrations on Wood. 8vo.16s.

\section{A Practical Treatise on Brewing;} with Formnla for Public Brewers, and Instractions for Private Families. By W. BrAck. Fifth Edition. 8vo. 10s.6d.

How to Brew Good Beer: a complete Guide to the Art of Brewing Ale, Bitter Ale, Table Ale, Brown Stout, Porter, and Table Beer. By JoHs Prtr. Revised Edition. Fep. 4s. 6 d.

Short Whist. By MaJor A. The Sixteenth Edition, revised, with an Essay on the Theory of the Modern Scientific Game by ProF. P. Fep. 3s. 6d.

Whist, What to Lead. By Cam. Third Edition. 32mo. 18.

Two Hundred Choss Problems, composed by F. Healey, including the Problems to which the Prizes were awarded by the Committees of the Era, the Manchester, the Birmingham, and the Bristol Chess Problem Tournaments; accompanied by the Socutross. Crown 8vo. with 200 Diagrams, $5 s$.

\section{Hints on Ftiquette and the} Usages of Society; with a Glance at Bad Habits. Revised, with Additions, by a LADY of RANK. Fep. 2s. $6 d$.
The Cabinet Lawyer; a Popular Digest of the Laws of England, Civil and Criminal. 21st Edition, extended by the Author; including the Acts of the Sessions 1864 and 1865. Fep. 10s. $6 d$.

The Philosophy of Health; or, an Exposition of the Physiological and Sanitary Conditions conducive to Human Longevity and Happiness. By Southwood SMitiI, M.D. Eleventh Edition, revised and enlarged; with 113 Woodcuts. 8vo. 158.

Hints to Mothers on the Management of their Health during the Period of Pregnancy and in the Lying-in Room. By T. BULL, M.D. Fep. 5s.

The Maternal Management of Children in Health and Disease. By the same Anthor. Fcp. 5 s.

Notes on Hospitals. By Florence Nightivgale. Third Edition, enlarged; with 13 Plans. Post 4to. 188.

The Law relating to Benefit Building Societies; with Practical Ubservations on the Act and all the Cases decided thereon, also a Form of Rules and Forms of Mortgages. By W. Tidd Pratt, Barrister. 2nd Edition. Fcp. 3s, $6 d$.

C. M. Willich's Popular Tables for Ascertaining the Value of Lifehold, Leasehold, and Church Property, Renewal Fines, \&c.; the Public Funds; Annual Average Price and Interest on Consols from 1731 to 1861; Chemical, Geographical, Astronomical, Trigonometrical Tables, \&c. Post 8ro. 10s.

Thomson's Tables of Interest, at Three, Fonr, Four and a Half, and Five per Cent., from One Pound to Ten Thousand and from 1 to 365 Days. $12 \mathrm{mo} .3 s .6 d$.

Maunder's Treasury of Knowledge and Library of Reference: comprising an English Dictionary and Grammar, Universal Gazetteer, Classical Dictionary, Chronology, Law Dictionary, Synopsis of the Peerage, useful Tables, \&c. Fcp. 10 s. 


\section{General and School Atlases.}

\section{An Atlas of History and Geo-} graphy, representing the Political State of the World at successive Epochs from the commencement of the Christian Era to the Present Time, in a Series of 16 coloured Maps. By J. S. Brewer, M.A. Third Edition, revised, \&c. by E. C. Brewer, LL.D. Royal 8vo. 15s.

Bishop Butler's Atlas of Modern Geography, in a Series of 33 full-coloured Maps, accompanied by a complete Alphabetical Index. New Edition, corrected and enlarged. Royal 8vo. 10s. $6 d$.

\section{Bishop Butler's Atlas of Ancient} Geography, in a Series of 24 full-coloured Naps, accompanied by a complete Accentuated Index. New Edition, corrected and enlarged. Royal 8vo. 12s.
School Atlas of Physical, Political, and Commercial Geography, in 17 full-coloured Maps, accompanied by descriptive Letterpress. By E. Hugitis F.R.A.S. Royal $8 \mathrm{ro} .10 \mathrm{~s} .6 d$.

Middle-Class Atlas of General Geography, in a Series of 29 full-coloured Maps, containing the most recent Territorial Changes and Discoveries. ByW ALTER M'LEOD, F.R.G.S. 4 to. 5 s.

\section{Physical Atlas of Great Britain} and Ireland; comprising 30 full-coloured Maps, with illustrative Letterpress, forming a concise Synopsis of British Physical Geography. By Walter M‘Leod, F.R.G.S. Fep. 4to. $7 s .6 d$.

\section{Periodical Publications.}

The Edinburgh Review, or Critical Journal, published Quarterly in January, April, July, and October. 8ro. price 6s. each No.

The County Seats of the Noblemen and Gentlemen of Great Britain and Ireland. Edited by the Rev. F. O. Mornis, B.A. Rector of Nunburnholme. In course of publication monthly, with coloured Views, in 4to. price $2 s$. 6d. each Part.

\section{Knowledge for the Young.}

\section{The Stepping Stone to Knowledge:} Containing upwards of 700 Questions and Answers on Miscellaneous Subjects, adapted to the capacity of Infant Minds. By a MOTHER. $18 \mathrm{mo}$. price $1 s$.

The Stepping Stone to Geography: Containing several Hundred Questions and Answers on Geographical Subjects. $18 \mathrm{mo} .1 \mathrm{~s}$.

The Stepping Stone to English History : Containing several Hundred Questions and Answers on the History of England. $1 s$.

The Stepping Stone to Bible Knowledge: Containing several Hundred Questions and Answers on the Old and New Testaments. $18 \mathrm{mo} .1 s$.

The Stepping Stone to Biography: Containing several Hundred Questions and Answers on the Lives of Eminent Men and Women. $18 \mathrm{mo} .1 \mathrm{~s}$.
Fraser's Magazine for Town and Country, publislied on the 1st of each Month. 8vo. price 2s. $6 d$. each No.

The Alpine Journal: a Record of Mountain Adventure and Scientific Observation. By Members of the Alpine Club. Edited by H. B. George, M.A. Published Quarterly, May 31, Aug. 31, Nov. 30, Feb. 28. 8vo. price $1 s .6 d$. each No.
Second Series of the Stepping Stone to Knowledge: containing upwards of Eight Hundred Questions and Answers on Miscellaneous Subjects not contained in the First Series. $18 \mathrm{mo} .1 \mathrm{~s}$.

The Stepping Stone to French Pronunciation and Conversation: Containing several Hundred Questions and Answers. By Mr. P. SAdLer. $18 \mathrm{mo} .1 s$.

The Stepping Stone to English Grammar: containing several Hundred Questions and Answers on English Grammar. By Mr. P. SADLER. $18 \mathrm{mo} .1 s$.

The Stepping Stone to $\mathrm{N}$ atural History: Verterbate or BackBoned Animals. Pant I. Mammalia; Part II. Birds, Reptiles, Fishes. 18mo. 1s. each Part. 


\section{N D E X.}

A Bвotr on Sigtt and Tonch ............. Acrox's Modern C'ookery ................ A LCock's Residence in Japan.............. A LLIES on Formation of Christianity ...... Alpine Guide (The) .................... A rJoH N'a Manual of the Metslloids........ ARAGo's Biogrsphies of Scientific Men .... Popular Astronomy ............. ARNOLD's Manual of English Literature.... Arxotr's Elements of Physics ............ Arnndines Cami ...................... Atherstone Priory .................... Autumn Holidays of a Country Parson .... AYRE's Treasury of Bible Knowledge......

BAcon's Essays, by Whately .......... Life and Letters, by Spevdixa.... Works.........................

Barx on the Emotions and Will............ on the Senses and Intellect........... on the Study of Character ............ BAINes's Explorations in S.W. Africa .... BALL's Guide to the Central Alps........... Guide to the Western Alps ........

BARNARD's Drawing from Nature ........

BAYLDON's Rents and Tillages ............

Bgaten Tracks .........................

BЕсквв's Charicles and Gallus ............

BeEthoven's Letters ...................

BENREY' 8 Sanskrit-English Dictionary ....

BERRY's Journals .....................

BLACk's Treatise on Brewing..............

BLACKLEY and FrIEDLANDER's German and English Dictionary ...............

Blaise's Rural Sports..................

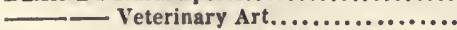

Виянт's Week at the Land'a End ........

BoAse's Essay on Human Nature ........

Philosophy of Nature ............

Bon ER's Transylvania .................

BONNEY's Alps of Dauphiné .............

Воотн's Epigrams......................

Bournk on Scren Propeller ................

BourNB's Catechism of the Steam Engine..

Handbook of Steam Engine ....

Treatise on the Steam Engine....

BowdLeR's Family Shakspeare.........

Boy d's Manual for Naval Cadets ..........

BRAMLEY-MOORE's Six Sisters of the Valleys

BRANDE's Dictionary of Science, Literature, and Art

BRAY's (C.) Education of the Feelings....... Philosophy of Necessity........

BREW KR's Atlas of History and Geography BaINTON on Food and Digestion .......... Bristow's Glossary of Mineralogy ........ BRODIE's Constitutional History ..........
Brodit's (Sir C. B.) Works............. 10 Autobiography....... 10

BrownE's Ice Caves of Frsnce and Switzerland ............................. I5

Land .................................... Exposition 39 Articles ........ 12

Pentateuch ................. I

BuckLE's History of Civilization ......... 2

BuLL's Hints to Mothers................. 19

Maternal Management of Children.. 19

Bunsen's Ancient Egypt............... 2

BUNsex on Apocrypha................ 13

BURER's Vicissitudes of Families ........ 4

Burton's Christian Church ............. 3

ButLen's Atlas of Ancient Geography .... 20 Modern Geogrsphy.............. 20

Cabinet Lawyer........................ 19

Calvert's Wife's Manual ............... 14

Campaigner at Home.................. 6

Cats and Farlie's Moral Emblems ........ 11

Chorale Book for England .............. 14

Clou oh's Lives from Plutarch ............ 2

Colenso (Bishop) on Pentateuch and Book of Joshua. ........................ 13

Coluiss's Horse Trainer's;Guide........ 18

Columbus's Voyagea. .................. 15

Commonplace Philosopler in Town and

Country ............................

Conington's Handbook of Chemical Analysis ...............................

Contanseav's Two French and English

Dictionarjes ........................ ConybenRE and Howsox's Life and Epistles of St. Paul ........................ 12

Cook's Voyages ...................... 15 Copland's Dictionary of Practical Medicine 10 Cox's Tales of the Great Persian War ...... 2

— Tales from Greek $\mathbf{M y}$ thology....... 16

- Tales of the Gods and Heroes........ 16

—Tales of Thebes and Argos ......... 16 CR esY's Encyclopadia of Civil Engineering 11 Critical Essays of a Country Parson........ 6 Crowe's History of France............. 2 Cussans's Grammar of Heraldry........ II

DART's Iliad of Homer ............... it D'A UBIONE's Ilistory of the Reformation in the time of CALviN ................... 2 DAYMAN's Dante's Divina Commedia...... 17 Dead shot (The), by MArksmas ........ 18 DE LA RIvE's Treatise on Electricity ...... 8 DELM A RD'\& Village Life in Switzerland.... 15 Dв la Pryan's Life of Chriat ........... 13 DE MOROAN on Matter and Spirit ....... 6 DE Toceurville's Democracy in America 2 Dorson on the $O x \ldots . . \ldots \ldots \ldots . . . \ldots . .18$ 
Duncan and Mullarp on Classification,

\&c. of the Idiotic................. 10

Dyer's City of Rome...................

Edinburgh Review (The) ...............

Enwards's Shipmaster's Guide ..........

Elements of Botany ..................

Ellice, a Tale.........................

BLLICOTT's Broad and Narrow Way.........

Commestary on Ephesians .... 13

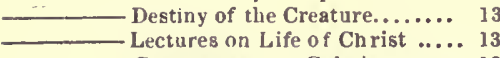

Commentary on Galatians .... 13 Pastoral Epist. 13 Plilippisns, \&c. 13 Thessalonians 13

Kasays and Reviews .................. 13 on Religion and Literature, edited by

Manning ............................

Fairbairn's Application of Cast and Wrought Iron to Building...............

- Intormation for Engineers ..

___ Treatise on Mills \& Millwork

FaIRBAIRN on Iron Ship Building ........

FARRAR's Chapters on Language ..........

Froulkes's Christendom's Divisions.......

Fraser's Magazine .....................

Freshfield's Alpine Byways .............

Tour in the Grisons .........

Frovde's History of England.............

Garratr's Marvels and Mysteries of Instinct GeE's Sunday to Sunday .................

GILBERT and CH URCH ILL's Dolomite Moun-

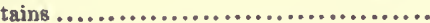

GiLly's Shipw recks of the Navy ..........

Goетне's Second Faust, by Anster........

Gooneve's Elements of Mechanism........

GORLE's Questions on BrownE's Exposition of the 39 Articles ...................

Grant's Ethics of Aristotle ...............

Graver Thoughts of a Country Parson......

GaAy's Anatomy .......................

GrEBNE's Corals and Sea Jellies .......... Sponges and Animalculae ......

Grove on Correlation of Physical Forces ..

Gwır's Encyclopædia of Architecture ....

Handbook of Angling, by EPHEMERA.....

HA RE on Election of Representatives ......

HA RTW IG's Harmonirs of Nature.......... Sea and its Living Wonders.... Tropical World .............

Havohton's Manual of Geology .............

HawkER's Instructions to Young Sports-

men .............................

Hraton's Notes on Rifle Shooting .........

Healey's Chess Problems ................

Herrs's Spanish Conquest in America ....

Herschel's Eseays from Reviews ........

Ontlines of Astronomy ...............

Haw 1TT on the Diseases of Women.........

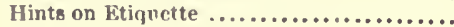

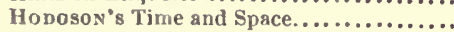

Holla n's Essays on Scientific Subjects...

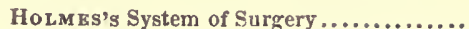

HOOKER and WALKER-ARNOTT'g British Flora............................ 8

Hok s's Introduction to the Scriptures.... 13

Compendium of the Scriptures .. 13

Horsley's Manual of Poisons ........... 9

Hoskyns's Talps .................... 12

How we Spent the Summer............ 15

Howitr's Australian Discovery ......... 15

— Rural Life of England ........ 16

Visits to Remarkable Places.... 16

Howson's Hulsean Lectures on St. Paul.... 12

HuGHES's (E.) Geographical Atlas ........ 20

(W.) Geography of British His-

tory and Manual of Geography ..........

Hulla H's History of Modern Music ......

- Transition Musical Lectures ......

Hum вoLd'r's Travels in South America....

HUмРн RкYS' Sentiments of Shakspeare....

Hutron's Studies in Parliament ..........

Hymns from Lyra Germanica............. 11 13 20 15 15 1

In

Icelaudic Legends, Sícond SkrIes........

InLE's Hints on Shooting ..............

JAMEsON's Legends of the Saints and Mar-

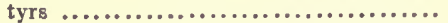
- Legends of the Madonna ...... Legends of the Monastic Orders

JAMESON and EASTLAKE's History of Our

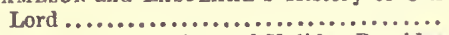

JoHns's Home Walks and Holiday Rambles Jounson's Patentee's Manual ............ Practical Draughtsman ......... Johnston's Gazettecr, or General Geographical Dictionary .................. JoN Es's Christianity and Common Sense ..

Kalisch's Commentary on the Bible...... Hebrew Grammar.............

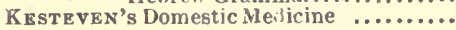
KIRBY and SPENCE's Entomology ........ KUrnes on Pentateuch and Joshna........

Lady's Tour round Monte Rosa............

LA non's (L. E. L.) Poetical Work8........

LAтнам's Englisl Dictionary ............

LECKY's History of Ra tionalism ..........

Leisure Hours in Town ..................

LEW Es's Biographical History of Philosophy

LEwin's Fasti Sacri ...................

LEwIs on Early Roman History .......... on Irish Disturbances ............ on Observation and Reasoning in

Politics............................. _ on Political Terms ................

LEWis's Essays on Administrations........ - Fables of BABRIUS................ LI DDELL and ScoTT's Greek-English Iexicon Life of Man Symbolised ......................... Abridged ditto

IIINDLEY and Moore's Treasury of Botany

2
0
7
3
3
6
1
6
4

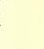 \\ 1

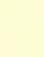

(

.


Longman's Lectures on History of England 1 Lo UDON's Kncyclopædia of Agriculture.... 12 Gardening .... 12 Plants ........ 9 Trees and Shrubs 9 -'Cottage, Farm, and Villa A rchitecture 12 Lowndzs's Engineer's Haudbook ....... 11 Lyra Domestica ....................... 14 Eucharistica...................... 14 Germsnice ....................10, 14 Messianica ........................ 14 Mystica.......................... 14 Sacra ............................ 14

Maca deay's (Lord) Essays................ History of England ..........

Lajs of Ancient Rome........ Miscellaneous Writings ...... Speeches ................... Works ....................

Macdougall's Theory of War ............ ManshMAN's Life of Havelock............ McLrod's Middle-Class Atlas of General Geography .......................... Physical Atlas of Great Britain

and Ireland

McCulloch's Dictionary of Commerce.... Geographical Dictionary ....

MaCriz's Vancouver Island .............. Ma aurre's Life of Father Mathew ........ Rome and its Rulers ..........

Maling's Indoor Gardener................ Mannine on Holy Ghost................. M assry's History of England.............. MAssinarerd's History of the Reformation MaUnder's Biographical Treasury ......... Geographical Treasury........ Hiatoricsl 'Treasury ........... Scientific and Literary'Tressury Treasury of Knowledge........ Treasury of Natural History ..

Ma uRy's Physical Geography.............. MaY's Constitutional History of England .. Melviluz'g Digby Grand ............... General Bounce .............. Gladiators .................. Good for Nothing ............. Holmby Honse .............. Interpreter ................ Kate Coventry............... Queen's Maries .............. M RN Dв Lssohn's Lettera .................. Menzins' Windsor Great Park ............. Mbrivale's (H.) Historical Studies .......

(C.) Fall of the Roman Republic Romans under the Empire Boyle Lectures...........

MrLes on Horse's Foot and Horse Shoeing. on Horses' Teeth and Stables ....... MrLL on Liberty ........................ on Representative Goverament ...... on Utllitarianism ...................

MiLL's Dissertations and Discnssions...... Political Economy ................ System of Logic.................... Hamilton's Philosophy ............
MILLBR's Elements of Chemistry......... 9

Monseld's Spiritual songs.............. 14

Beatitudes................... 14

Monтоoмery on Pregnancy............... 9

Moors's Irish Melodies ............... 11, 17 -Lalla Rookh .................. 17

Jonrnal and Correspundence .... 3

-Poetical Works................ 17

MORBLL's Elements of Psychology ........ 6

Mental Philosophy.............. 6

Morning Clouds ....................... 14

Morris's County Seats ................. 20

Mosнвıм's Ecclesiastical History......... 14

Mozart's Letters ..................... 3

MÜLLER's (Max) Lectures on the Science of

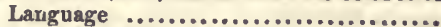
$\longrightarrow$ (K. O.) Literature of Ancient

Greece...........................

Murchison on Continued Fevers............ M UвE's Language and Literature of Greece

New Testament illustrated with Wood Engravings from the Old Masters ......... 10 NEWMAN's History of bis Religious Opinions Nightingare's Notes on Hospltals ......

Odung's Animal Chemistry .............. Course of Practical Chemistry.... OrMseY's Rambles in Algeria and Tunis ... O'Sн ва's Guide to Spain................. OW EN's Comparative Anatomy and Physio-

logy of Vertebrate Animals .............. Oхвм нам on Atonement. ................

PAcke's Guide to the $P$ renees ......... 15 PAG8T's Lectures on - argical Pathologr .. 10 PARK's Life and Travels ................ 16 Perkira's Elements of Materia Medica.... 10 - Manual of Materia Medica..... 10

Perkins's Tuscan Sculptors .............. II

Рн זchips's Guide to Geology .............. 8

-Introduction to Mineralogy.... 8

Pinssk's art of Perfumery .............. 12 - Chemical, Natural, and Physical Magic 12 Prtr on Brewing..................... 19

Playtime with the Poets................. 17

Practicai Mechanic's Journal ............. il

Pratr's Law of Building Societies ........ 19

PRescotT's Scripture Difficulties ......... 13

Proctor's Saturn ...................... 7

Pycrort's Course of English Reading .... 5

Cricket Field ............... 18

Cricket Tutor ................ 18

Cricketana ............... 18

READk's Poetical Works .............. 17

Recreations of a Conutry Parson ......... 6

RkiLLy's Map of Mont Blanc............ 15

RIDDLE's First Sundays at Church ....... 14

Krvers's Rose Amateur's Guide ......... 9 
ROOERS's Correspondence of Greyson...... liclipse of Faith................ Defence of ditto ............... Essays from the Edinburgh Review -Fulleriana ....................

RoakT's Thesaurus of English Words and

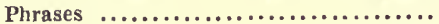

Ronalds's Fly-Fisher's Entomology ......

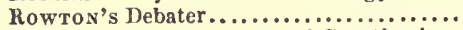

Russell on Government and Constitution.

SANDARs's Justinian's Institutes .......... ScotT's Handbook of Volumetrical Analysis Scrope, on Volcanos Senion's Historical and Philosophical

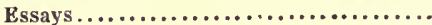

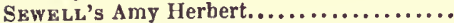

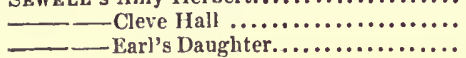

Experience of Life .............

Gertrude ..................... Glimpse of the World...........

Ilistory of the Early Church......

Ivors .......................

-Katharine Ashton..............

-Laneton Parsonage ..............

Margaret Percival .............

Night Lessons from Scripture....

Passing Thoughts on Religion....

Preparation for Communion......

Principles of Education..........

Readings for Confirmation ......

Readings for Lent..............

Examination for Confirmation .. Stories and Tales..............

Thoughts for the Holy Week. . ....

Ursula ......................

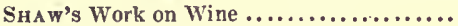

SHEDDEN's Elements of Logic ............

SHIPLEY's Church and the World ........

Short Whist ..........................

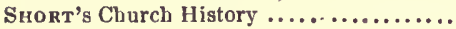

Sievekina's (Amelia) Life, by Wrak-

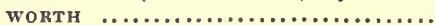

Simpson's Handbook of Dining.......... 19

Smith's (Southwood) Philosophy of Health 19

(J.) Paul's Voyage and Shipwreck 13

(G.) Wesleyan Methodism ........ 3

(SYDNFY) Memoir and Letters.... 3

Miscellancous Works .. Moral Philosophy......

Wit and wisdom .......

Smrtu on Cavalry Drill and Manouvres....

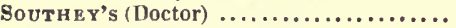

Poetical Works..............

Stanley's History of British Birds.........

STrBnino's Analysis of Mill's Logic......

Stephen's Essays in Ecclesiastical Biography ...

Lectures on History of France Stepping-Stone (The) to Knowledge, \&c. .. Stririno's Secret of Hegel ...............

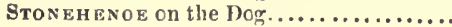
on the Greyhonnd ................

.

,

\begin{tabular}{l|l}
3 \\
3
\end{tabular}

Strange on Sea Air................. 10 - Restoration of Health ...........

TAsso's Jerusalem, by JA M Es.......... 17 TAYLOR's (Jeremy) Works, edited by EDEN 14 Tennent's Ceylon .................. 8

- Natural History of Ceylon .... 8

ThinLwa LL'S History of Greece ......... 2

THomson's (Archbishop) Laws of Thought 4

(J.) Tables of Interest ........ 19

Conspectus, by B 1 RK ET'T...... 10
Todn's Cyclopædia of Anatomy and Physiology ........................... 10 and Bowman's Anatomy and Physiology of Man ................... 10

TROLLOPE's Barchester Tower......... .16 Warden .................... 16

Twiss's Law of Nations .............. is

TyNDALL's Lectures on Heat............. 8

URE's Dictionary of Arts, Manufactures, and Mines ...........................

VAN DER HoEven's Handbook of Zoology Vauahax's (R.) Revolutions in English

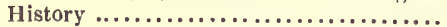
(R. A.) Hours with the Mystics Way to Rest................

WALkER on the Rifle............... 17

Watson's Principles and Practice of Physic 10 WATTs's Dictionary of Chemistry......... 9 Wrä's Objects for Common Telescopes .. : WEBSTER \& WiLkinson's Greek Testament 13 WELD's Last Winter in Rome.......... 13 WeLlinoton's Life, by BRIALMONT and

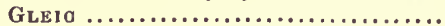
by GLEIG ..........

West on Children's Diseases ............. Whately's English Synonymes ..........

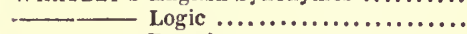
Remains................... Rhetoric .................. Sermons.................. Paley's Moral Phylosophy.....

WHEWELL's History of the Inductive Sciences............................. Scientific Ideas ...............

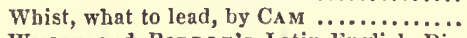
WhITE and RIDDLE's Latin-linglish Dictionaries ......................... WILBERFORCE (W.) Recollections of, by

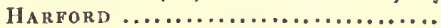

Willich's Popular Tables ...............

Wruson's Bryologia Britannica...........

WindнA M's Diary.....................

WooD's Homes without Hands ............

WOODWARD's Historical and Chronological

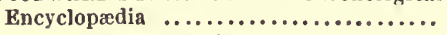

WRioHT's Homer's Iliad............ 1t

YoNas's English-Greek Lexicon ........

Yo Abridged ditto $\ldots \ldots \ldots \ldots \ldots \ldots \ldots$. 5

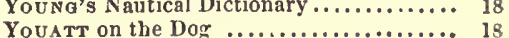

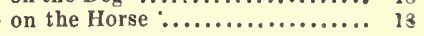





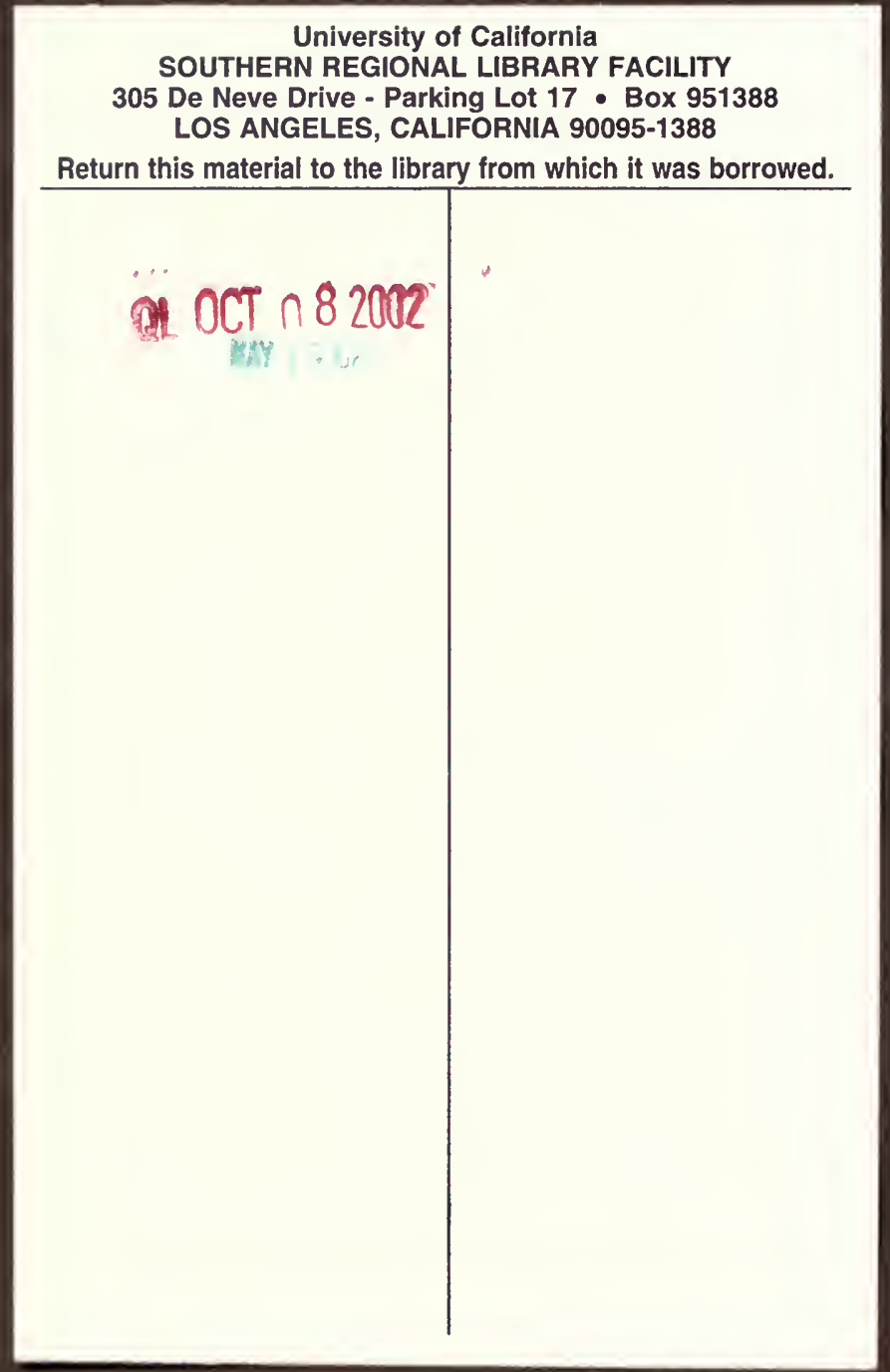



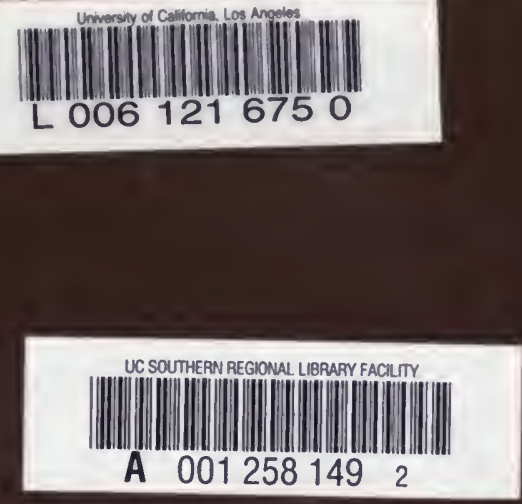


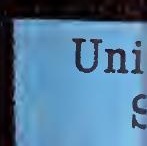

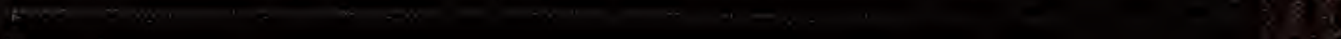

